\title{
Same but different : functional correlates of different psychopathy dimensions in (antisocial) youth
}

Citation for published version (APA):

Feilhauer, J. (2013). Same but different : functional correlates of different psychopathy dimensions in (antisocial) youth. [Doctoral Thesis, Maastricht University]. Maastricht University. https://doi.org/10.26481/dis.20130412jf

Document status and date:

Published: 01/01/2013

DOI:

10.26481/dis.20130412jf

Document Version:

Publisher's PDF, also known as Version of record

\section{Please check the document version of this publication:}

- A submitted manuscript is the version of the article upon submission and before peer-review. There can be important differences between the submitted version and the official published version of record.

People interested in the research are advised to contact the author for the final version of the publication, or visit the DOI to the publisher's website.

- The final author version and the galley proof are versions of the publication after peer review.

- The final published version features the final layout of the paper including the volume, issue and page numbers.

Link to publication

\footnotetext{
General rights rights.

- You may freely distribute the URL identifying the publication in the public portal. please follow below link for the End User Agreement:

www.umlib.nl/taverne-license

Take down policy

If you believe that this document breaches copyright please contact us at:

repository@maastrichtuniversity.nl

providing details and we will investigate your claim.
}

Copyright and moral rights for the publications made accessible in the public portal are retained by the authors and/or other copyright owners and it is a condition of accessing publications that users recognise and abide by the legal requirements associated with these

- Users may download and print one copy of any publication from the public portal for the purpose of private study or research.

- You may not further distribute the material or use it for any profit-making activity or commercial gain

If the publication is distributed under the terms of Article $25 \mathrm{fa}$ of the Dutch Copyright Act, indicated by the "Taverne" license above, 



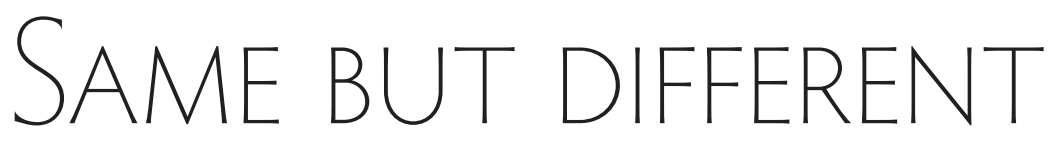

FUNCTIONAL CORRELATES OF DIFFERENT PSYCHOPATHY DIMENSIONS IN (ANTISOCIAL) YOUTH 
Feilhauer, Johanna Christiane. Same but different: Functional correlates of different psychopathy dimensions in (antisocial) youth.

Thesis Maastricht University, the Netherlands - With ref. - With summary in Dutch.

ISBN 978-3-00-041231-8

Copyright $\odot$ Johanna C. Feilhauer, Maastricht 2013

Cover design: Tobias Feilhauer

Typesetting \& production: * studio Michał Sławiński, thesisprint.eu

All rights reserved. No parts of this thesis may be reproduced or transmitted in any form or by any means, electronic or mechanical, including photocopy, recording or any other information storage or retrieval system, without permission in writing from the author, or, when appropriate, from the publishers holding the copyright of the published articles. 


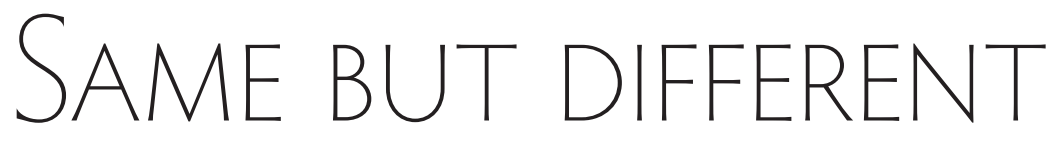

FUNCTIONAL CORRELATES OF DIFFERENT PSYCHOPATHY DIMENSIONS IN (ANTISOCIAL) YOUTH

\begin{abstract}
PROEFSCHRIFT
ter verkrijging van de graad van doctor aan de Universiteit Maastricht, op gezag van de Rector Magnificus, Prof. dr. L.L.G. Soete, volgens het besluit van het College van Decanen, in het openbaar te verdedigen op vrijdag 12 April 2013 om 14.00 uur
\end{abstract}

door

JOHANNA Christiane FEILHAUER 
PROMOTOR

Prof. dr. A.R. Arntz

COPROMOTOR

Dr. M.J. Cima

BEOORDELINGSCOMMISSIE

Prof. dr. M.J.H. Huibers (voorzitter)

Prof. dr. D.P. Bernstein

Prof. dr. C. de Ruiter

Prof. dr. C. van Nieuwenhuizen (Universiteit Tilburg)

Prof. dr. T.A.H. Doreleijers (Universiteit Leiden; Vrije Universiteit Amsterdam) 


\section{CONTENTS}

Introduction

CHAPTER 1 Conceptual framework and research aims

CHAPTER 2 Assessing callous-unemotional traits across different groups of youths: further cross-cultural validation of the inventory of callous-unemotional traits

CHAPTER 3 Differential associations between psychopathy dimensions, types of aggression, and response inhibition

CHAPTER 4 Salivary cortisol and psychopathy dimensions in detained antisocial adolscents

CHAPTER 5 Knowing right from wrong, but just not always feeling it: relations among callous-unemotional traits, psychopathological symptoms, and cognitive and affective morality in 8- to 12-year-old boys

CHAPTER 6 Summary and general discussion

Dutch summary

Dankwoord

Curriculum vitae 



\section{Introduction}

Psychopathy is a complex personality disorder with affective, interpersonal and behavioral characteristics. Overall, psychopaths are emotionally callous, narcissistic and manipulative, antisocial and impulsive. The concept of psychopathy is defined as a factorial construct, which captures these aspects (Cooke, Michie, \& Hart, 2006; Hare, 2003). The majority of studies concentrated on a taxonic, categorical approach, viewing psychopaths as a discrete class, comparing them to non-psychopaths based on total psychopathy scores, thereby neglecting its factorial and dimensional structure. More recently, a dimensional approach to psychopathy, in which factors are viewed as dimensions existing along a continuum, is promoted (Edens, Marcus, Lilienfeld, \& Poythress, 2006; Guay, Ruscio, Knight, \& Hare, 2007; Murrie et al., 2007). This view of a dimensional latent structure of psychopathy suggests that differences in psychopathic traits between individuals describe differences in degree (i.e., being more or less psychopathic on a continuum) rather than taxonic differences (i.e., psychopath versus nonpsychopath; Edens, Marcus, \&Vaughn, 2011).

Over the last decades research has extended the concept of psychopathy to children and adolescents. The occurrence of callous-unemotional traits (CU traits) has received much attention in this context. CU-traits describe an interpersonal style associated with a lack of guilt and an inability to show empathy and emotions (Christian, Frick, Hill, Tyler, \& Frazer, 1997). Children high on CU traits show high levels of thrill and adventure seeking, are less sensitive to punishment in reward-oriented task conditions and are less reactive to threatening and emotionally distressing stimuli (Frick, Cornell, Bodin et al., 2003; Loney, Frick, Clements, Ellis, \& Kerlin, 2003). First longitudinal evidence suggests that the presence of CU-traits in early childhood may predict later severe conduct problems (Frick, Cornell, Barry, Bodin, \& Dane, 2003) and that these traits remain fairly stable into early adulthood (e.g., Burke, Loeber, \& Lahey, 2007). However, whereas children with severe conduct problems and CU traits show a substantial number of characteristics associated with adult psychopathy (e.g., Barry et al., 2000; e.g., Christian et al., 1997) also dissimilarities have been found, including greater levels of comorbidity (externalizing and internalizing) and differences in neuropsychological task performance (Salekin, Rosenbaum, Lee, \& Lester, 2009). Thus, whereas more research is needed, these findings generally support the downward extension of psychopathy to children and adolescents. In this 
view children with a combination of severe conduct problems and CU traits are believed to be particularly at risk to develop the most severe forms of antisocial and delinquent behavior, including psychopathy, in adulthood (Frick \& White, 2008).

However, others raised serious concerns about a downward extension of the concept. Scientists worried that psychopathic traits might be overrepresented in child and particularly youth samples as several symptoms of psychopathy, for instance not caring about long-term goals, egocentricity and also impulsive behavior would occur as part of normative adolescent development (Seagrave \& Grisso, 2002). Furthermore, Hart, Watt and Vincent (2002) extend the argument raised by Seagrave and Grisso (2002) through pointing out that what is known about youth psychopathy rather looks like an impressionist painting 'fine from a distance, but the closer you get, the messier it looks' (p.241) with differing findings occurring across studies.

Research regarding the utility of CU traits in the developmental study of psychopathy as well as the caution raised about this approach have inspired the field and led to a large increase of studies concerning the topic across the last decade. However, in line with the notion stated by Hart et al. (2002) so far findings raise many more questions than they answer. One important question in this respect would be whether CU traits alone are representative of psychopathy in young samples (Salekin et al., 2009).

Besides the $\mathrm{CU}$ dimension, the contribution of the remaining psychopathy dimensions is still unclear. Whereas adult research long focused on the use of global psychopathy indices, research in children and adolescents mainly focuses on the role of CU traits. How many dimensions best describe the psychopathy construct in youth and adult samples is still debated. However, at least three dimensions regularly occur. They are in line with the classical clinical description of the psychopathy construct as described by Cleckley (1941); 1) the affective (CU traits); 2) the interpersonal (narcissism and manipulative behavior); and 3) the behavioral (impulsive and irresponsible) characteristics associated with the disorder (Cleckley, 1941; Cooke et al., 2006; Frick \& White, 2008).

Given that psychopathic individuals can score differently on the underlying psychopathy dimensions, it seems reasonable that the solitary use of either global indices or CU traits might shadow relevant differential correlates of psychopathy (Salekin, Neumann, Leistico, \& Zalot, 2004; Vitacco, Neumann, Caldwell, Leistico, \& Van Rybroek, 2006). By focusing on one dimension or global psychopathy scores, one might think that psychopaths are all the same, while actually, psychopaths are very different. The heterogeneity of psychopathic groups (D'Silva, Duggan, \& McCarthy, 2004) that lets them appear as an impressionist painting lies in the different contributions of these distinct dimensions, which is unique for every individual. Understanding the distinct correlates of these different psychopathy dimensions in youth, is therefore an important step in expanding our understanding of psychopathy, the identification of dimensional profiles, and the invention of successful treatment plans. 
Besides the heterogeneity within the concept of psychopathy, there is general consensus that psychopathy is related to deficits across different areas of functioning, i.e. fear conditioning and lack of moral emotions (Blair, Richell et al., 2006; Lykken, 1957; Patrick, Cuthbert, \& Lang, 1994). However, in other areas there still is much controversy about whether psychopathy is related to certain deficits, particularly in children and adolescents. Past research often did not take (all) different psychopathy dimensions into account.

The aim of the current dissertation is twofold. The first aim is to validate a new self-report measure of youth psychopathy that exclusively assesses CU traits. The second aim is to unravel some of the existing controversies on cognitive, behavioral and affective correlates of the different psychopathy dimensions, beyond the assessment of CU traits in those currently believed to be particularly at risk to develop adult psychopathy. Therefore, this dissertation is divided into 2 main parts.

The first part of the present dissertation conceptually focuses on different dimensions of psychopathy in youths (chapter $\mathbf{1}$ and $\mathbf{2}$ ). Examining psychopathic traits within children and adolescents is not without controversy. In order to investigate different correlates of the psychopathy dimensions, the first two chapters outline psychopathic dimensions and measurements respectively, within children and adolescents. More specifically, Chapter 1 offers the theoretical framework for the studies conducted in the present doctoral dissertation and will conclude with the main research objectives. Based on the important role that is attributed to the occurrence of CU traits as a risk factor for the development of psychopathy by some researchers, in chapter $\mathbf{2}$, the validity of a recently developed self-report measure of CU traits, the Inventory of Callous Unemotional Traits (ICU), was explored. The study investigated the psychometric and discriminating qualities of the Dutch translation of the questionnaire across different groups of youths by examining its structure, distribution and correlates. In line with Seagrave and Grisso (2002) it will be investigated whether psychopathic traits can reliably be measured by self-report during adolescence without leading to an overrepresentation of these traits.

The second part of the dissertation describes three chapters that investigated differential cognitive, behavioral and affective correlates of psychopathy dimensions in those youths who show the most severe and violent forms of antisocial behavior as compared to a community comparison sample. Three studies describe this part, one focusing on executive functioning in relation to different psychopathy dimensions and types of aggression, one study focusing on the stress hormone cortisol in relation to different psychopathy dimensions, and one study focusing on moral emotions in relation to psychopathic traits. More precisely, Chapter 3, examined the role of psychopathy dimensions and types of aggression in relation to response inhibition among detained antisocial adolescents. Furthermore, possible effects of intelligence and a diagnosis of attention-deficit hyperactivity disorder (ADHD) on response inhibition were assessed. Chapter $\mathbf{4}$ investigated whether cortisol levels are uniquely associated with CU traits as compared to other 
psychopathy dimensions. This study examined whether low cortisol levels may serve as a biological marker for a severe antisocial subgroup high on psychopathy dimensions. In chapter $\mathbf{5}$ particularly the combination of CU traits and externalizing symptoms in relationship with cognitive and affective morality was examined within a preadolescent community sample.

The doctoral dissertation ends with a general discussion of the presented research. In this final chapter, chapter $\mathbf{6}$, the main findings will be summarized and discussed. Further, methodological issues and suggestions for future research will be considered. 


\section{Conceptual framework}

\section{and research aims}

Based on: Feilhauer, J. \& Cima, M. (2013). Youth Psychopathy: Differential correlates of Callous-Unemotional Traits, Narcissism, and Impulsivity. Forensic Science International, 224 (1-3), 1-7. 
This chapter offers the conceptual framework for the studies conducted in the present dissertation. First, the concept of psychopathy and its dimensions in adult and youth samples will be described. We proceed with a review of the newest developments in the dimensional study of psychopathy and its correlates in clinical and incarcerated child and adolescent samples. However, a wide range of possible functional correlates exist. Examining psychopathy dimensions from one approach only, will give a one-sided view. In the present dissertation we therefore concentrate on three important areas of cognitive, behavioral and affective (functional) correlates in clinical and incarcerated child and adolescent samples as compared to community comparison samples. Also, links to the adult literature are presented. The chapter concludes with the research objectives of the present doctoral research project. 


\section{The Psychopathy CONCEPT}

The classical clinical conceptualization describes psychopathy as a constellation of affective, interpersonal and behavioral characteristics. According to Cleckleys' (1941) classical observations, the affective characteristics are defined by callousness, a lack of empathy and remorse together with short lived emotions. The interpersonal characteristics of the psychopath include narcissism, good intelligence, verbal and manipulative abilities, superficial charm, egocentricity and glibness. Behaviorally, psychopaths were described as impulsive, irresponsible, prone to boredom, novelty seeking and antisocial. Based on Cleckley's description and empirical research the Psychopathy Checklist - Revised (PCL-R) was developed (Hare, 1991). Factor analyses of the PCL-R items obtained two moderately correlated psychopathy dimensions, also named factors. Factor 1 (F1) represents the affective/interpersonal personality components of psychopathy. They are viewed as the core characteristics of psychopathy. Factor 2 (F2) represents the impulsive/antisocial behavioral aspects of psychopathy. However, there is still substantial debate about how many dimensions best describe the disorder (e.g., Cooke \& Michie, 2001; Forth, Kosson, \& Hare, 2003; Hare, 2003; Neumann, Kosson, Forth, \& Hare, 2006). Two to four factor models have been suggested (the latter being referred to as four facets in order to distinguish them from the two factor model).

The four facets separate the original affective/interpersonal factor into an (1) interpersonal facet reflecting the superficial, manipulative and deceitful characteristics and an (2) affective facet reflecting emotional shallowness and CU-traits. Likewise, the antisocial factor is divided into a (3) lifestyle facet reflecting an impulsive, irresponsible and poorly planned lifestyle, and an (4) antisocial facet, which reflects the criminal and antisocial behavior and poor behavioral control. In recent research at least three dimensions consistently emerge (Cooke et al., 2006; Salekin et al., 2004). In adults they describe an arrogant and deceitful narcissistic/interpersonal dimension, a callous-unemotional/affective deficient dimension, and a third dimension representing irresponsible, impulsive behavior. In this model antisocial behavior is considered more as a result of the three dimensions than as part of the psychopathy construct (Cooke \& Michie, 2001). Figure 1 presents and integrated overview of the different factor models of psychopathy. For matters of clarity in the remainder of this dissertation the different dimensional factors are named the callous/narcissistic and impulsive/antisocial dimensions when talking about the two factor model of psychopathy. Accordingly, we will talk about the callous, narcissistic, impulsive (three factor model) and antisocial dimensions (four facet model).

The different psychopathy dimensions find support in differing psychophysiological and brain correlates. In incarcerated samples, the callous/narcissistic dimension has been linked to deficits in fear-potentiated startle and reduced electrodermal activity (e.g., Patrick, Bradley, \& Lang, 1993; Verona, Patrick, Curtin, Bradley, \& Lang, 2004). The impulsive/antisocial dimension was more related to electrodermal hyperreactivity (Patrick et 


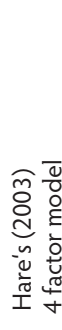
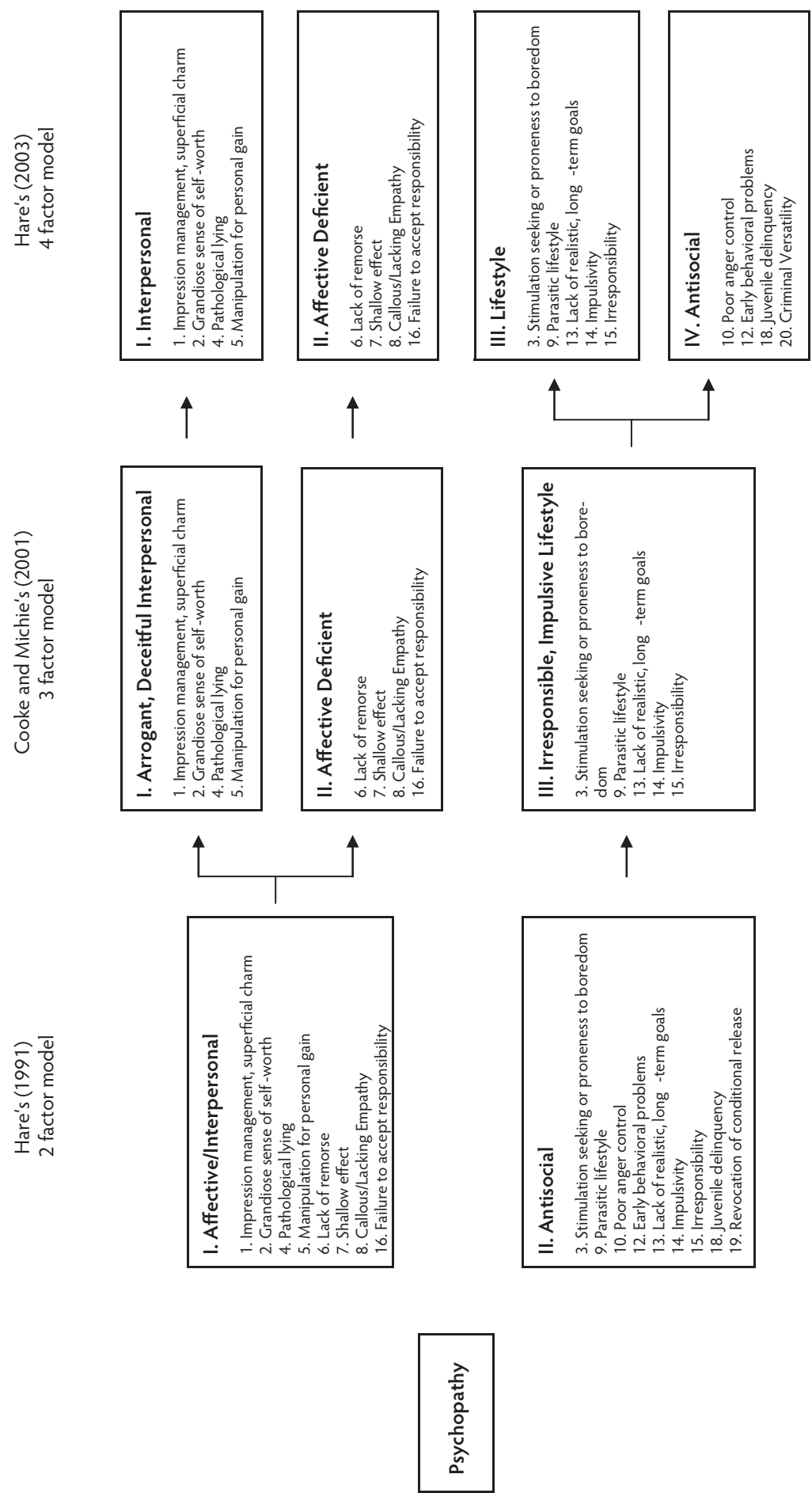
al., 1994). At brain level, amygdala dysfunction has been related to the emotional deficits captured by the callous dimension, including deficits in the interpretation of emotional stimuli such as facial expressions, fear or sadness in others, and deficits in emotional learning in the form of stimulus-reinforcement associations (e.g., Blair, Mitchell, \& Blair, 2005; e.g., Blair, 2007; Finger et al., 2008). Also, the orbitofrontal cortex (OFC) and a distorted communication between the OFC, the amygdala and other paralimbic structures are believed to be related to difficulties in basic forms of emotional learning and decision making in psychopathy (Blair, 2010; see e.g., Kiehl, 2006 for a more detailed discussion). Different genetic polymorphisms affect amygdala reactivity and its interaction with the OFC (Hariri et al., 2002; Pezawas et al., 2005). A genetic risk for psychopathy might therefore depend on the number of polymorphisms that cause a reduced emotional and amygdala functioning (Blair, 2007).

\section{Child ANd Adolescent Measures of Psychopathy Dimensions}

In children and adolescents also two to four factor models of psychopathy have been obtained. However, questionnaires in this field of research often apply the three factor model. In children and adolescents the three dimensions are often described as narcissism, callous-unemotional traits (CU traits) and impulsivity (Frick, Bodin, \& Barry, 2000), and are combined in the term psychopathic traits (Flight \& Forth, 2007). The narcissistic dimension describes an arrogant and deceitful interpersonal style involving a narcissistic view of one's self, conning, manipulative behavior, lack of responsibility, superficial charm, egocentrism, untruthfulness. The callous-unemotional dimension stands for the affective deficit that is at the core of the disorder of psychopathy and is defined by a cold-blooded lack of guilt, remorse, shame, empathy and a general poverty of affect and emotions. The impulsive dimension is characterized by an impulsive and irresponsible behavioral style involving poorly planned behavior and proneness to boredom and sensation seeking (e.g., Frick \& White, 2008).

Given the first evidence for the importance of psychopathic traits to the downward extension of the psychopathy construct, efficient reliable and valid measures are needed. Psychopathic traits are generally assessed either by semi-structured clinical interviews, so-called expert ratings, or with the help of either self-report or informant questionnaires. To date the vast majority of studies assessing psychopathic traits in conduct disordered children and adolescents made use of either the Psychopathy Checklist: Youth Version (PCL:YV) or the Antisocial Screening Device (APSD).

The Psychopathy Checklist: Youth Version, a downward extension of the PCL-R interview has been developed for the use with adolescent samples (PCL:YV; Forth et al., 2003). Like the adult version of the Psychopathy Checklist (PCL-R; Hare, 1991), it consists of 20 items, which can be subdivided into two to four factors. Ratings on the separate 
items are based on a semi-structured interview together with the subjects' interpersonal presentation and collateral information consisting of clinical, legal, school reports and information from significant others (parents/caregivers). The PCL:YV is designed for the use with institutionalized adolescent delinquents (ages 12-18). It is difficult to use without collateral information. The interview tabs topics as the youth's family background, past relationships, friendships, employment history, alcohol and drug use, school, delinquent behavior and future plans. The PCL:YV has adequate psychometric properties (Forth et al., 2003). As with the adult version two to four factor models can be applied.

The Antisocial Process Screening Device (APSD; Frick \& Hare, 2001) is typically used in samples of young children, aged 6-13 years. It comes in teacher and parent versions. Additionally, a self-report version for the use with adolescents has been developed, which is used in juvenile offenders (Munoz \& Frick, 2007; Spain, Douglas, Poythress, \& Epstein, 2004). The APSD consists of 20 items. Like the PCL:YV it is originally based on the PCL-R. The items map onto 15 PCL-R items. Items not relevant for children and adolescents were excluded. Research indicates a three factor model for the APSD (Frick et al., 2000). However, the factor composition differs form the composition of the PCL-R factors (Forth et al., 2003). The APSD factors are named Narcissism (NAR), Callous/Unemotional (CU), and Impulsivity (IMP). Early research with the APSD utilized a two factor model (Christian et al., 1997). The APSD has to deal with a number of psychometric shortcomings like very limited numbers of items measuring each factor. Internal consistency measures were generally adequate for the APSD total in the range of 0.78-81, and lower for the different factors, ranging form 0.50 to 0.68 , with the $\mathrm{CU}$ factor being the lowest and IMP being the highest (Munoz \& Frick, 2007; Spain et al., 2004)

The present chapter concentrates on studies which utilized one of these reliable and valid instruments. Past studies used a variety of different samples. This made an integration of the findings difficult. Therefore, we concentrate on studies using clinical or detained child and adolescent samples with severe behavioral problems. It is still questioned how many dimensions best describe the psychopathy concept. Therefore, all approaches are integrated in the present literature review.

\section{COGNITION}

\section{Intelligence}

Antisocial behavior in children and adolescents has long been related to intellectual, especially verbal, and executive (frontal lobe) functioning deficits (Morgan \& Lilienfeld, 2000; Nigg \& Huang-Pollock, 2003). Verbal intellectual deficits are even viewed as one of the most stable predictors of antisocial behavior (Moffitt \& Silva, 1988; Nigg \& Huang-Pollock, 2003). It is, therefore, not surprising to find positive as- 
sociations between the impulsive dimension of psychopathy and intellectual deficits. The associations of the callous and the narcissistic dimensions with intellectual deficits are less clear.

According to Cleckley (1941), psychopaths present with good intelligence, especially verbal, creative, practical and analytic abilities. This is reasonable as psychopathic characteristics like deceit and manipulative behavior seem to warrant a certain level of intelligence. One could easily think of good verbal, forethought and planning abilities. Salekin, Neumann, Leistico and Zalot (2004) examined the relation between the psychopathy dimensions and intelligence in a detained youth sample ( $N=122$, age 11-18) using the PCL:YV (three factor model). The callous dimension was negatively associated with verbal intelligence and with measures of creativity, practicality, and analytic thinking. The narcissistic dimension on the other hand, was positively associated with all these intellectual abilities. The impulsive dimension was positively associated with measures of creativity, practicality, and analytic thinking, but not with verbal abilities (Salekin et al., 2004). Thus, whereas high levels on the callous dimension were related to poorer intellectual abilities, high levels on the narcissistic dimension were related to better intellectual abilities. High levels on the impulsive dimension were related to higher creativity, practicality and better analytic thinking, but not to verbal abilities. Although not conclusive, these findings partly support Cleckley's traditional conceptualization. Similar patterns of results come from the adult literature (Vitacco, Neumann, \& Wodushek, 2008). Moreover, the sparse literature suggests that the presented associations are not age dependent. Thus, studies using the PCL-R and PCL:YV point to a specific positive association between narcissism and intellectual, mainly verbal, abilities.

\section{Response Inhibition}

Like deficits in verbal intelligence, neuropsychological deficits, for example deficits in executive functioning, are well documented in child and adult antisocial behavior (Moffitt, 1993; Morgan \& Lilienfeld, 2000). Executive functions control and regulate information processing in the brain and are necessary for socially appropriate behavior, self-control, responsiveness to punishment, and ethical behavior (Gazzaniga, Ivry, \& Mangun, 2002). The question whether psychopaths present with executive functioning deficits is not conclusively answered yet. Impairments have been shown in executive functions that are related to the orbitofrontal/ventromedial frontal cortex and the limbic system, i.e., the amygdala (e.g., risk related decision making and affect regulation). Other executive functions related to the dorsolateral prefrontal cortex, e.g., planning and inhibition, seem to be less impaired (Blair, Newman et al., 2006; Gazzaniga et al., 2002).

Given that psychopaths are known for their goal-directed, planned and manipulative behavior they might be able to control their behavioral responses, i.e., present with normal or even advanced response inhibition abilities and show less impulsivity. 
Two studies investigated response inhibition with the use of neuropsychological tests in youth and adult psychopaths. They found psychopaths to be even more impulsive than non-psychopaths based on their PCL:YV/PCL-R total scores (Lapierre, Braun, \& Hodgins, 1995; Roussy \& Toupin, 2000). However, damage to the dorsolateral cortex, which would be associated with poor planning and inhibition abilities, is generally related to antisocial behavior, i.e., the impulsive and antisocial dimensions (Gazzaniga et al., 2002; Ishikawa \& Raine, 2003). It seems, therefore, reasonable that poor response inhibition as one aspect of impulsivity would be mainly attributable to high scores on these dimensions. To date, no study has assessed the relationship between response inhibition and the different psychopathy dimensions in antisocial youth. In college students, using the Psychopathic Personality Inventory (PPI, a two factor psychopathy measure developed for community samples), the callous/narcissistic dimension was found to be unrelated to response inhibition, as assessed with neuropsychological testing, and positively related to other measures of executive functioning (Lilienfeld \& Andrews, 1996; Sellbom \& Verona, 2007). The impulsive/antisocial dimension, on the other hand, was related to poorer performance on all general executive functioning tasks and response inhibition (Sellbom \& Verona, 2007). Furthermore, a recent study in adult offenders found the impulsive and antisocial dimensions ( $P C L-R$, two and four factor model) to be related with high scores on a self-report questionnaire of impulsivity, whereas there was evidence for reduced impulsivity in relation to the callous and narcissistic dimensions (Snowden \& Gray, 2011). Still, the presented evidence has to be regarded as preliminary. Future research will have to explore the presented rational across samples using comparable methodologies.

In summary, deficits in verbal intelligence and response inhibition are long known problems in child and adult impulsive, antisocial behavior (Morgan \& Lilienfeld, 2000; Nigg \& Huang-Pollock, 2003). The presented data suggest that adequate intellectual capacities, i.e., on the verbal, creative, practical and analytic realm are necessary for an individual to behave in a narcissistic, manipulative interpersonal way. Furthermore, it could be suspected that poor response inhibition is less important in relation to the callous and narcissistic dimensions. There is, thus, first evidence for differing associations of intelligence and response inhibition with the different psychopathy dimensions.

One aim of the present dissertation is to investigate differential associations between psychopathy dimensions and aspects of cognitive functioning, particularly response inhibition, in children and adolescents most at risk to develop psychopathy later in life (chapter 3). 


\section{BEHAVIOR}

\section{Aggression}

Another aspect of executive functioning, besides intelligence and response inhibition, is self-control. A lack of self-control is found in some forms of severe aggression. Severe aggression has often been documented in children and adults with psychopathic traits (Kruh, Frick, \& Clements, 2005; Porter \& Woodworth, 2006). Two forms of aggression have repeatedly been associated with psychopathic traits (Cima \& Raine, 2009; Meloy, 2006). Reactive (impulsive) aggression is unplanned, and driven by heightened emotional arousal. It occurs in reaction to provocation, frustration or threatening events. Proactive (instrumental) aggression is planned and emotionless. It is used to achieve a particular desired goal (Berkowitz, 1993). At brain level, reactive aggression is often associated with low frontal lobe functioning and increased amygdala functioning leading to strong and inappropriately intensive reactions to threatening and frustrating events. Proactive aggression, a condition particularly associated with psychopathy, has rather been found to be related to underactive subcortical brain areas, especially the amygdala (Blair, 2010; Raine et al., 1998). Additionally, a recent molecular genetic twin study found first evidence for shared genetic influences of psychopathic traits and aggression. This genetic relation with psychopathic traits was stronger for proactive than reactive aggression based on child self-report (Bezdjian, Tuvblad, Raine, \& Baker, 2011). For an overview of several correlates of both reactive and proactive aggression, see Cima and Raine (2009).

Different conceptualizations of aggressive behavior exist in the literature. The reactive-proactive differentiation has been found appropriate in relation to adult psychopathy and has been investigated by numerous studies. They generally found higher total PCL-R scores in proactive aggressive adult offenders than in other offenders. Furthermore, total scores on the PCL:YV correlated positively with a measure of instrumentality and with both types of aggression in adolescent samples (e.g. Brandt, Kennedy, Patrick, \& Curtin, 1997; e.g. Cornell et al., 1996; Woodworth \& Porter, 2002). Additionally, in adult offenders the impulsive/antisocial dimension was associated with poor planning and instrumentality during aggressive offences (two factor solution; Woodworth \& Porter, 2002). Recent evidence indicates that proactive aggression and instrumentality are specifically associated with higher scores on the callous and narcissistic dimensions, with instrumentality being associated with the narcissistic dimension only in adult inmates (four factor solution; Hare, 2003; Walsh, Swogger, \& Kosson, 2009). Thus, the narcissistic dimension seems to be of special importance in instrumentality and proactive aggression in adult samples.

Few studies accounted for the differential contributions of the psychopathy dimensions in relation to the two types of aggression in child and adolescent samples. Barry et al. (2007) applied the APSD (three factor model), in aggressive children who were assigned to an intervention program ( $N=160$, age 9-12). Interestingly, the narcissistic di- 
mension predicted high levels of both types of aggression, whereas the impulsive dimension only predicted increased reactive aggression. The callous dimension was unrelated to aggression (Barry et al., 2007). The authors view the narcissistic dimension as a unique positive predictor of both types of aggression in this at risk sample, with higher levels on the narcissistic dimension being related to higher levels of reactive and proactive aggression, relative to the other psychopathy dimensions (Barry et al., 2007). This unique relationship between narcissistic, manipulative behavior and aggression leans some support to the idea that individuals high on psychopathic traits could use reactive aggression more consciously than impulsive, i.e., in a manipulative way (Munoz, Frick, Kimonis, \& Aucoin, 2008; Woodworth \& Porter, 2002).

Somewhat different associations were found applying the APSD (three factor model) in a clinical child sample ( $N=105$, age 6-12; Fite, Stoppelbein, \& Greening, 2009). Based on caregiver reports, higher levels on the callous and narcissistic dimensions were both related to higher reactive and proactive aggression, with slightly stronger associations for the narcissistic dimension. Higher levels on the impulsive dimension were exclusively related to higher reactive aggression. In contrast, child reports of proactive aggression were related to higher levels on all three psychopathy dimensions. Associations with reactive aggression were negative, but non-significant (Fite et al., 2009). These results suggest that patterns of associations tend not only to vary between studies, but also across informants.

Two studies in detained youths report on associations between psychopathy dimensions and the two different aggression types, applying the PCL:YV. The first study found high levels on the narcissistic dimension to be related to increased proactive aggression ( $N=122$, age 12-17; four factor model). High levels on the antisocial dimension (added fourth dimension) were related to less proactive aggression (Vitacco et al., 2006). In the second study by Flight and Forth (2007) proactive aggression was related to higher levels on the callous dimension, whereas reactive aggression was most strongly related to increased levels on the antisocial dimension ( $N=51$, age 16-20). These authors suggest a distinctive role of $\mathrm{CU}$ traits for the understanding of proactive/instrumental violence (Flight \& Forth, 2007; four factor solution). Callous-unemotional (CU) traits are associated with a lack of empathy and emotions, low levels of autonomic arousal and a lack of responsibility. According to the authors particularly these features of psychopathy predispose a psychopathic individual to act in proactive ways (Flight \& Forth, 2007; Meloy, 2006). Vitacco et al. (2006) underline the importance of the narcissistic dimension in this regard. The authors suggest that characteristics as deceitfulness, manipulative behavior, a grandiose sense of self-worth and impression management might put psychopathic individuals at risk to become violent when feeling disrespected in their position (Cale \& Lilienfeld, 2006; Vitacco et al., 2006). Thus, the presented results underline the importance of the narcissistic dimension for proactive aggression. However, they also point to a substantial role of the callous-unemotional dimension in the occurrence of both types of aggres- 
sion in child, adolescent and adult samples. In summary, proactive aggression seems to be especially associated with the callous-unemotional and narcissistic dimensions, representing the psychopathic personality traits associated with the disorder, and less with the impulsive and antisocial dimensions, i.e., the behavioral aspects of psychopathy. At the same time, the presented studies support the almost exclusive association of the impulsive (and antisocial) dimension with reactive aggression. These findings lean indirect support to the importance of the psychopathic personality traits for the occurrence of proactive aggression.

In the present dissertation we will investigate whether this pattern also holds for those youth scoring high on the different psychopathy dimensions (chapter 3).

\section{AfFeCT}

\section{Cortisol and emotion processing}

The hormonal basis of psychopathy is still relatively unknown. What is known is that psychopaths exhibit low autonomic and emotional reactivity (Munoz et al., 2008). On the behavioral level this underarousal seems to be related to their insensitivity to punishment and fear (Holi, Auvinen-Lintunen, Lindberg, Tani, \& Virkkunen, 2006) and their low stress reactivity (Munoz et al., 2008). Stress reactivity generally depends on the availability of the stress hormone cortisol, which is produced by the hypothalamic-pituitary-adrenal axis (HPA-axis; Nicolson, 2007). Physical and psychological stressors excite the limbic system, which has an excitatory influence on the HPA-axis. In psychopaths the limbic system, including the amygdala, is underresponsive (Blair, 2006). Cortisol is an important mediator in the communication between the limbic system and executive cortical structures; a communication that is believed to be essential for emotion-processing, i.e., the experience of emotions. Especially, the deficient affective aspects, i.e., the callous-unemotional dimension of psychopathy are, therefore, believed to be associated with a reduced cortisol secretion (Shirtcliff et al., 2009).

Due to the scarce number of available studies, their methodological diversity and certain limitations it is still difficult to determine the precise nature of the association between cortisol and psychopathic traits. Studies examined the association in highly different samples and varied in whether they examined the tonic functioning, i.e., basal cortisol levels, the cortisol awakening response or the stress responsivity of the HPA-axis. Furthermore, cortisol was measured either in blood serum or salivary samples. Albeit these difficulties there is first evidence linking psychopathy to low cortisol levels (Cima, Smeets, \& Jelicic, 2008). As a whole, the available literature points to a critical role of CU traits in the association between cortisol and psychopathic traits (see Hawes, Brennan, \& Dadds, 2009 for a more detailed discussion). In support of this hypothesis it has 
been found that in children with severe conduct problems, CU traits are similarly associated with low autonomic activity and a lack of emotional reactivity to aversive stressors (Loney et al., 2003).

Two studies explored the relationship between cortisol and the dimensions of the PCL-R (two factor model). In a longitudinal study of clinically-referred youths ( $N=66-124$, age 7-16) with conduct problems, low basal cortisol levels, which are associated with low autonomic activity, predicted later elevated scores on the callous /narcissistic dimension (Burke et al., 2007). In line with these findings, a related study in young adult offenders $(\mathrm{N}=20$, age 16-22) meeting criteria for the antisocial personality disorder found low basal cortisol levels to be related to increased levels on the callous/narcissistic PCL-R dimension (two factor model, Holi et al., 2006). No correlations were observed with the impulsive/ antisocial dimension. Given the fact that low cortisol has been proposed to be a biological marker for CU-traits in particular, the findings concerning narcissism is interesting in this context. In sum, findings suggest reduced cortisol levels, i.e., HPA-axis hypoactivity, as a biological marker for the callous/narcissistic psychopathy dimension. More research is warranted to support these preliminary findings, to overcome methodological limitations and to further investigate the role of low cortisol levels in relation to all psychopathy dimensions and psychopathy related concepts.

Thus, given the scarcity of studies on the relationship between cortisol levels and CU traits in antisocial adolescents, the current dissertation further investigates whether cortisol levels are uniquely associated with CU traits as compared to other psychopathy dimensions in those children and adolescents believed to be most at risk to develop psychopathy (chapter 4).

In adults, a number of studies have demonstrated that psychopathy is associated with emotion processing deficits, e.g., a deficient startle reflex which is seen as a physiological correlate to anxiety and fear and deficits in the interpretation of emotional language (Blair, Richell et al., 2006; Patrick, 1994; Williamson, Harpur, \& Hare, 1991). Research on emotional deficits in youth samples is less extensive, but obtained similar findings. As emotion processing deficits are believed to be related to the affective deficit seen in individuals high on CU traits, past research mainly focused on these traits. Specifically, youth high on CU traits are impaired in recognizing sad and fearful expressions (Blair, Colledge, Murray, \& Mitchell, 2001) and in responding to words with negative emotional content (Loney et al., 2003). They show reduced electrodermal responses to distress and stress pictures and are also less emotionally responsive to pictures indicating distress in others (Blair, Morris, Frith, Perrett, \& Dolan, 1999; Kimonis, Frick, Fazekas, \& Loney, 2006). The affective deficit seen in youth high on the callous dimension thus seems to be particularly related to deficits in the experience of and reaction to negative emotions such as distress, sadness and fear. This deficit in the experience of emotions could play an important role in the development of morality. Moral socialization is based on the repeated experience of an unpleasant internal state that is elicited by the caregivers' affective negative responses (i.e., threatening of punishment) to the childs'immoral be- 
havior. The impaired emotional experiences of children high on psychopathic traits are thus believed to interfere with their early moral socialization and the development of moral emotions (Blair et al., 2005).

Given the evidence of emotional processing deficits within psychopathic samples, one would expect that especially the callous unemotional psychopathy dimension is related to a lack of morality. However, a recent study demonstrated adequate moral reasoning of right and wrong in adult psychopaths. Therefore, the current dissertation examines in more detail whether the callous unemotional psychopathy dimension differentially relates to cognitively 'knowing' right from wrong versus 'feeling' right from wrong in a pre-adolescent sample (Chapter 5).

\section{CONCLUSION}

Although the literature concerning high risk samples is still sparse, it facilitates our insight into the subtle differences in the relationship between psychopathy dimensions (and aspects of cognition, behavior and affect) in children and adolescents.

With regard to cognitive ability, increased levels on the narcissistic dimension seem to be particularly associated with at least adequate overall, particularly verbal, intelligence compared to other psychopathy dimensions. A finding that has recently been replicated in a large community sample (Fontaine, Barker, Salekin, \& Viding, 2008). Interestingly, in all studies increased levels on the callous dimension were related to lower verbal and overall intelligence. This finding contradicts earlier ideas in which especially the callous-unemotional aspects of psychopathy were thought to be related to good intelligence (Loney, Frick, Ellis, \& McCoy, 1998). Results support the importance of unraveling the psychopathy concept into different dimensions. Regarding response inhibition, studies in community samples and studies applying self-report measures of impulsivity have obtained promising results, which are in line with the presented line of reasoning (Sellbom \& Verona, 2007; Snowden \& Gray, 2011). Across samples and studies the callous and narcissistic dimensions were either unrelated to response inhibition or related to better inhibition, whereas the impulsive and antisocial dimensions were related to poorer response inhibition. In line with these findings a recent review suggests that the long assumed general psychopathy-impulsivity association has to be reconsidered (Poythress \& Hall, 2011). Different dimensions of impulsivity might be differently related to psychopathy. The study of response inhibition as one dimension of impulsivity might be of special interest in this respect.

The findings concerning associations of psychopathy dimensions with behavioral aspects give rise to differing interpretations. Whereas some studies underscore the relevance of the narcissistic dimension for proactive aggression to occur (Barry et al., 2007; Vitacco et al., 2006), others attribute this function to the callous dimension (Flight 
\& Forth, 2007). The impulsive and antisocial dimensions, however, seem to be particularly related to reactive aggression. With respect to affect, past literature points to low cortisol levels as a unique biological marker for the callous-unemotional dimension (Loney, Butler, Lima, Counts, \& Eckel, 2006). However, the two studies that took a dimensional approach in clinical populations indirectly also suggest low cortisol as a potential marker for narcissism as part of the callous/narcissistic dimension (two factor model; Burke et al., 2007; Holi et al., 2006). Research will have to clarify the distinctive role of the narcissistic dimension in this context.

A general difficulty in research on the psychopathy concept in children and adolescents concerns the fact that studies utilize divergent (statistical) methodologies. Furthermore, studies on children use different informants, caregiver reports and self-reports, both of which have to deal with certain caveats. Likewise the number of instruments and theoretical frameworks applied to measure cognition, behavior, affect and psychopathy dimensions makes it difficult to make comparisons and to draw conclusions. In addition, the partly differing associations between the behavioral measures and the psychopathy dimensions in children, adolescents and adults illustrate the need for caution in generalizing findings over the lifespan. Although the psychopathy dimensions seem to have considerable construct validity in children and adolescents, there exist a number of important differences with the picture seen in adult psychopathy. Children and adolescents with psychopathic traits show more comorbidity (externalizing and internalizing) and better performance on neuropsychological tasks (Salekin et al., 2009). Given the intense social, behavioral and biological changes that occur between childhood, adolescence and adulthood, one should be cautious when talking about psychopathy in children (Seagrave \& Grisso, 2002; Steinberg, 2002, 2005).

Overall, in line with Frick and others the presented evidence supports the role of CU traits in the development of adult psychopathy. Additionally, it also underscores the importance of the narcissistic dimension for the understanding of psychopathy in children and adolescents (e.g., Barry et al., 2007).

The DSM 5 workgroup on disruptive behavioral disorders suggests the inclusion of a specifier to the diagnosis of CD based on the presence of CU traits (Frick \& Moffitt, 2010). In order to study and diagnose CU traits in youth, it is important to have a valid instrument which is not time-consuming and provides a comprehensive and reliable assessment of these traits in different types of children and adolescents. So far, the most widely used measures of psychopathic traits are the Psychopathy Checklist: Youth Version (PCL-R:YV; Forth, Kosson, \& Hare, 2003) and the Antisocial Process Screening Device (APSD; Frick \& Hare, 2001). However, whereas the PCL:YV can only be applied in antisocial samples and is very time consuming, the APSD has a very limited number of items that specifically assess CU traits. Acting on this, Frick developed the 24-item Inventory of Callous-Unemotional Traits (ICU; Frick, 2003) to provide a more comprehensive assessment of CU traits which overcomes some of these psychometric limitations. 
Based on the important role that is particularly attributed to the presence of CU traits as a risk factor for the development of psychopathy the present dissertation investigated the psychometric and discriminating qualities of the Dutch questionnaire across different groups of youths by examining its structure, distribution and behavioral as well as conceptual correlates (Chapter 2 ).

Taken together, the presented findings confirm the necessity of the multidimensional approach to psychopathy, and indeed lead one to assume the existence of different psychopathic profiles with distinct (combinations of) expressions based on a child's position on each psychopathy dimension. Future research will have to further illuminate these different profiles. Concluding from the presented literature, we believe that the identification of differing psychopathy profiles might make major contributions to the design of specific (early) intervention methods based on an individuals' position on each dimension, i.e., dimensional profile.

\section{RESEARCH AIMS OF THE PRESENT DOCTORAL DISSERTATION}

The main research topics of this dissertation are based on the presented literature review. More specifically, the following research questions will be addressed:

* Can CU traits be reliably and validly measured by use of a self-report questionnaire, the Inventory of Callous-Unemotional Traits (ICU). As the occurrence of CU traits is regarded to be highly important in the development of psychopathy the question arises whether a measure of CU traits would be able to distinguish between antisocial and healthy control samples? (Chapter2)

* Is psychopathy in youths associated with a general inhibition problem or might mutually contradictory past research findings be related to the fact that most research did not take the role of the different psychopathy dimensions into account? (Chapter 3)

* Are reactive and proactive aggression differentially associated with response inhibition? (Chapter 3)

* How are the different psychopathy dimensions related to basal cortisol in antisocial youth as compared to a control sample? Is there support for the notion of cortisol as a biological marker for CU traits? (Chapter 4)

* Is the combination of the callous psychopathy dimension and externalizing symptoms differentially related to cognitive versus affective morality?

\section{(Chapter 5)}




\section{REFERENCES}

Barry, C. T., Frick, P. J., DeShazo, T. M., McCoy, M. G., Ellis, M., \& Loney, B. R. (2000). The importance of callousunemotional traits for extending the concept of psychopathy to children. Journal of Abnormal Psychology, 109(2), 335-340.

Barry, T. D., Thompson, A., Barry, C. T., Lochman, J. E., Adler, K., \& Hill, K. (2007). The importance of narcissism in predicting proactive and reactive aggression in moderately to highly aggressive children. Aggress Behav, 33(3), 185-197.

Berkowitz, L. (1993). Aggression: Its causes, consequences, and control. Philadelphia: Temple University Press.

Bezdjian, S., Tuvblad, C., Raine, A., \& Baker, L. A. (2011). The genetic and environmental covariation among psychopathic personality traits, and reactive and proactive aggression in childhood. Child Development, 82(4), 1267-1281.

Blair, J., Mitchell, D., \& Blair, K. (2005). The psychopath: emotion and the brain. Oxford, UK: Blackwell

Blair, K. S., Newman, C., Mitchell, D. G., Richell, R. A., Leonard, A., Morton, J., et al. (2006). Differentiating among prefrontal substrates in psychopathy: neuropsychological test findings. Neuropsychology, 20(2), 153-165.

Blair, K. S., Richell, R. A., Mitchell, D. G., Leonard, A., Morton, J., \& Blair, R. J. (2006). They know the words, but not the music: affective and semantic priming in individuals with psychopathy. Biological Psychology, 73(2), 114-123.

Blair, R. J. (2007). Dysfunctions of medial and lateral orbitofrontal cortex in psychopathy. Annals of the New York Academy of Sciences, 1121, 461-479.

Blair, R. J. (2010). Neuroimaging of psychopathy and antisocial behavior: a targeted review. Current Psychiatry Reports, 12(1), 76-82.

Blair, R. J., Colledge, E., Murray, L., \& Mitchell, D. G. (2001). A selective impairment in the processing of sad and fearful expressions in children with psychopathic tendencies. Journal of Abnormal Child Psychology, 29(6), 491-498.

Blair, R. J., Morris, J. S., Frith, C. D., Perrett, D. I., \& Dolan, R. J. (1999). Dissociable neural responses to facial expressions of sadness and anger. Brain, 122 (Pt 5), 883-893.

Blair, R. J. R. (2006). Subcortical Brain Systems in Psychopathy. In C. J. Patrick (Ed.), Handbook of psychopathy (pp. 296-312). New York, NY: Guilford Press.

Brandt, J. R., Kennedy, W. A., Patrick, C. J., \& Curtin, J. J. (1997). Assessment of Psychopathy in a Population of Incarcerated Adolescent Offenders. Psychological Assessment, 9(4), 429-435.

Burke, J. D., Loeber, R., \& Lahey, B. B. (2007). Adolescent conduct disorder and interpersonal callousness as predictors of psychopathy in young adults. Journal of Clinical Child and Adolescent Psychology, 36(3), 334-346.

Cale, E. M., \& Lilienfeld, S. O. (2006). Psychopathy factors and risk for aggressive behavior: a test of the "threatened egotism" hypothesis. Law and Human Behavior, 30(1), 51-74.

Christian, R. E., Frick, P. J., Hill, N. L., Tyler, L., \& Frazer, D. R. (1997). Psychopathy and conduct problems in children: II. Implications for subtyping children with conduct problems. Journal of the American Academy of Child and Adolescent Psychiatry, 36(2), 233-241. 
Cima, \& Raine, A. (2009). Distinct characteristics of psychopathy relate to different subtypes of aggression. Personality and Individual Differences, 47(8), 835-840.

Cima, M., Smeets, T., \& Jelicic, M. (2008). Self-reported trauma, cortisol levels, and aggression in psychopathic and non-psychopathic prison inmates. Biological Psychology, 78(1), 75-86.

Cleckley, H. (1941). The mask of sanity. St. Louis, MO: C.V. Mosby.

Cooke, D. J., \& Michie, C. (2001). Refining the construct of psychopathy: towards a hierarchical model. Psychological Assessment, 13(2), 171-188.

Cooke, D. J., Michie, C., \& Hart, S. (2006). Facets of clinical psychopathy: Toward clearer measurement. In C. J. Patrick (Ed.), The handbook of psychopathy (pp. 91-106). New York: Guilford Press.

Cornell, D. G., Warren, J., Hawk, G., Stafford, E., Oram, G., \& Pine, D. (1996). Psychopathy in instrumental and reactive violent offenders. Journal of Consulting and Clinical Psychology, 64(4), 783-790.

D'Silva, K., Duggan, C., \& McCarthy, L. (2004). Does treatment really make psychopaths worse? a review of the evidence. Journal of Personality Disorders, 18(2), 163-177.

Edens, J. F., Marcus, D. K., Lilienfeld, S. O., \& Poythress, N. G., Jr. (2006). Psychopathic, not psychopath: taxometric evidence for the dimensional structure of psychopathy. Journal of Abnormal Psychology, 115(1), 131-144.

Edens, J. F., Marcus, D. K., \& Vaughn, M. G. (2011). Exploring the taxometric status of psychopathy among youthful offenders: is there a juvenile psychopath taxon? Law and Human Behavior, 35(1), 13-24, online publication.

Finger, E. C., Marsh, A. A., Mitchell, D. G., Reid, M. E., Sims, C., Budhani, S., et al. (2008). Abnormal ventromedial prefrontal cortex function in children with psychopathic traits during reversal learning. Archives of General Psychiatry, 65(5), 586-594.

Fite, P. J., Stoppelbein, L., \& Greening, L. (2009). Proactive and reactive aggression in a child psychiatric inpatient population: Relations to psychopathic characteristics. Criminal Justice and Behavior, 36(5), 481493.

Flight, J. I., \& Forth, A. E. (2007). Instrumentally violent youths. The Roles of Psychopathic Traits, Empathy, and Attachment. Criminal Justice and Behaviour, 34(6), 739-751.

Fontaine, N., Barker, E. D., Salekin, R. T., \& Viding, E. (2008). Dimensions of psychopathy and their relationships to cognitive functioning in children. Journal of Clinical Child and Adolescent Psychology, 37(3), 690-696.

Forth, A. E., Kosson, D. S., \& Hare, R. D. (2003). Hare Psychopathy Checklist: Youth Version. Toronto, Ontario: Multi-Heath Systems.

Frick, P. J., Bodin, S. D., \& Barry, C. T. (2000). Psychopathic traits and conduct problems in community and clinic-referred samples of children: further development of the psychopathy screening device. Psychological Assessment, 12(4), 382-393.

Frick, P. J., Cornell, A. H., Barry, C. T., Bodin, S. D., \& Dane, H. E. (2003). Callous-unemotional traits and conduct problems in the prediction of conduct problem severity, aggression, and self-report of delinquency. Journal of Abnormal Child Psychology, 31(4), 457-470.

Frick, P. J., Cornell, A. H., Bodin, S. D., Dane, H. E., Barry, C. T., \& Loney, B. R. (2003). Callous-unemotional traits and developmental pathways to severe conduct problems. Developmental Psychology, 39(2), 246-260.

Frick, P. J., \& Hare, R. D. (2001). The antisocial process screening device. Toronto, ontario: Multi-Health Systems. 
Frick, P. J., \& Moffitt, T. (2010). A Proposal to the DSM-V Childhood Disorders and the ADHD and Disruptive Behavior Disorders Work Groups to Include a Specifier to the Diagnosis of Conduct Disorder based on the Presence of Callous-Unemotional Traits. American Psychiatric Association. DSM IV Development. http://www.dsm5.org/ProposedRevision/Pages/proposedrevision.aspx?rid = 424\#.

Frick, P. J., \& White, S. F. (2008). Research review: the importance of callous-unemotional traits for developmental models of aggressive and antisocial behavior. Journal of Child Psychology and Psychiatry and Allied Disciplines, 49(4), 359-375.

Gazzaniga, M. S., Ivry, R. B., \& Mangun, G. R. (2002). Executive Functions and Frontal Lobes. In M. S. Gazzaniga, R. B. Ivry \& G. R. Mangun (Eds.), Cognitive Neuroscience (2nd ed., pp. 499-535). New York: Norton \& Company, Inc.

Guay, J. P., Ruscio, J., Knight, R. A., \& Hare, R. D. (2007). A taxometric analysis of the latent structure of psychopathy: evidence for dimensionality. Journal of Abnormal Psychology, 116(4), 701-716.

Hare, R. D. (1991). The Psychopathy Checklist-Revised. Toronto, Ontario: Multi-Health Publishers.

Hare, R. D. (2003). The Psychopathy Checklist-Revised technical manual (2nd ed.). Toronto: Multi-Health Systems.

Hariri, A. R., Mattay, V. S., Tessitore, A., Kolachana, B., Fera, F., Goldman, D., et al. (2002). Serotonin transporter genetic variation and the response of the human amygdala. Science, 297(5580), 400-403.

Hawes, D. J., Brennan, J., \& Dadds, M. R. (2009). Cortisol, callous-unemotional traits, and pathways to antisocial behavior. Current Opinion in Psychiatry, 22(4), 357-362.

Holi, M., Auvinen-Lintunen, L., Lindberg, N., Tani, P., \& Virkkunen, M. (2006). Inverse correlation between severity of psychopathic traits and serum cortisol levels in young adult violent male offenders. Psychopathology, 39(2), 102-104.

Ishikawa, S. S., \& Raine, A. (2003). Prefrontal Deficits and Antisocial Behaviour. In B. B. Lahey, T. Moffitt \& A. Caspi (Eds.), Causes of Conduct Disorder and Juvenile Delinquency (pp. 277-304). London, New York: The Guilford Press.

Kiehl, K. A. (2006). A cognitive neuroscience perspective on psychopathy: evidence for paralimbic system dysfunction. Psychiatry Research, 142(2-3), 107-128.

Kimonis, E. R., Frick, P. J., Fazekas, H., \& Loney, B. R. (2006). Psychopathy, aggression, and the processing of emotional stimuli in non-referred girls and boys. Behavioral Sciences and the Law, 24(1), 21-37.

Kruh, I. P., Frick, P. J., \& Clements, C. B. (2005). Historical and Personality Correlates to the Violence Patterns of Juveniles Tried as Adults. Criminal Justice and Behaviour, 32(1), 69-96.

Lapierre, D., Braun, C. M., \& Hodgins, S. (1995). Ventral frontal deficits in psychopathy: neuropsychological test findings. Neuropsychologia, 33(2), 139-151.

Lilienfeld, S. O., \& Andrews, B. P. (1996). Development and preliminary validation of a self report measure of psychopathic personality traits in noncriminal populations. Journal of Personality Assessment, 66, 488-524.

Loney, B. R., Butler, M. A., Lima, E. N., Counts, C. A., \& Eckel, L. A. (2006). The relation between salivary cortisol, callous-unemotional traits, and conduct problems in an adolescent non-referred sample. Journal of Child Psychology and Psychiatry and Allied Disciplines, 47(1), 30-36. 
Loney, B. R., Frick, P. J., Clements, C. B., Ellis, M. L., \& Kerlin, K. (2003). Callous-unemotional traits, impulsivity, and emotional processing in adolescents with antisocial behavior problems. Journal of Clinical Child and Adolescent Psychology, 32(1), 66-80.

Loney, B. R., Frick, P. J., Ellis, M., \& McCoy, M. G. (1998). Intelligence, callous-unemotional traits, and antisocial behaviour. Journal of Psychopathology and Behavioural Assessment, 20(3), 231-247.

Lykken, D. T. (1957). A study of anxiety in the sociopathic personality. Journal of Abnormal Psychology, 55(1), 6-10.

Meloy, J. R. (2006). Empirical basis and forensic application of affective and predatory violence. Australian and New Zealand Journal of Psychiatry, 40(6-7), 539-547.

Moffitt, T. E. (1993). Adolescence-limited and life-course-persistent antisocial behavior: a developmental taxonomy. Psychological Review, 100(4), 674-701.

Moffitt, T. E., \& Silva, P. A. (1988). Self-reported delinquency, neuropsychological deficit, and history of attention deficit disorder. Journal of Abnormal Child Psychology, 16, 553-569.

Morgan, A. B., \& Lilienfeld, S. O. (2000). A meta-analytic review of the relation between antisocial behavior and neuropsychological measures of executive function. Clinical Psychology Review, 20(1), 113-136.

Munoz, L. C., \& Frick, P. J. (2007). The reliability, stability, and predictive utility of the self-report version of the Antisocial Process Screening Device. Scandinavian Journal of Psychology, 48(4), 299-312.

Munoz, L. C., Frick, P. J., Kimonis, E. R., \& Aucoin, K. J. (2008). Types of aggression, responsiveness to provocation, and callous-unemotional traits in detained adolescents. Journal of Abnormal Child Psychology, 36(1), 15-28.

Murrie, D. C., Marcus, D. K., Douglas, K. S., Lee, Z., Salekin, R. T., \& Vincent, G. (2007). Youth with psychopathy features are not a discrete class: a taxometric analysis. Journal of Child Psychology and Psychiatry and Allied Disciplines, 48(7), 714-723.

Neumann, C. S., Kosson, D. S., Forth, A. E., \& Hare, R. D. (2006). Factor structure of the Hare Psychopathy Checklist: Youth Version (PCL: YV) in incarcerated adolescents. Psychological Assessment, 18(2), 142154.

Nicolson, N. A. (2007). Hypothalamic-Pituitary-Adrenocortical Hormones. In L. J. Luecken \& L. C. Gallo (Eds.), Handbook of Physiological Research Methods in Health Psychology. Thousand Oaks, CA: Sage Publications.

Nigg, J.T., \& Huang-Pollock, C. L. (2003). An Early-Onset Model of the Role of Executive Functions and Intelligence in Conduct Disorder/Delinquency In B. B. Lahey, T. E. Moffitt \& A. Caspi (Eds.), Causes of Conduct Disorder and Juvenile Delinquency (pp. 227-253). London; New York: The Guilford Press.

Patrick, C. J. (1994). Emotion and psychopathy: startling new insights. Psychophysiology, 31(4), 319-330.

Patrick, C. J., Bradley, M. M., \& Lang, P. J. (1993). Emotion in the criminal psychopath: startle reflex modulation. Journal of Abnormal Psychology, 102(1), 82-92.

Patrick, C. J., Cuthbert, B. N., \& Lang, P. J. (1994). Emotion in the criminal psychopath: fear image processing. Journal of Abnormal Psychology, 103(3), 523-534.

Pezawas, L., Meyer-Lindenberg, A., Drabant, E. M., Verchinski, B. A., Munoz, K. E., Kolachana, B. S., et al. (2005). 5-HTTLPR polymorphism impacts human cingulate-amygdala interactions: a genetic susceptibility mechanism for depression. Nature Neuroscience, 8(6), 828-834. 
Porter, S., \& Woodworth, M. (2006). Psychopathy and aggression. In C. J. Patrick (Ed.), Handbook of Psychopathy. New York: The Guilford Press.

Poythress, N. G., \& Hall, J. R. (2011). Psychopathy and impulsivity reconsidered. Aggression and Violent Behavior, 16(2), 120-134.

Raine, A., Meloy, J. R., Bihrle, S., Stoddard, J., LaCasse, L., \& Buchsbaum, M. S. (1998). Reduced prefrontal and increased subcortical brain functioning assessed using positronemission tomography in predatory and affective murderers

Behavioural Sciences and the Law, 16, 319-332.

Roussy, S., \& Toupin, J. (2000). Behavioural Inhibition Deficits in Juvenile Psychopaths. Aggressive Behaviour, 26, 413-424.

Salekin, R. T., Neumann, C. S., Leistico, A. M., \& Zalot, A. A. (2004). Psychopathy in youth and intelligence: an investigation of Cleckley's hypothesis. Journal of Clinical Child and Adolescent Psychology, 33(4), 731742.

Salekin, R. T., Rosenbaum, J., Lee, Z., \& Lester, W. S. (2009). Child and adolescent psychopathy like a painting by Monet. Youth Violence and Juvenile Justice, 7(3), 239-255.

Seagrave, D., \& Grisso, T. (2002). Adolescent development and the measurement of juvenile psychopathy. Law and Human Behavior, 26(2), 219-239.

Sellbom, M., \& Verona, E. (2007). Neuropsychological correlates of psychopathic traits in a non-incarcernated sample. Journal of Research in Personality, 41, 276-294.

Shirtcliff, E. A., Vitacco, M. J., Graf, A. R., Gostisha, A. J., Merz, J. L., \& Zahn-Waxler, C. (2009). Neurobiology of empathy and callousness: implications for the development of antisocial behavior. Behavioral Sciences and the Law, 27(2), 137-171.

Snowden, R. J., \& Gray, N. S. (2011). Impulsivity and psychopathy: associations between the barrett impulsivity scale and the psychopathy checklist revised. Psychiatry Research, 187(3), 414-417.

Spain, S. E., Douglas, K. S., Poythress, N. G., \& Epstein, M. (2004). The relationship between psychopathic features, violence and treatment outcome: the comparison of three youth measures of psychopathic features. Behavioral Sciences and the Law, 22(1), 85-102.

Steinberg, L. (2002). The juvenile psychopath: Fads, fictions, and facts. National Institutes of Justice Perspectives on Crime and Justice: 2001 Lecture Series 5, 35-64.

Steinberg, L. (2005). Cognitive and affective development in adolescence. TRENDS in Cognitive Sciences, 9(2), 69-74.

Verona, E., Patrick, C. J., Curtin, J. J., Bradley, M. M., \& Lang, P. J. (2004). Psychopathy and physiological response to emotionally evocative sounds. Journal of Abnormal Psychology, 113(1), 99-108.

Vitacco, M. J., Neumann, C. S., Caldwell, M. F., Leistico, A. M., \& Van Rybroek, G. J. (2006). Testing factor models of the Psychopathy Checklist: Youth Version and their association with instrumental aggression. Journal of Personality Assessment, 87(1), 74-83.

Vitacco, M. J., Neumann, C. S., \& Wodushek, T. (2008). Differential relationships between the dimensions of psychopathy and intelligence: Replication with adult jail inmates. Criminal Justice and Behavior, 35(1), 48-55. 
Walsh, Z., Swogger, M. T., \& Kosson, D. S. (2009). Psychopathy and Instrumental Violence: Facet Level Relationships. Journal of Personality Disorders, 23(4), 416-424.

Williamson, S., Harpur, T. J., \& Hare, R. D. (1991). Abnormal processing of affective words by psychopaths. Psychophysiology, 28(3), 260-273.

Woodworth, M., \& Porter, S. (2002). In cold blood: characteristics of criminal homicides as a function of psychopathy. Journal of Abnormal Psychology, 111(3), 436-445. 



\title{
Assessing callous-unemotional
}

\author{
traits across different
}

groups of youths: further

cross-cultural validation

of the inventory of callous-

\section{unemotional traits}

Based on: Feilhauer, J., Cima, M. \& Arntz, A. (2012). Assessing callous-unemotional traits across different groups of youths: Further cross-cultural validation of the Inventory of CallousUnemotional Traits. International Journal of Law and Psychiatry; 35(4):251-62. 


\section{Abstract}

The Inventory of Callous-Unemotional (CU) Traits (ICU) is a self-report questionnaire which was developed to measure the affective features of psychopathy in children and adolescents. Previous studies reported both support and difficulties with this promising new measure. The present study investigated the psychometric and discriminating qualities of the Dutch questionnaire across different groups by examining its structure, distribution and correlates. The ICU was administered to young clinical offenders (detained, $N=127$ ), healthy controls (community, $N=172$ ), non-clinical offenders (not detained, $\mathrm{N}=42$ ) and an externalizing non-offender group (under treatment for behavioral problems, $N=42$ ). The age range for all groups was $13-20$ years. Since confirmatory factor analysis of models from earlier research did not yield an acceptable fit, exploratory factor analysis was conducted. Five factors were extracted: Lack of Conscience, Uncaring, Unemotional, Callousness and Lack of Empathy. The results indicated moderate to good test-retest stability and adequate internal consistency. CU traits correlated well with measures of conduct problems and aggression, indicating a good criterion and convergent validity. Results indicate weak associations with expert (Psychopathy Checklist: Youth Version, PCL:YV) and informant (Antisocial Process Screening Device, APSD) measures of psychopathic traits. Although groups could be differentiated on a statistical basis, no meaningful distinction based on CU traits alone was possible. Results of this study cast doubt on the validity of the current ICU. Suggestions are made for improvement. 


\section{INTRODUCTION}

In order to understand psychopathy as a developmental disorder, it is necessary to assess psychopathic traits in children and youths. Psychopathy describes a severe personality disorder which refers to a pattern of affective (e.g., lack of remorse, callousness), interpersonal (e.g., narcissism, manipulation, grandiosity), and behavioral characteristics (e.g., antisocial behavior, boredom, impulsivity, lack of realistic long-term goals). Particularly the affective deficits, also called callous-unemotional (CU) traits, are closely related to a profound underlying emotional dysfunction, which has been described as the core characteristic of the disorder (Cleckley, 1941; Hare, 2003). Today, psychopathy is generally assumed to be a developmental disorder, and the combination of behavioral problems with CU traits seems to be correlated with a particularly high risk of developing psychopathy later in life (Frick \& White, 2008). These children show more severe aggressive behavior and delinquency. This pattern holds for forensic, clinical and community samples (Frick, Cornell, Barry, Bodin, \& Dane, 2003; Kruh, Frick, \& Clements, 2005). Furthermore, youth with high CU traits have a decreased sensitivity to punishment (Barry et al., 2000; Fisher \& Blair, 1998) and react less to stimuli showing distress in others (Frick, Kimonis, Dandreaux, \& Farell, 2003; Loney, Butler, Lima, Counts, \& Eckel, 2006), which agrees with results from the adult literature on psychopathy. It seems thus that CU traits designate a group of children and adolescents with behavioral problems who early in their development display characteristics which can be associated with psychopathy.

In order to study CU traits in youth, it is important to have a valid instrument which is not time-consuming and provides a comprehensive and reliable assessment of these traits in different types of children and adolescents. So far, the most widely used measures of psychopathic traits are the Psychopathy Checklist: Youth Version (PCL-R:YV; Forth, Kosson, \& Hare, 2003) and the Antisocial Process Screening Device (APSD; Frick \& Hare, 2001).

The PCL:YV is a downwards extension of the adult PCL-R. Both instruments measure all aspects of the psychopathy construct and information is collected in a standardized, systematic fashion. The youth version was developed for detained juvenile offenders, aged 12-18. Like the adult version, it consists of a semi-structured interview which is combined with a thorough review of the adolescent's legal reports. The 20 items of the interview must be rated by specifically trained clinicians. It is, therefore, a time-consuming instrument and not appropriate for non-detained samples. Furthermore, only four items of the PCL:YV directly assess CU traits.

Due to these difficulties, much research on children and adolescents used the APSD to assess CU traits. The APSD is a 20-item rating scale comprising ratings by either parents, teachers (Frick \& Hare, 2001) or self -report ratings (Munoz \& Frick, 2007). It is applicable to detained and community samples. Like the PCL:YV, it examines the different aspects of psychopathy. Consequently, only six items form the callous-unemotional (CU) subscale. Items are rated on a 3-point scale. The few items and limited number of 
response options restrict the range of measure and could contribute to the moderate internal consistency found in many studies, especially those using the self-report version (e.g. Loney, Frick, Clements, Ellis, \& Kerlin, 2003; e.g. Munoz \& Frick, 2007). Furthermore, all but one of the items are worded positively, making it likely that ratings could be influenced by a specific response set (Essau, Sasagawa, \& Frick, 2006).

Acting on this, Frick developed the 24-item Inventory of Callous-Unemotional Traits (ICU; Frick, 2003) to provide a more comprehensive assessment of CU traits which overcomes some of the psychometric limitations of the six-item APSD subscale and the difficulties associated with the use of the PCL:YV. The items are built on the $4 \mathrm{CU}$ items of the APSD which consistently loaded on the CU scale of the APSD in both community and clinically referred samples (Frick, Bodin, \& Barry, 2000). For each of these 4 items, 5 additional content-related items were developed resulting in 6 items per content ( 3 positively and 3 negatively worded items). Furthermore, the ICU is rated on a 4-point Likert scale, thereby not allowing for a middle rating.

The ICU was originally developed as a unidimensional scale. In an initial test of its psychometric properties, Essau et al. (2006) conducted an exploratory factor analysis on a large German community sample ( $N=1443$, both boys and girls). Three factors were identified: Callousness, describing a callous attitude towards others; Uncaring, describing a lack of care about one's own performance; and Unemotional, describing a lack of emotional expression (Essau et al., 2006). With the best fitting factor structure, all items loaded on the three distinct factors as well as on a general factor including all CU traits (bifactor model; e.g. Patrick, Hicks, Nichol, \& Krueger, 2007). These results justify the use of subscales or the total ICU scale (Essau et al., 2006). Kimonis et al. (2008b) replicated these results in an American sample of detained youth ( $\mathrm{N}=248$, both boys and girls). Furthermore, studies with Greek and Belgian community samples ( $N=347$ and $N=455$, both boys and girls) were conducted (Fanti, Frick, \& Georgiou, 2009; Roose, Bijttebier, Claes, Decoene, \& Frick, 2009).

Although results were promising a number of limitations occurred. First, in the initial analysis, the best fitting factor model required an increased number of correlated error terms ( $n=25)$ to improve the model, which could have been sample-dependent (Essau et al., 2006; Kimonis, Frick, Skeem et al., 2008). Although later analyses did replicate the factor structure suggested by Essau et al. (2006), the bifactor model failed to achieve an acceptable fit on all indices (Fanti et al., 2009; Kimonis, Frick, Skeem et al., 2008; Roose et al., 2009). Furthermore, the bifactor model applied by Essau et al. (2006) specifies that in addition to the three independent, uncorrelated subfactors, there is a general "callousunemotional" factor underlying each ICU item. However, in the studies by Kimonis et al. (2008b) and Fanti et al. (2009), the Uncaring items in particular loaded on the general factor, and Callousness and Unemotional items loaded only slightly on the general factor, thus violating the initial assumptions of the model. Hence, when controlling for the general factor, item loadings of the Uncaring factor tended to be low. Furthermore, although positively and negatively worded items are equally distributed across the ICU, the 
Callousness subscale consists largely of negatively worded items, whereas the Uncaring subscale consists largely of positively worded items. This raises the question whether the occurrence of these different subscales is more a function of method variance rather than real construct variance (Burke, 1999; Cordery \& Sevastos, 1993; Schmitt \& Stults, 1985).

Second, three of the four studies reported only a marginal internal consistency for the Unemotional subscale (Essau et al., 2006; Fanti et al., 2009; Kimonis, Frick, Skeem et al., 2008). This might be due to the rather small item number of only five items.

Third, apart from difficulties regarding reliability and model fit, earlier studies did not compare the ICU to CU trait measurements other than self-report, such as the PCL:YV.

Fourth, none of the earlier studies compared the validity of the ICU across various settings, including community, clinical and detained samples of youths. High levels of CU traits have been shown to characterize youths showing severe antisocial and aggressive tendencies. However, certain degrees of CU traits are normative and change over the life-course (Seagrave \& Grisso, 2002). Different aspects of CU traits naturally occur during puberty, with youths being e.g. grandiose, prone to boredom, irresponsible and goalless (Steinberg, 2002, 2004, 2005). CU traits might thus not be as stable in youth as they are in adults (Seagrave \& Grisso, 2002). It would therefore be important to know whether a selfreport questionnaire can discriminate between various groups of youths based on CU traits so as to identify children and adolescents high on these traits as early as possible.

Therefore, the aim of this study was to investigate the psychometric properties of the ICU in a mixed sample drawn from the community, clinical patients and offenders. More specifically, the first aim was to explore the ICU factor structure by using confirmative as well as exploratory factor analysis. The second aim was to assess the convergent validity of the ICU using measures designated to tap similar personality traits and measures of diverse forms of aggression. On the whole, positive correlations with the ICU total were expected, while analyses were more exploratory at the subscale level. Furthermore, criterion validity was assessed by relating it to measures of externalizing symptoms. Third, and most important, the discriminant validity of the ICU was assessed by comparing the different samples on the ICU questionnaire and calculating receiver operating characteristic (ROC) curves. It was hypothesized that clinical offenders would differ from the healthy controls, with the other two groups falling in between.

\section{METHODS}

\section{Participants}

A total of 383 male children and youths were examined. Since data was collected from different research projects, not all subjects completed all reported measurements, and so sample sizes differ between instruments. 
Externalizing non-offenders ( $\mathrm{N}=42$, under treatment for behavioral problems) were recruited from a child and adolescent mental health division for behavioral problems (mean age 10.60 (1.7), range 8-14).

Clinical offenders ( $N=127$, detained) were recruited from youth detention centers in the Dutch provinces of Limburg and Brabant (mean age 15.74 (1.22), range 13-20).

Non-clinical offenders ( $N=42$, not detained) were recruited through the Dutch Child Protection Board, which is part of the Dutch Ministry of Justice (mean age 16.30 (1.50), range 12-18).

Healthy controls $(\mathrm{N}=72)$ were recruited from local public schools (mean age 12.80 (3.21), range 8-17).

\section{Procedures}

This research was approved by the University Ethical Committee. In the information letter it was made clear that participation was voluntary and that participants were free to discontinue their participation at any time. In case the participants were below 18, parents and child gave informed consent.

Externalizing non-offenders: All participants and parents received written information and gave informed consent.

Clinical offenders: At the time of incarceration, parents were asked to give permission for their child's participation in scientific research. The youths were individually approached for participation. It was made clear that participation would by no means influence their treatment or legal standing. They received written information and gave informed consent.

Non-clinical offenders: After permission from the ethical committee of the Dutch Child Protection Board, written information and entry forms were distributed to the offenders by the psychologist. After receiving informed consent, researchers contacted the family and made appointments.

Healthy controls: Control subjects were approached at school by either the school counselor or the researchers. After receiving informed consent, testing took place at school. It was made clear that results would not be communicated to the teachers.

\section{INSTRUMENTS}

The Inventory of Callous-Unemotional Traits (ICU) is a self-report instrument which measures the occurrence and intensity of CU traits (Frick, 2003). The 24 items are scored on a four-point Likert scale (ranging from $0=$ not at all true to $3=$ definitely true), thus not allowing for an exact middle rating. Half of the items are positively worded and must be reversed before calculating the total and subscales (see Essau et al., 2006). Previous 
research recommended 3 subscales measuring Uncaring, Callousness and Unemotional. Internal consistency is adequate, with a range of .74-.85 for the total scale and .53-.81 for the subscales, the Unemotional scale showing only marginal internal consistency (Essau et al., 2006; Kimonis, Frick, Skeem et al., 2008). The construct validity of the questionnaire was found to be appropriate (Kimonis, Frick, Skeem et al., 2008). Translation was done following accepted practical guidelines (van de Vijver \& Hambleton, 1996). All 383 participants completed the ICU.

The Aggression Questionnaire (AQ; Buss \& Perry, 1992; Meesters, Muris, Bosma, Schouten, \& Beuving, 1996), is a 29-item questionnaire assessing aggression in three components: a behavioral component represented by the subscales of physical aggression and verbal aggression, an emotional component covered by the anger subscale, and a cognitive component represented by hostility. Items were scored on a 5-point Likert scale (from $1=$ extremely unlike me to $5=$ extremely like me). The $A Q$ is a reliable and valid measure with sufficient internal consistency in Dutch student and offender samples ranging from .51 to .86 and appropriate construct validity (Meesters et al., 1996; Morren \& Meesters, 2002). In the present study, internal consistency was acceptable to good for physical aggression, hostility and the total scale, ranging from .70 to .88. Alphas for verbal aggression and anger ranged from .53 to .67. This questionnaire was completed by 198 participants.

The Reactive-Proactive Aggression Questionnaire (RPQ; Raine et al., 2006), is a 23item self-report questionnaire which distinguishes between motivated, proactive aggression (physical and verbal, 12 items) and reactive aggression (in response to external stimuli, 11 items). Items were scored on a three-point scale $(0=$ never, $1=$ sometimes, 2 =often). The questionnaire has high internal consistency (Cronbach's $a=.89-.91$ ), and good validity (Raine et al., 2006). In this study, consistency measures were comparable, with a Cronbach's a of .90 for the total scale, .80 for the reactive, and .86 for the proactive subscale. Translation of the RPQ (Cima, Otgaar, \& Merkelbach, in preparation) was done following accepted practical guidelines (van de Vijver \& Hambleton, 1996). The RPQ was completed by 256 participants.

The Narcissistic Personality Inventory for Children (NPIC; Barry, Frick, \& Killian, 2003) is a 40-item forced-choice inventory with items which closely mirror items from the adult NPI (Raskin \& Terry, 1988) but which are developmentally appropriate. Respondents choose one statement out of two. Further the endorsed statement is rated as either "sort of true" or "really true", thus creating a 4-point scale. Adaptive and maladaptive composites were formed from the seven dimensions (Barry et al., 2003). The Self-sufficiency and Authority scales were summed to form the adaptive narcissism composite (Cronbach's $a=.62$ ). The maladaptive narcissism composite was formed using items from the Exhibitionism, Exploitativeness and Entitlement scales (Cronbach's $a=.66)$. The internal consistency coefficient for the total scale was good here (Cronbach's $a=0.88$ ). Results agreed with earlier research (Barry et al., 2007). Composites have been shown to be indicators of current and predictors of later behavioral problems in youths (e.g. Barry et al., 2003). The 
vanity and superiority dimensions were not included in the analyses because they could not be placed in either the adaptive or the maladaptive dimension (Barry et al., 2003). Translation was done following accepted practical guidelines (van de Vijver \& Hambleton, 1996). 137 participants completed the NPIC.

The Antisocial Process Screening Device (APSD; Frick \& Hare, 2001) is a 20-item scale assessing psychopathic traits in children and adolescents. The questionnaire can be completed by a parent, a teacher or as self-report. Also, parent and teacher ratings can be combined. In this study, the Dutch APSD parent version was used (Bijttebier \& Decoene, 2009). Items were rated on a three-point scale $(0=$ not at all, $1=$ sometimes true, $2=$ definitely true), total score range 0 to 40. Factor analysis revealed a three-factor structure: Narcissism (7 items); Callous-Unemotional Traits ( 6 items, 5 of which are reverse-scored); and Impulsivity (5 items). Items 2 and 6 were excluded (Vitacco, Rogers, \& Neumann, 2003). In this study, internal consistency was acceptable to good, with .63 for the Callous-Unemotional scale, .79 for the Impulsivity scale, .80 for the Narcissism scale, and .88 for the total APSD. This questionnaire was completed by 76 participants.

Aspects of psychopathy were measured using the Psychopathy Checklist: Youth version (PCL:YV, unpublished authorized Dutch research version: (de Ruiter, de Vries, \& Das, 2002). Traditionally, the 20 items are divided into 2 factors, with Factor 1 (F1) representing the affective-interpersonal dimension and Factor 2 (F2) the antisocial dimension. All items were scored on a three-point scale $(0=$ does not apply, $1=$ applies to a certain extent, 2 = fully applies), yielding a dimensional total score of 0-40. Ratings were based on an interview and collateral information. The validity of the two-factor model regarding external criteria is well documented (Fowles \& Dindo, 2006). The PCL:YV has good psychometric qualities (see Das, de Ruiter, Doreleijers, \& Hillege, 2009; Das, de Ruiter, Lodewijks, \& Doreleijers, 2007). In this study, consistency measures were comparable, with a Cronbach's a of .95 for the total scale, .90 for Factor 1, and .91 for Factor 2. Interrater reliability (ICC; two-way random, absolute agreement) was good for Factor 1 (.66) and excellent for Factor 2 (.87), with a PCL-R total of .84 (Fleiss, 1986). This interview was administered to 70 detained youths.

\section{Clinical evaluation}

The National Institute of Mental Health Diagnostic Interview Schedule for Children (DISC) Dutch version 2002 was used for this study. After appropriate training, this interview can be administered by lay interviewers without formal clinical training. It consists of a child and a parent/guardian form and addresses diagnostic criteria for DSM-IV diagnoses. In the present study, module E of the child form was used to clinically assess symptoms of ADD, HY, ODD and CD (Fisher, Wicks, Shaffer, Piacentini, \& Lapkin, 1992; Verhulst, van der Ende, Ferdinand, \& Kasius, 1997). Reliability and validity of the English version are adequate (Lahey \& Loeber, 1994; Shaffer, Fisher, Lucas, Dulcan, \& Schwab-Stone, 2000). Inter- 
rater reliability for $C D$ is excellent. Good reliability and validity of the Dutch version were taken for granted since it is very close to the original text (Verhulst et al., 1997). The DISC, which was developed for children and youths aged 6-17 years, assesses the presence of clinically significant symptoms over the range of the past 12 months and during the last 4 weeks (Shaffer et al., 2000). For CD, it also assesses the number of lifetime symptoms. Since most of the subjects had already been in detention for much of the last 12 months, the number of lifetime CD symptoms was used as an index for CD. Indices for ADD, HY and ODD contain symptoms which occurred over the last 12 months. The DISC interview was given to 138 subjects.

\section{ANALYSES}

Distribution of variables was examined in the entire sample. For outliers on the ICU, change scores were calculated to bring them back to \pm 3 SDs, yielding skewness and kurtosis values between -1.0 and +1.0. Random missing values occurred on ICU and AVL items. A missingvalue analysis applying the Examination Maximization (EM) method was done. There were no missing values for the remaining variables. Skewness and kurtosis ranged from -2.0 to +2.0 , as would be expected from the sample distribution .Examining all pairwise scatterplots to assess linearity was deemed unfeasible and not done. Pairs of scatterplots were randomly selected for comparison. All variables appeared to be linearly related, if at all.

First, the ICU factor structure was examined using confirmatory factor analysis (CFA) with maximum likelihood estimation using LISREL 8.54. The ratio of cases to observed variables was 16:1, and the ratio of cases to estimated parameters was 8:1. Goodness of fit was evaluated based on indices of model fit applied by previous ICU factor analyses (Essau et al., 2006; Fanti et al., 2009; Kimonis, Frick, Skeem et al., 2008; Roose et al., 2009). Tests done included the chi-square fit, the $X 2 /$ df ratio, the Standardized Root Mean Residual (SRMR), the Root Mean-square Error of Approximation (RMSEA), the Comparative Fit Index (CFI), the Goodness of Fit Index (GFI), the Adjusted GFI (AGFI), the Akaike Information Criterion (AIC), and the consistent AIC (Akaike, 1987; Hu \& Bentler, 1998; Kline, 1998; CAIC, Schermelleh-Engel, Moosbrugger, \& Mueller, 2003). An adequate model fit is indicated by a X2/df ratio of 2-3, SRMR $\leq 0.09$, RMSEA $\leq 0.06, \mathrm{CFI}$ and GFI $\geq 0.95$ and AGFI $\geq 0.90$ (Schermelleh-Engel et al., 2003; Schumacker \& Lomax, 1996). As for AIC and CAIC, smaller values indicate a better model fit (Akaike, 1987). Models were statistically compared to each other using pairwise chi-square difference tests. The determinant of the covariance matrix is not given in the LISREL output, but the programme converged so the covariance matrix was assumed not to be singular.

Due to the poor CFA results, an exploratory factor analysis (EFA) was conducted. Scree test and principal-component analysis were done with varimax rotation and Kaiser normalization. 
Reliability of ICU was analyzed using internal consistency (Cronbach's a) and testretest stability. Convergence and criterion validity were assessed using Pearson correlations. Discriminant validity was assessed with a one-way analysis of variance (ANOVA), with group as the fixed factor and ICU total as the dependent variable. Furthermore, a multivariate analysis of variance (MANOVA) was done, again with group as the fixed factor. The ICU subscales constituted the dependent variables. Furthermore, sensitivity and specificity as well as the positive and negative predictive value of the ICU total were assessed by calculating receiver operating characteristic (ROC) curves and crosstabs. Offenders (combined clinical and non-clinical group) were compared to the healthy controls or the externalizing group.

\section{RESULTS}

\section{Descriptive statistics}

Table 1 shows the means and standard deviations of ICU, RPQ, PQC, AQ, NPIC, APSD and PCL:YV total and subscales.

\section{Factor analysis}

Four sets of confirmatory factor analysis were conducted to test which of the models applied by earlier researchers fit the data best (Essau et al., 2006; Fanti et al., 2009; Kimonis, Frick, Skeem et al., 2008; Roose et al., 2009). The first model was a single-factor model where all items load to a single callous-unemotional factor (Model 1). The second model was a three-factor intercorrelated model where items can be separated into the three intercorrelated factors (Model 2). The third model was a three-factor hierarchical model where items load to the three distinct intercorrelated lower-order factors, which in turn load to a higher-order callous-unemotional factor (Model 3). This shows that the domain being modeled describes one construct which can be broken down into increasingly specific facets (Patrick et al., 2007). The fourth model was a bifactor model where all items load to a general callous-unemotional factor as well as to three distinct factors (Model 4). All factors are measures of the general factor, but some also index more specific constructs which do not correlate with the general factor (Patrick et al., 2007). 
Table1. Means and standard deviations [M (SD)] of all scales included in the correlation analyses arranged by group

\begin{tabular}{|c|c|c|c|c|}
\hline & $\begin{array}{l}\text { Healthy } \\
\text { controls }\end{array}$ & $\begin{array}{l}\text { Clinical } \\
\text { offenders }\end{array}$ & $\begin{array}{l}\text { Non-clinical } \\
\text { offenders }\end{array}$ & $\begin{array}{l}\text { Externalizing } \\
\text { non-offenders }\end{array}$ \\
\hline & $N=172$ & $N=127$ & $N=42$ & $N=42$ \\
\hline \multicolumn{5}{|c|}{ M (SD) } \\
\hline ICU & $N=172$ & $N=127$ & $N=42$ & $\mathrm{~N}=42$ \\
\hline Lack of Conscience & $5.47(3.27)$ & $7.39(3.31)$ & $8.15(3.75)$ & $7.00(3.25)$ \\
\hline Uncaring & $2.43(2.78)$ & $2.24(2.15)$ & $3.23(2.76)$ & $5.88(2.83)$ \\
\hline Unemotional & $3.94(2.28)$ & $4.99(2.79)$ & $5.45(2.70)$ & $4.17(2.08)$ \\
\hline Callousness & $4.50(2.52)$ & $5.18(2.59)$ & $4.98(2.97)$ & $3.88(2.74)$ \\
\hline Lack of Empathy & $7.12(2.57)$ & $7.99(2.50)$ & $7.85(2.72)$ & $7.60(2.54)$ \\
\hline ICU Total & $23.45(8.06)$ & $27.80(8.85)$ & $29.45(8.99)$ & $28.52(6.38)$ \\
\hline PCL:YV & $N=0$ & $N=70$ & $N=0$ & $N=0$ \\
\hline Affective/Interpersonal & & $5.61(3.81)$ & & \\
\hline & & $8.23(3.44)$ & & \\
\hline Antisocial (F2) & & $13.84(6.48)$ & & \\
\hline PCL-R:YVTotal & & & & \\
\hline APSD (parent -report) & $N=37$ & $N=0$ & $N=0$ & $N=39$ \\
\hline CU-Traits & $2.65(1.44)$ & & & $4.46(2.64)$ \\
\hline Narcissism & $2.81(2.12)$ & & & $7.51(2.79)$ \\
\hline Impulsivity & $2.62(1.50)$ & & & $6.41(1.98)$ \\
\hline APSD Total & $8.08(3.88)$ & & & $18.38(6.03)$ \\
\hline NPIC & $N=67$ & $N=70$ & $N=0$ & $N=0$ \\
\hline Adaptive Narcissism & $18.63(5.24)$ & $21.70(7.82)$ & & \\
\hline Maladaptive Narcissism & $21.03(5.88)$ & $26.37(10.08)$ & & \\
\hline NPIC Total & $48.94(12.64)$ & $59.87(20.75)$ & & \\
\hline $\mathrm{RPQ}$ & $N=87$ & $N=127$ & $N=42$ & $N=0$ \\
\hline Proactive Aggression & $4.84(6.03)$ & $5.66(4.34)$ & $17.98(4.77)$ & \\
\hline Reactive Aggression & $10.08(5.70)$ & $10.54(4.38)$ & $21.29(3.98)$ & \\
\hline RPQ Total & $14.92(11.34)$ & $16.20(7.91)$ & $39.26(7.91)$ & \\
\hline $\mathrm{AQ}$ & $N=86$ & $N=70$ & $N=42$ & $N=0$ \\
\hline Physical Aggression & $23.62(6.26)$ & $30.21(7.10)$ & $28.21(7.79)$ & \\
\hline Verbal Aggression & $13.58(2.12)$ & $15.80(2.51)$ & $15.05(3.18)$ & \\
\hline Anger & $15.97(4.04)$ & $19.99(4.99)$ & $17.71(4.65)$ & \\
\hline Hostility & $18.04(5.31)$ & $20.76(5.40)$ & $20.38(5.76)$ & \\
\hline AQ Total & $71.21(13.86)$ & $86.76(16.04)$ & $81.36(15.61)$ & \\
\hline
\end{tabular}

Note: ICU =inventory of Callous-Unemotional Traits, PCL: YV=Psychopathy Checklist: Youth Version, APSD = Antisocial Process Screening Device, NPIC = Narcissistic Personality Inventory for Children, RPQ = Reactive-Proactive Aggression Questionnaire, Aggression Questionnaire 
Model 1 was tested as a baseline model. Fit indices were not acceptable, suggesting the existence of meaningful ICU subscales. Table 2 gives an overview of the models and fit indices reported here and in earlier studies. For Model 2, analysis gave an inadequate fit to the data. Model 3 showed further improvement of the model fit, although it remained insufficient. Although Model 4, the bifactor model, fit the data better than the other three, it also failed to yield an adequate fit. Statistical comparison of model fit revealed a significantly better fit of Model 2 than Model $1\left(\Delta x 2_{(3)}=207.92, p<.001\right)$. There also were significant differences between Models 3 and $4\left(\Delta x 2_{(21)}=139.67, p<.001\right)$.

Consequently, an exploratory factor analysis was done to examine the ICU dimensionality. Factor analyses with oblique promax rotation did not yield factor correlations $>.25$, indicating less than 10\% overlap between factors, justifying orthogonal rotation (Tabachnick \& Fidell, 2007). Principal-component analysis with varimax rotation and Kaiser normalization was used to explore the ICU factor structure. Kaiser's measure of sampling adequacy indicated adequate factorability $(K M O=.76)$. Seven scree test components had eigenvalues $>1$. Inspection of the scree plot indicated a crease after components 3 and 5 . The 5-factor solution (Table 3) yielded the best acceptable solution, which explained $46 \%$ of the total variance after rotation. The first factor consisted of items related to a Lack of Conscience (e.g., "I apologize (say I am sorry) to persons I hurt"; reverse scoring). Lack of Conscience explained $11.4 \%$ of the variance and had an eigenvalue of 2.7. A second factor consisted of items related to a lack of caring about one's own performance and others (e.g., "I do not care about doing things well") and was termed Uncaring. Uncaring explained $9.8 \%$ of the variance and had an eigenvalue of 2.3 . The third factor consisted of items describing a lack of emotional expression (e.g., "I do not show my emotions to others") and was termed Unemotional. Unemotional explained 8.5\% of the variance and had an eigenvalue of 2.0. A fourth factor described items related to a callous attitude (e.g.,"I do not feel remorseful when I do something wrong") and was named Callousness. Callousness explained $8.3 \%$ of the variance and had an eigenvalue of 2.0.The final factor described items related to a lack of empathy (e.g., "I am concerned about the feelings of others"; reverse scoring) and was named Lack of Empathy. Lack of Empathy explained $8.0 \%$ of the variance and had an eigenvalue of 1.9.

Comparison of the rotated oblique and orthogonal factor rotations indicated similar results across the different rotation methods, indicating stability of the solution found. Still, factor loadings suggest lack of a simple structure on several variables in both solutions. Certain items loaded high on more than one factor and were moved to another subscale for contextual reasons in both solutions (see table 3 for the orthogonal rotation). 


\section{Reliability}

Two aspects of reliability were assessed: internal consistency and test-retest reliability. The internal consistency in the mixed sample for the ICU was acceptable (Cronbach's $a=.71)$. The internal consistency of the factors Lack of Conscience and Uncaring also was acceptable with .71 and .72. Cronbach's alpha was marginal for the Unemotional factor, with .63. The factors Callousness and Lack of Empathy had poor consistencies, $a=.46$ and .48. Item-total correlations did not suggest that the deletion of any item would significantly improve internal consistency. The low consistency scores probably were due to the small number of factor items (Unemotional, 4 items; Callousness, 5 items; Lack of Empathy, 5 items). Applying the Spearman-Brown Prophecy to these factors showed that increasing the factor length to 10 items by adding items with the same properties as those in the current factors would increase the internal consistency of these factors to .95 for Unemotional, .63 for Callousness and .65 for Lack of Empathy. The ICU subscales were weakly $(r=.08)$ to moderately $(r=.41)$ interrelated. 


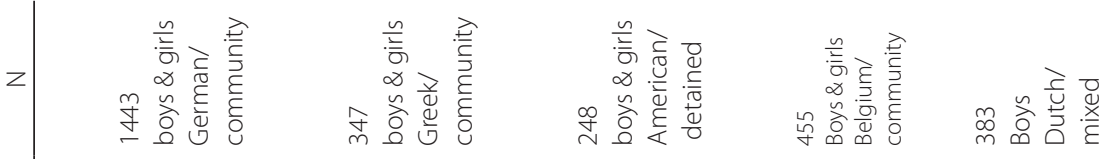

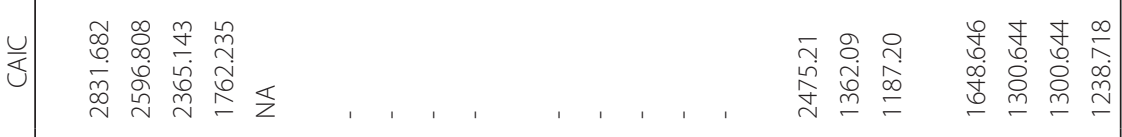

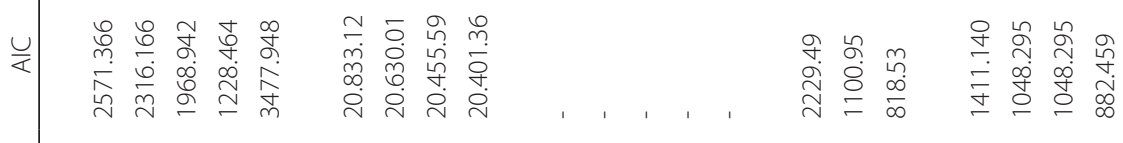

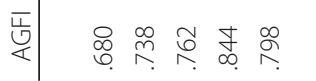

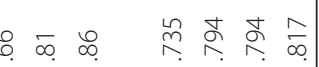

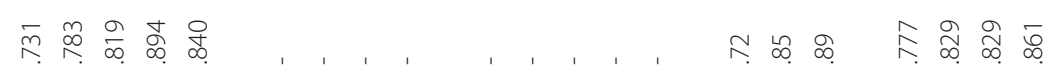

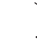

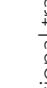

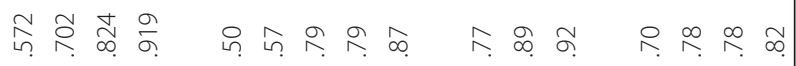

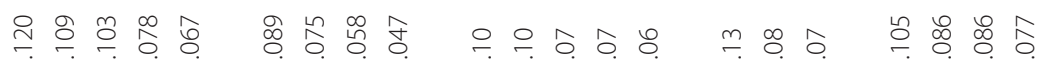
우요.

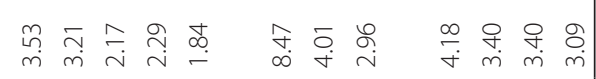

$\sqrt{x}$

인

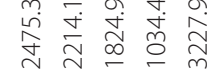

$\stackrel{\infty}{\infty} \underset{\infty}{\infty} \underset{\sim}{\stackrel{n}{i}} \underset{\infty}{\infty} \underset{\infty}{\stackrel{n}{i}}$

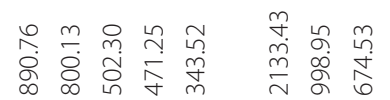

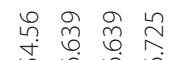

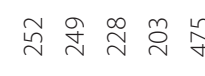
f ్ㅗㄱ 웛

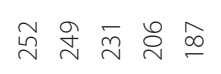

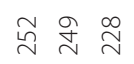

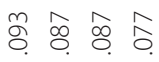
(2) $\frac{O}{\infty}$
$\infty$
$\tilde{y}$
$\underline{\underline{y}}$<smiles>[CH]1CC1</smiles>

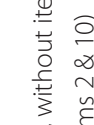

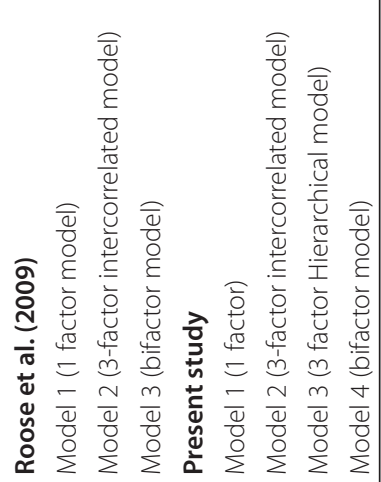


Table 3. Factor structure of the Inventory of Callous-Unemotional Traits (ICU) for the total sample $(\mathrm{N}=383)$

\section{Lack of Conscience}

*23. I work hard on everything I do.

*15. I always try my best.

$\begin{array}{lrrrr}.761 & .023 & .061 & -.013 & -.011 \\ .727 & -.036 & .021 & -.199 & -.145 \\ .652 & -.101 & -.175 & -.155 & .183 \\ .566 & -.163 & -.100 & -.083 & .264 \\ .543 & -.046 & -.093 & .179 & .319 \\ .376 & .050 & .022 & -.138 & .198 \\ & & & & \\ & & & & \\ .055 & .805 & .151 & .042 & -.015 \\ .214 & -.702 & -.085 & .018 & .188 \\ .016 & .602 & .134 & .328 & -.078 \\ -.168 & .438 & .088 & .459 & -.072\end{array}$

\section{Uncaring}

4. I do not care who I hurt to get what I want.

*3. I care about how well I do at school or work.

11. I do not care about doing things well.

.438

.088

$-.072$

well.

\section{Unemotional}

6. I do not show my emotions to others.

22. I hide my feelings from others.

12. I seem very cold and uncaring to others.

*1. I express my feelings openly.

.045

.019
.077
.205

.767

$.076 \quad-.042$

$-.113$

.715

$.074 \quad .031$

.603

$.214 \quad .112$

.130

$-.531$

$.064 \quad .409$

\section{Callousness}

9. I do not care if I get into trouble.

18. I do not feel remorseful when I do something wrong.

10. I do not let my feelings control me.

7. I do not care about being on time.

2. What I think is 'right' and 'wrong' is different from what other people think.

$\begin{array}{rrrrr}-.144 & .069 & .176 & \mathbf{. 6 8 1} & .009 \\ -.079 & .130 & -.048 & \mathbf{. 5 8 7} & -.299 \\ & & & & \\ .231 & -.418 & .143 & . \mathbf{4 6 1} & -.177 \\ -.158 & .059 & .282 & . \mathbf{4 3 5} & .014 \\ -.103 & .034 & .084 & . \mathbf{4 0 4} & .400\end{array}$

\section{Lack of Empathy}

*8. I am concerned about the feelings of others.

*5. I feel bad or guilty when I do something wrong.

$\begin{array}{rrrrr}.194 & -.057 & .092 & -.020 & \mathbf{. 6 8 5} \\ .324 & -.062 & .003 & -.240 & . \mathbf{4 7 3} \\ -.057 & .242 & .071 & .225 & \mathbf{- . 4 3 8} \\ .225 & .300 & -.106 & -.064 & .363 \\ .008 & .425 & -.153 & .064 & .359\end{array}$

21. The feelings of others are unimportant to me.

*14. It is easy for others to tell how I am feeling.

*19. I am very expressive and emotional.

Note: Boldface indicates factor loadings larger than or equal to .40. 0.40 (or the highest factor loading for the item) was the cut-off point for factor loadings. Extraction method: Principal component Analysis. Rotation Method: Varimax with Kaiser Normalization; ${ }^{*}=$ Items which require reverse scoring before calculation of the total score. Items 19 and 20 were moved to another subscale for contextual reasons 
Test-retest stability (mean interval 43 weeks) of the ICU was reasonably good for the total scale $(r=.72, p<.001)$ and moderate for the subscales (all $\left.r^{\prime} s>.42, p<.036\right)$ in a mixed sample of 13 healthy controls and 17 clinical offenders. Table 4 shows the means and standard deviations at the two measurement points.

Table 4. Means (SD) of ICU total and subscales at the two measurement points $(\mathrm{N}=30)$

\begin{tabular}{lcccccc} 
& ICU Total & $\begin{array}{c}\text { Lack of } \\
\text { Conscience }\end{array}$ & Uncaring & Unemotional & Callousness & $\begin{array}{c}\text { Lack of } \\
\text { Empathy }\end{array}$ \\
\hline Measure 1* & $22.50(8.20)$ & $5.70(2.74)$ & $1.47(1.74)$ & $3.63(2.46)$ & $4.53(1.96)$ & $7.17(2.70)$ \\
Measure 2 & $24.83(8.80)$ & $6.20(2.85)$ & $1.70(1.77)$ & $4.17(2.76)$ & $4.97(3.00)$ & $7.80(2.64)$ \\
\hline
\end{tabular}

Note: ${ }^{*}$ mean in terval in months $=10.70$ (6.10); Range of total scale 0-72

\section{Convergent validity}

Table 5 shows correlations of the ICU with aggression (RPQ, AQ), psychopathic and personality traits (APSD, PCL: YV and NPIC).

The ICU was significantly and positively related to the RPQ and AQ aggression measures. The magnitude of the correlations differed according to the specific subscale. Only correlations with Lack of Empathy did not reach significance for any of the RPQ subscales and the AQ subscales Verbal Aggression, Anger and Hostility. On the whole, correlations for the RPQ were strongest with Uncaring and the ICU total. The AQ showed the strongest correlations with the ICU total.

Regarding correlations with other measures of psychopathy traits, the strongest correlations were found with the ICU total. Correlations between the ICU total and PCL:YV (two-factor model) were generally positive, but not significant. The PCL:YV affective/interpersonal factor showed significant correlations with the ICU factors Lack of Conscience and Uncaring. The PCL:YV antisocial factor was significantly related to Uncaring, and the PCL:YV total significantly related to the ICU factors Lack of Conscience and Uncaring.

On the whole, there were positive correlations between ICU and APSD (parent version). More specifically, the ICU total factor was significantly related to the APSD Impulsivity subscale. Furthermore, there were significant correlations between Lack of Conscience and the APSD total, the Callous-Unemotional and Impulsivity subscales of the APSD.

Regarding correlations between the ICU and the NPIC, significant positive correlations with the ICU Lack of Conscience factor were seen for the Maladaptive Narcissism scale and the NPIC total. 
Table 5. Associations between ICU scales PCL-YV (N=70), APSD $(N=76), N P I C(N=137), R P Q(N=256)$ and $\mathrm{AQ}(\mathrm{N}=198)$

ICU Lack of
Total conscience Uncaring Unemotional Callousness $\begin{gathered}\text { Lack of } \\ \text { Empathy }\end{gathered}$

\begin{tabular}{|c|c|c|c|c|c|c|}
\hline \multicolumn{7}{|l|}{ PCL:YV } \\
\hline Affective/ Interp. (F1) & .14 & $27^{*}$ & $.27^{*}$ & -.12 & .13 & -.07 \\
\hline Antisocial (F2) & .09 & .15 & $.25^{*}$ & -.09 & .14 & -.11 \\
\hline PCL:YV Total & .13 & $.24^{*}$ & $.29^{*}$ & -.12 & .15 & -.10 \\
\hline \multicolumn{7}{|l|}{ APSD (Parent-report) } \\
\hline CU-Traits & .11 & $.30^{* *}$ & -.02 & -.21 & .04 & .03 \\
\hline Narcissism & .19 & .16 & .21 & -.01 & -.03 & .07 \\
\hline Impulsivity & $.25^{*}$ & $.24^{*}$ & .17 & .03 & .01 & .07 \\
\hline APSD Total & .21 & $.26^{*}$ & .15 & -.06 & .004 & .07 \\
\hline \multicolumn{7}{|l|}{ NPIC } \\
\hline Adaptive Narcissism & .12 & .15 & .16 & -.02 & .13 & -.01 \\
\hline Maladaptive & .11 & $.22^{*}$ & .14 & -.05 & .13 & -.04 \\
\hline Narcissism & .08 & $.17^{*}$ & .15 & -.09 & .14 & -.07 \\
\hline NPIC Total & & & & & & \\
\hline \multicolumn{7}{|l|}{$\mathrm{RPQ}$} \\
\hline Proactive Aggression & $.39 * *$ & $.29^{* *}$ & $.45^{* *}$ & $.25^{* *}$ & $.23^{* *}$ & .10 \\
\hline Reactive Aggression & $.31 * *$ & $.26^{* *}$ & $.34^{* *}$ & $.18^{* *}$ & $.20^{* *}$ & .09 \\
\hline RPQ Total & $.36^{* *}$ & $.29^{* *}$ & $.41^{* *}$ & $.22^{* *}$ & $.23^{* *}$ & .10 \\
\hline \multicolumn{7}{|l|}{ AQ } \\
\hline Physical Aggression & $.39^{* *}$ & $.32^{* *}$ & $.31^{* *}$ & $20^{* *}$ & $.29^{* *}$ & $.20^{* *}$ \\
\hline Verbal Aggression & $.32 * *$ & $.23^{* *}$ & $.24^{* *}$ & $.21 * *$ & $.29 * *$ & .12 \\
\hline Anger & $.36^{* *}$ & $.30^{* *}$ & $.28^{* *}$ & $.26^{* *}$ & $.27^{* *}$ & .13 \\
\hline Hostility & $.27^{* *}$ & $.19^{*}$ & $.17^{*}$ & $.28^{* *}$ & $.15^{*}$ & .12 \\
\hline AVL Total & $.43^{* *}$ & $.34^{* *}$ & $.32^{* *}$ & $.30^{* *}$ & $.31 * *$ & $.19^{* *}$ \\
\hline
\end{tabular}

Note: ${ }^{* *} \mathrm{p} \leq .001 ;{ }^{*} \mathrm{p} \leq .05$ (two-sided); ICU = inventory of Callous-Unemotional Traits, PCL: YV = Psychopathy Checklist: Youth Version, APSD = Antisocial Process Screening Device, NPIC = Narcissistic Personality Inventory for Children , RPQ = Reactive-Proactive Aggression Questionnaire, Aggression Questionnaire 


\section{Criterion validity}

Table 6 shows correlations of the ICU with DISC-assessed externalizing symptoms (ADD, $\mathrm{HY}, \mathrm{ODD}$, and CD). Self-reported CU traits correlated positively with externalizing symptoms. Thus, the more CU traits were reported, the more externalizing symptoms were seen.

Table 6. Associations between ICU and clinically important behavioural symptoms; $N=138$

\begin{tabular}{lcccccc} 
& ICU Total & $\begin{array}{c}\text { Lack of } \\
\text { Conscience }\end{array}$ & Uncaring & Unemotional & Callousness & $\begin{array}{c}\text { Lack of } \\
\text { Empathy }\end{array}$ \\
\hline $\mathrm{ADD}^{\mathrm{a}}$ & $.27^{* *}$ & $.22^{*}$ & $.38^{*}$ & .11 & $.24^{*}$ & .06 \\
$\mathrm{HY}^{\mathrm{a}}$ & .15 & .13 & $.21^{*}$ & .07 & .11 & .02 \\
$\mathrm{ODD}^{\mathrm{a}}$ & $.35^{* *}$ & .16 & $.36^{* *}$ & $.29^{* *}$ & $.33^{* *}$ & .14 \\
$\mathrm{CD}^{\mathrm{b}}$ & $.37^{* *}$ & $.26^{*}$ & $.28^{* *}$ & $.29^{* *}$ & $.24^{*}$ & $.22^{*}$ \\
\hline
\end{tabular}

Note: ${ }^{* *} \mathrm{p} \leq .001 ;{ }^{*} \mathrm{p} \leq .05$ (two-sided); ${ }^{a}$ number of symptoms during last year; ${ }^{b}$ number of lifetime symptoms; $\mathrm{ADD}=$ Attention Deficit Disorder; $\mathrm{HY}=$ Hyperactivity-Impulsivity; ODD = Oppositional Deviant Disorder; Conduct Disorder

\section{Discriminant validity}

ANOVA and MANOVA group comparisons were conducted to investigate the discriminant validity of the ICU total and its factors. Results of the analysis of variance showed that the four groups differed significantly regarding their mean ICU total score $(F(3,379)=11.21$, $p<.001)$. Post-hoc t-tests with Bonferroni corrections were conducted to evaluate pairwise differences between groups (see figure 1). The healthy controls had significantly lower mean scores than the two offender groups (clinical offenders: $\mathrm{t}(379)=4.46, p<.001$, $d=.52$; non-clinical offenders: $\mathrm{t}(379)=4.32, p<.001, d=.74)$ and the clinical non-offenders $(\mathrm{t}(379)=3.52, p=.003, d=.61)$. There were no significant group differences between the externalizing non-offenders and the two offender groups (clinical offenders: $\mathrm{t}(379)=.48$, $p=1.0$; non-clinical offenders: $\mathrm{t}(379)=.63, p=1.0)$. Likewise, the two offender groups did not differ significantly in their mean ICU total values $(\mathrm{t}(418)=1.25, p=1.0)$. 


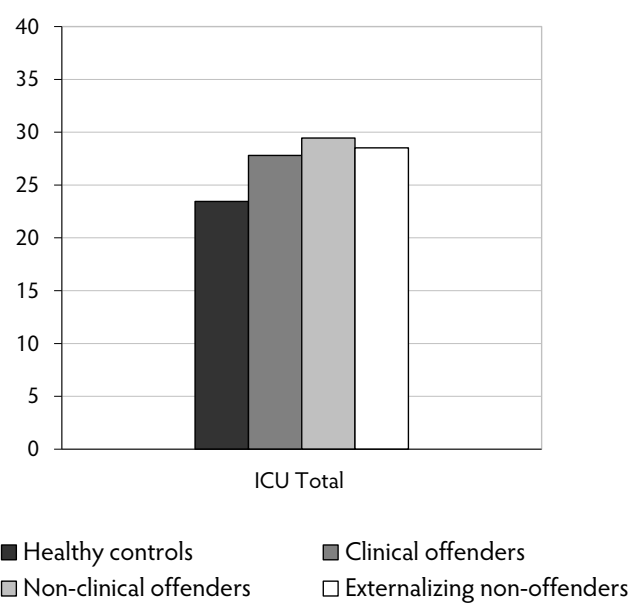

Figure 1. Group means of ICU Total scale, $N=383$

Furthermore, multivariate analysis of variance revealed a number of group differences on the five ICU subscales $(\Lambda=.70, F(15,1036)=9.65, p<.001)$. Again, post-hoc tests with Bonferroni corrections were conducted (figure 2). For the sake of brevity, only significant group differences are reported. Regarding Lack of Conscience, the healthy controls differed significantly from the two offender groups (clinical offenders: $t(379)=.4 .93$, $p<.001, d=.58$; non-clinical offenders: $\mathrm{t}(379)=4.67, p<.001, d=.80)$ and the clinical nonoffender group $(\mathrm{t}(379)=2.66, p=.047, d=.46)$. On the Uncaring factor, the clinical nonoffender group differed significantly from the two offender groups (clinical offenders: $\mathrm{t}(379)=7.9, p<.001, d=1.4$; non-clinical offenders: $\mathrm{t}(379)=4.68, p<.001, d=1.0$ ) and the healthy controls $(\mathrm{t}(379)=7.74, p=.000, d=1.3)$. The Unemotional factor showed significant differences between the healthy controls and the two offender groups (clinical offenders: $\mathrm{t}(379)=3.6, p=.002, d=.43$; non-clinical offenders: $\mathrm{t}(379)=3.5, p=.003, d=.61$ ). Regarding Callousness, only the difference between the clinical offenders and the clinical non-offenders reached significance $(\mathrm{t}(379)=2.79, p=.033, d=.52)$. Lack of Empathy showed significant differences only between the clinical offenders and the healthy controls $(\mathrm{t}(379)=2.91, p=.022, d=.34)$. Due to the low internal consistencies and the number of items of some of the subscales, these differences must be interpreted with caution. 


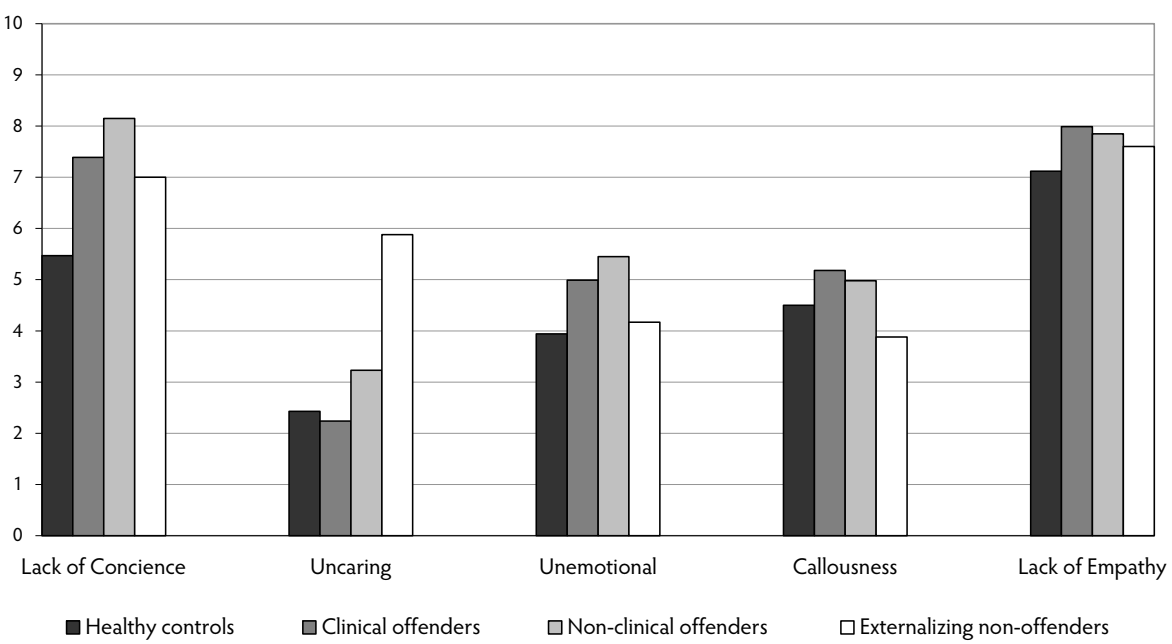

Figure 2. Group means of ICU subscales, $N=383$

\section{ROC analyses}

No meaningful cutoff scores were obtained when comparing offenders (clinical and nonclinical group) and externalizing boys. With a sensitivity of $16 \%$ and a specificity of $90 \%$, at a cutoff value of 36 , the ICU total is unable to discriminate between offenders and an externalizing clinical group. The tests area under the curve was .48 , indicating a poor diagnostic accuracy. Diagnostic accuracy was greater when comparing offenders to healthy controls, but remained poor (area under the curve .65, sensitivity 59\%, specificity 67\%, cutoff score 26). The positive predictive power (PPP) was 62\%, the negative predictive power (NPP) 63\%. These results indicate a false negative rate of some $40 \%$ and a false positive rate of $33 \%$.

\section{Discussion}

This was the first study to investigate the psychometric properties of the Inventory of Callous-Unemotional Traits (ICU, Frick, 2003) across a mixed youth sample drawn from the community, clinical patients and offenders.

First, to investigate the factor structure of the ICU, a one-factor model, a threefactor intercorrelated model, a three-factor hierarchical model and a three factor bifactor model were compared. Although fit indices increased, neither model of the tested models showed sufficient fit. Due to the difficulties with model fit found in this and in earlier studies, an exploratory factor analysis was conducted. A five-factor model for the ICU emerged. 
The first factor (Lack of Conscience) describes behavior related to a lack of conscience, the second factor (Uncaring) consisted of items related to a lack of caring about one's own performance and about others, the third factor (Unemotional) described a lack of emotional expression, the fourth factor (Callousness) described a general callous attitude. The final fifth factor (Lack of Empathy) described items related to a lack of concern for others. Results on the ICU reliability were mixed. Internal consistencies were acceptable for the ICU total and for the subscales Lack of Conscience and Uncaring, whereas the internal consistencies of the remaining subscales were generally below a level considered acceptable. One reason for this lies in the small number of items on these scales (4-5 items). Increasing the item number would increase internal consistency of these factors. Although only a modest internal consistency was achieved, the ICU showed some stability of ratings, particularly for the total scale. The estimates obtained were higher than often found for personality self-reports in this age group (Roberts \& DelVecchio, 2000). A recent ICU factor analysis on a large Greek Cypriot child and parent elementary school sample $(N=1755)$ also failed to replicate the originally assumed factor structure (Lordos \& Fanti, 2011).

The second aim of the present study was to assess the convergent and criterion validity of the ICU with measures designated to tap psychopathic and personality traits using different methods and responders (PCL:YV expert rating; APSD parent-report; NPIC self-report) together with measures related to the psychopathy construct (aggression, externalizing symptoms).

Regarding the ICU total, associations with PCL:YV, APSD (parent-report) and NPIC were moderate. Only the association with the APSD Impulsivity scale reached significance. This finding might have its origin in the fact that impulsive behavior is more overt and hence easier to observe than personality traits. Also, narcissistic and CU traits are generally seen as negative attributes, which might have affected parent ratings. Furthermore, parent ratings of youths are less reliable (Kamphaus \& Frick, 2005). This might also go some way towards explaining the weak correlations seen between these measures. Furthermore, as mentioned in the introduction, only a small number of items on both the PCL:YV and the APSD are directly related to CU traits, making them much broader measures. These findings are in line with studies reporting restricted conceptual overlap and modest correlations between self-report measures of psychopathy traits and the PCL:YV (Lee, Vincent, Hart, \& Corrado, 2003; Skeem \& Cauffman, 2003). Method and content variance between the ICU, the APSD (parent-report) and the PCL:YV could thus have affected correlations substantially. At the ICU subscale level, Lack of Conscience and Uncaring showed significant and strong positive associations with PCL:YV, APSD and NPIC. Although not exclusively, there were also significant associations to all forms of aggression. This would suggest that these aspects of CU traits are shared by the different conceptualizations of psychopathy applied in the current study. Furthermore, they might be of particular importance in placing an individual at risk for an antisocial development. It is possible, of course, that the small number of items and the low internal consistencies 
of some ICU subscales may have caused type II errors (non-detection of existing correlations). As for NPIC, associations are supportive of earlier findings indicating that the maladaptive aspects of narcissism, defined by a) a desire to achieve status over others, b) a desire to be viewed as more important than others, and c) a need to receive attention and praise from others, are positively associated with CU traits in youth and adult samples (Barry et al., 2003; Raskin \& Terry, 1988)

Regarding aggression, all ICU scales except for Lack of Empathy showed signifcant positive associations with the two aggression measures. This finding agrees with expectations and supports the notion that high levels of CU traits are associated with more severe aggressive tendencies, including reactive as well as proactive aggression (e.g., Frick, Cornell et al., 2003; e.g., Frick \& White, 2008). They also agree with findings reported in earlier validation studies (Fanti et al., 2009; Kimonis, Frick, Skeem et al., 2008).

The ICU criterion validity was examined through associations with externalizing behavior symptoms. The present findings are in line with earlier research that links especially ODD and CD symptoms to the occurrence of CU traits (Barry et al., 2000). Correlations with ADD and HY symptoms were less pronounced.

Thus, although not all associations with the ICU reached significance, a number of promising correlations with related measures could be obtained. The present findings thus lean some support to the questionnaires convergent and criterion validity.

Last, and most importantly, we investigated the discriminant validity of the ICU. The early occurrence of CU traits is believed to designate youths who are at particular risk to develop psychopathy later in life. If it were possible to discriminate these youths from other groups, this would allow early intervention.

In the present study, it was not possible to differentiate between externalizing non-offenders, non-clinical offenders and clinical offenders. Statistically significant group differences were only found when differentiating the healthy controls from the externalizing and the offender groups. However, this finding must be interpreted with caution. The mean ICU total scores were rather low and fairly similar across groups, ranging from 21-29 at a possible total score of 72 . This poor discriminant validity of the ICU was puzzling, and so it was ascertained whether the ICU scores were specific to this study or consistent with data from others. A literature search on studies applying the ICU showed that their subjects were either detainees or were drawn from the community. No study applied the ICU within different groups (i.e., community, clinical patients, offenders). A meta-analysis was conducted including both male detainees and normal males from the community. A total of 11 studies could be identified. For Roose et al. (2009) data on male participants was obtained from the authors. The standard deviation of the White et al. (2009) ICU total was estimated from the weighted SD of all other studies included in the analysis (White, Cruise, \& Frick, 2009). Where ICU total scores were based on 22 items only (Kimonis, Frick, Skeem et al., 2008), 24 item-based total scores and SDs were estimated by multiplying the means and SDs by 22/24. Screening 
of study populations showed substantial overlap in four studies (Kimonis, Frick, Munoz, \& Aucoin, 2007, , 2008; Munoz, Frick, Kimonis, \& Aucoin, 2008a, , 2008b), so that the largest sample (Munoz et al. 2008b) was included in the analyses. Analyses were performed with Meta Analyst, Version 2, Beta 3.13., assuming a random effects model with unequal variances. Furthermore, (multiple) meta-regression analyses were conducted for the effect of sample (community vs. detained) and age (mean age of the sample) on ICU total scores.

Results indicated no systematic difference between community and detained samples on the ICU total (see figure 3 for forest plot). When controlling for age, detained samples tended to report lower average ICU total scores. Thus, the meta-analysis suggests that ICU does not differentiate between detained and community samples.

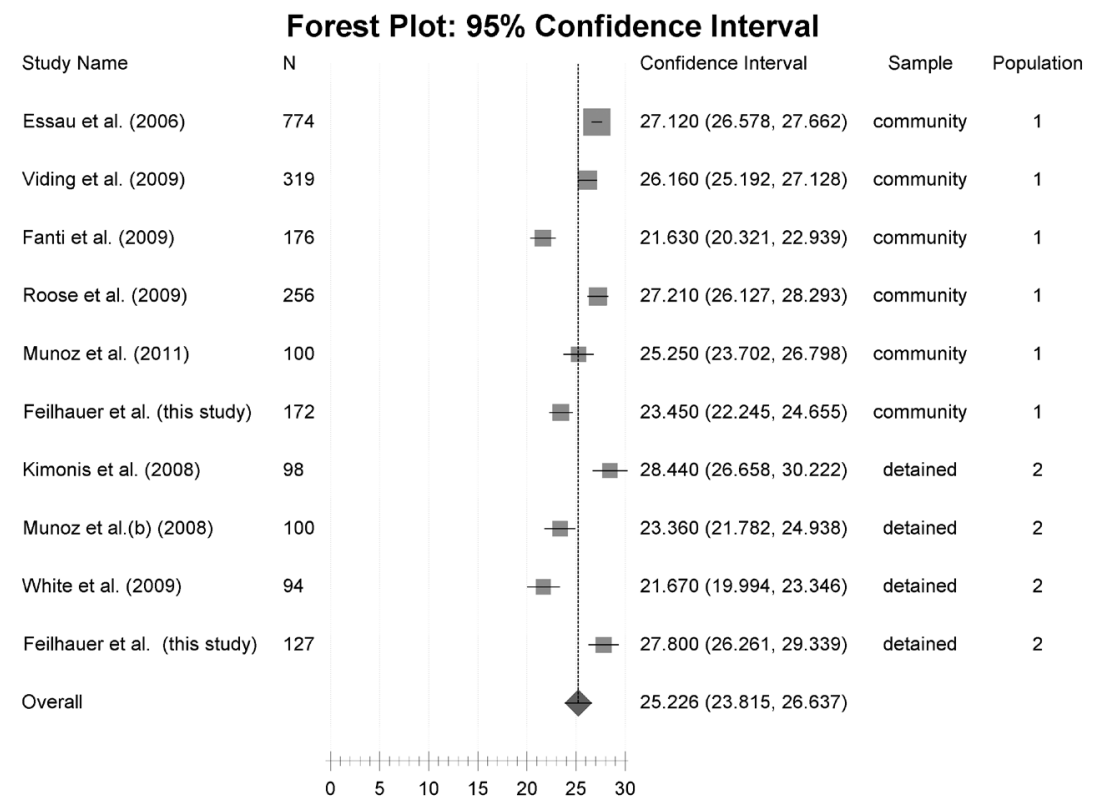

Figure 3. Forest plot of the meta-analysis on the ICU total (community and detained samples)

Taken together, whereas results of the present analyses lean some support to the ICU's convergent and criterion validity, the questionnaires discriminant validity seems to be poor. Also, the conducted meta-analyses revealed no systematic evidence for the ICU's discriminant validity. Thus, although these findings support the conceptual soundness of the ICU, it seems evident that the instrument in its current form cannot compensate for population-dependent biases. 
There exist different possible explanations for this finding. First, since the ICU does not include a social desirability scale, it is not clear whether the findings might be related to a socially desirable response style. Antisocial/externalizing and criminal individuals tend to be evaluated negatively by others. As psychopathic traits and antisocial behavior are related to deceit and manipulation, it seems possible that individuals from the externalizing and offender groups consciously or subconsciously manipulated their answers on the ICU to make them socially more acceptable (Cima, Smeets, \& Jelicic, 2008). In community samples, on the other hand, peer pressure and social acceptability might elevate their ratings, letting them appear more self-assured and less dependent on others. Regarding the ICU, social acceptability might therefore work in opposite ways for individuals from the community and externalizing/detained groups, decreasing the difference between the two sample types.

Second, a certain level of CU traits is normal during puberty (Seagrave \& Grisso, 2002; Steinberg, 2002, 2005). Certain ICU items might therefore measure behavior which is considered age-appropriate for adolescents, such as e.g. not caring about one's own performance, hiding one's feelings, not caring about being on time. Thus, certain ICU items might not accurately distinguish individuals with strong CU traits from their normal peers (Kotler \& McMahon, 2010).

Third, normal children and youths (community group) could misinterpret the content of the questions by underestimating their meaning and seriousness. This could lead to artificially higher CU trait scores within community samples.

Fourth, youth offenders and youths with externalizing problems often have been exposed to severe negative environmental risk factors, e.g., poor parenting, maltreatment and trauma (e.g. Raine, 2002). It might be possible that the detained youths in the present study had much stronger externalizing characteristics than CU traits. This could also be indicated by the PCL:YV factor scores (F1: mean $=5.61$ (35\% of scale); F2: mean $=8.23(45,5 \%$ of scale)).

Fifth, evaluating one's own personality characteristics and behavior requires a degree of self-refection that may not be sufficiently and evenly developed in youths. This might explain the increase in CU traits with age.

Taken together, simple self-report may not be valid enough to assess CU traits. Future research should investigate alternative forms. One possibility would be developing an ICU interview which could be administered by trained clinicians to counter biases and misunderstanding. Another possible strategy could be the implantation of explanations or short stories (vignettes) into the questionnaire to provide a framework for evaluating ones' own behavior and feelings. This strategy is already being used in the study of empathy, which is a related concept that is equally difficult to grasp for children and adolescents (Cimbora \& Mclntosh, 2003). 
Future research should also investigate the possibility of incorporating a social desirability scale. Even if correct answers are given in a research setting, it is unknown how youths with strong CU traits would respond in a non-anonymous setting like a clinical assessment.

The present study had a number of limitations. First, due to the correlational analysis, it was not possible to make statements about causality or rule out third variables. Second, the low internal consistencies of some ICU scales are problematic. The low consistencies might be due to the small number of items. Third, the small sample sizes on some of the tests constitute another weakness of the study.

Concluding, it is very important to assess CU traits in youths at risk. This validation study showed a moderate reliability and validity of the Dutch ICU, but it also showed that this scale has room for improvement. Future research should focus on how to distinguish between youths who are uncaring, within the normal range of puberty, and those who are truly cold and callous.

\section{ACKNOWLEDGMENTS}

The authors kindly thank the legal and clinical institutions and schools for their participation and support. We would also like to thank the undergraduate students and research assistants who assisted us with data collection. 


\section{Appendix A. Factor loadings of three factor bifactor model}

Table 1. Factor loadings for the three-factor bifactor model of the Inventory of Callous-Unemotional Traits

(ICU) for the total sample $(\mathrm{N}=383)$

Items

Factor

Factor

Factor General

$\begin{array}{llll}1 & 2 & 3 & \text { factor }\end{array}$

\section{Callousness}

2. What I think is 'right'and 'wrong' is different from what .285 other people think.

4. I do not care who I hurt to get what I want. $\quad .499$

7. I do not care about being on time.

9. I do not care if I get into trouble.

10. I do not let my feelings control me.

11. I do not care about doing things well.

$-.031$

12. I seem very cold and uncaring to others.

.611

.260

18. I do not feel remorseful when I do something wrong.

.298

20. I do not like to put the time into doing things well.

21. The feelings of others are unimportant to me.

*8. I am concerned about the feelings of others.

\section{Uncaring}

*3. I care about how well I do at school or work.

$\begin{array}{ll}.150 & .306 \\ .046 & .535 \\ .174 & .296 \\ .554 & .304 \\ .289 & .608 \\ .217 & .574 \\ .703 & .271 \\ .309 & .390\end{array}$

*5. I feel bad or guilty when I do something wrong.

*13. I easily admit to being wrong.

* 15 . I always try my best.

* 16. I apologize ('say I am sorry') to persons I hurt.

* 17. I try not to hurt others' feelings.

*23. I work hard on everything I do.

\section{Unemotional}

6.I do not show my emotions to others. $\quad .601$

22. I hide my feelings from others. $\quad \begin{array}{ll}.546 & .176\end{array}$

${ }^{*}$ 1. I express my feelings openly. $\quad 372 \quad .356$

${ }^{*} \mathbf{1 4}$. It is easy for others to tell how I am feeling. $\quad .090 \quad .256$

$\begin{array}{lll}{ }^{*} \mathbf{1 9} \text {. I am very expressive and emotional. } & .113 & .089\end{array}$

Note: all factors are uncorrelated. 


\section{Appendix B. Factor structure of 5 factor model after oblimin rotation}

Table 1. Factor structure of the Inventory of Callous-Unemotional Traits (ICU) for the total sample ( $N=383)$

Items

Factor 1 Factor 2 Factor 3 Factor 4 Factor 5

\begin{tabular}{|c|c|c|c|c|c|}
\hline \multicolumn{6}{|l|}{ Lack of Conscience } \\
\hline *23. I work hard on everything I do. & .800 & .056 & .082 & -.127 & .089 \\
\hline *15. I always try my best. & .762 & .007 & .048 & -.297 & -.061 \\
\hline *16. I apologize ('say I am sorry') to persons I hurt. & .649 & -.059 & -.150 & .046 & -.066 \\
\hline *17. I try not to hurt others' feelings. & .556 & -.131 & -.077 & .164 & -.036 \\
\hline *24. I do things to make others feel good. & .543 & -.029 & -.086 & .279 & .204 \\
\hline *13. I easily admit to being wrong. & .379 & .075 & .045 & .100 & -.135 \\
\hline \multicolumn{6}{|l|}{ Uncaring } \\
\hline 4. I do not care who I hurt to get what I want. & .112 & .810 & .148 & -.071 & -.007 \\
\hline *3. I care about how well I do at school or work. & .168 & -.699 & -.073 & .210 & .050 \\
\hline 11. I do not care about doing things well. & .073 & .587 & .112 & -.039 & .299 \\
\hline *14. It is easy for others to tell how I am feeling. & .219 & .321 & -.094 & .279 & -.109 \\
\hline 20. I do not like to put the time into doing things well. & -.127 & .405 & .054 & .039 & .417 \\
\hline \multicolumn{6}{|l|}{ Unemotional } \\
\hline 6. I do not show my emotions to others. & .064 & -.004 & .788 & .000 & -.052 \\
\hline 22. I hide my feelings from others. & .088 & .053 & .732 & .080 & .012 \\
\hline 12. I seem very cold and uncaring to others. & -.079 & .175 & .610 & .185 & .053 \\
\hline *1. I express my feelings openly. & .146 & .150 & -.540 & .361 & .087 \\
\hline \multicolumn{6}{|l|}{ Lack of Empathy } \\
\hline *8. I am concerned about the feelings of others. & .154 & -.048 & .119 & .645 & -.166 \\
\hline $\begin{array}{l}\text { 2. What I think is 'right' and 'wrong' is different from } \\
\text { what other people think. }\end{array}$ & -.188 & .004 & .069 & .510 & .280 \\
\hline 21. The feelings of others are unimportant to me. & -.004 & .226 & .046 & -.381 & .280 \\
\hline *5. I feel bad or guilty when I do something wrong. & .293 & -.032 & .037 & .360 & -.301 \\
\hline *19. I am very expressive and emotional. & .002 & .431 & -.157 & .327 & -.008 \\
\hline \multicolumn{6}{|l|}{ Callousness } \\
\hline 9. I do not care if I get into trouble. & -.177 & .018 & .137 & .203 & .623 \\
\hline 18. I do not feel remorseful when I do something wrong. & -.037 & .092 & -.096 & -.145 & .649 \\
\hline 10. I do not let my feelings control me. & .252 & -.445 & .125 & -.053 & .529 \\
\hline 7. I do not care about being on time. & -.136 & .019 & .261 & .153 & .355 \\
\hline
\end{tabular}

Note: Extraction method: Principal component Analysis. Rotation Method: Oblimin with Kaiser Normalization; ${ }^{*}=$ Items which require reverse scoring before calculation of the total score. Boldface indicates factor loadings larger than or equal to .40 .0 .40 (or the highest factor loading for the item) was the cut-off point for factor loadings. Items 14, 19 and 20 were moved to another subscale for contextual reasons. When applying the varimax rotation, Item 2 loads on the Callousness factor. 
Table 2. Factor correlation matrix of the Inventory of Callous-Unemotional Traits (Oblimin rotation with Kaiser Normalization)

\begin{tabular}{crrrrr} 
Component & 1 & 2 & 3 & 4 & 5 \\
\hline 1 & - & -.099 & -.124 & .203 & -.209 \\
2 & -.099 & - & .058 & .072 & .113 \\
3 & -.124 & .058 & - & -.060 & .252 \\
4 & .203 & .072 & -.060 & - & -.043 \\
5 & -.209 & .113 & .252 & -.043 & - \\
\hline
\end{tabular}




\section{REFERENCES}

Akaike, H. (1987). Factor Analysis and AIC. Psychometrika, 52(3), 317-332.

Barry, C. T., Frick, P. J., DeShazo, T. M., McCoy, M. G., Ellis, M., \& Loney, B. R. (2000). The importance of callousunemotional traits for extending the concept of psychopathy to children. Journal of Abnormal Psychology, 109(2), 335-340.

Barry, C. T., Frick, P. J., \& Killian, A. L. (2003). The relation of narcissism and self-esteem to conduct problems in children: a preliminary investigation. Journal of Clinical Child and Adolescent Psychology, 32(1), 139-152.

Barry, T. D., Thompson, A., Barry, C. T., Lochman, J. E., Adler, K., \& Hill, K. (2007). The importance of narcissism in predicting proactive and reactive aggression in moderately to highly aggressive children. Aggress Behav, 33(3), 185-197.

Bijttebier, P., \& Decoene, S. (2009). Assessment of Psychopathic Traits in Children and Adolescents Further Validation of the Antisocial Process Screening Device and the Childhood Psychopathy Scale. European Journal of Psychological Assessment, 25(3), 157-163.

Burke, B. G. (1999). Item reversals and response validity in the job diagnostic survey. Psychological Reports, 85(1), 213-219.

Buss, A. H., \& Perry, M. (1992). The aggression questionnaire. Journal of Personality and Social Psychology, 63(3), 452-459.

Cima, M., Otgaar, H., \& Merkelbach, H. (in preparation). Development and validation of a psychpathic inventory for children.

Cima, M., Smeets, T., \& Jelicic, M. (2008). Self-reported trauma, cortisol levels, and aggression in psychopathic and non-psychopathic prison inmates. Biological Psychology, 78(1), 75-86.

Cimbora, D. M., \& McIntosh, D. N. (2003). Emotional responses to antisocial acts in adolescent males with conduct disorder: a link to affective morality. Journal of Clinical Child and Adolescent Psychology, 32(2), 296-301.

Cleckley, H. (1941). The mask of sanity. St. Louis, MO: C.V. Mosby.

Cordery, J. L., \& Sevastos, P. P. (1993). Responses to the Original and Revised Job Diagnostic Survey - Is Education a Factor in Responses to Negatively Worded Items. Journal of Applied Psychology, 78(1), 141-143.

Das, J., de Ruiter, C., Doreleijers, T., \& Hillege, S. (2009). Reliability and construct validity of the Dutch psychopathy checklist: youth version: findings from a sample of male adolescents in a juvenile justice treatment institution. Assessment, 16(1), 88-102.

Das, J., de Ruiter, C., Lodewijks, H., \& Doreleijers, T. (2007). Predictive validity of the Dutch PCL:YV for institutional disruptive behavior: findings from two samples of male adolescents in a juvenile justice treatment institution. Behavioral Sciences and the Law, 25(5), 739-755.

de Ruiter, C., de Vries, J. K., \& Das, J. (2002). Psychopathie Checklist: Jeugd Versie:Geautoriseerde Nederlandse vertaling [Psychopathy Checklist: Youth Version: Authorized Dutch translation]: Unpublished research version.

Essau, C. A., Sasagawa, S., \& Frick, P. J. (2006). Callous-unemotional traits in a community sample of adolescents. Assessment, 13(4), 454-469. 
Fanti, K. A., Frick, P. J., \& Georgiou, S. (2009). Linking Callous-Unemotional Traits to Instrumental and Non-Instrumental Forms of Aggression. Journal of Psychopathology and Behavioral Assessment, 31(4), 285-298.

Fisher, L., \& Blair, R. J. (1998). Cognitive impairment and its relationship to psychopathic tendencies in children with emotional and behavioral difficulties. Journal of Abnormal Child Psychology, 26(6), 511-519.

Fisher, P., Wicks, J., Shaffer, D., Piacentini, J., \& Lapkin, J. (1992). Diagnostic Interview Schedule for Children: User's Manual, version 2.3. New York: Division of Child and Adolescent Psychiatry, Columbia University.

Fleiss, J. L. (1986). The design and analysis of clinical experiments. NY: Wiley.

Forth, A. E., Kosson, D. S., \& Hare, R. D. (2003). Hare Psychopathy Checklist: Youth Version. Toronto, Ontario: Multi-Heath Systems.

Fowles, D. C., \& Dindo, L. (2006). A Dual-Deficit Model of Psychopathy. In C. J. Patrick (Ed.), Handbook of Psychopathy (pp. 14-34). NY: Guilford Press.

Frick, P. J. (2003). The Inventory of Callous-Unemotional Traits. University of New Orleans.

Frick, P. J., Bodin, S. D., \& Barry, C. T. (2000). Psychopathic traits and conduct problems in community and clinic-referred samples of children: further development of the psychopathy screening device. Psychological Assessment, 12(4), 382-393.

Frick, P. J., Cornell, A. H., Barry, C. T., Bodin, S. D., \& Dane, H. E. (2003). Callous-unemotional traits and conduct problems in the prediction of conduct problem severity, aggression, and self-report of delinquency. Journal of Abnormal Child Psychology, 31(4), 457-470.

Frick, P. J., \& Hare, R. D. (2001). The antisocial process screening device. Toronto, ontario: Multi-Health Systems.

Frick, P. J., Kimonis, E. R., Dandreaux, D. M., \& Farell, J. M. (2003). The 4 year stability of psychopathic traits in non-referred youth. Behavioral Sciences and the Law, 21(6), 713-736.

Frick, P. J., \& White, S. F. (2008). Research review: the importance of callous-unemotional traits for developmental models of aggressive and antisocial behavior. Journal of Child Psychology and Psychiatry and Allied Disciplines, 49(4), 359-375.

Hare, R. D. (2003). The Psychopathy Checklist-Revised technical manual (2nd ed.). Toronto: Multi-Health Systems.

Hu, L. T., \& Bentler, P. M. (1998). Fit indices in covariance structure modeling: Sensitivity to underparameterized model misspecification. Psychological Methods, 3(4), 424-453.

Kamphaus, R. W., \& Frick, P. J. (2005). Clinical assessment of child and adolescent personality and behavior (2nd ed.). New York: Springer.

Kimonis, E. R., Frick, P. J., Munoz, L. C., \& Aucoin, K. J. (2007). Can a laboratory measure of emotional processing enhance the statistical prediction of aggression and delinquency in detained adolescents with callous-unemotional traits? Journal of Abnormal Child Psychology, 35(5), 773-785.

Kimonis, E. R., Frick, P. J., Munoz, L. C., \& Aucoin, K. J. (2008). Callous-unemotional traits and the emotional processing of distress cues in detained boys: Testing the moderating role of aggression, exposure to community violence, and histories of abuse. Development and Psychopathology, 20(2), 569-589.

Kimonis, E. R., Frick, P. J., Skeem, J. L., Marsee, M. A., Cruise, K., Munoz, L. C., et al. (2008). Assessing callousunemotional traits in adolescent offenders: validation of the Inventory of Callous-Unemotional Traits. International Journal of Law and Psychiatry, 31(3), 241-252. 
Kline, R. B. (1998). Principles and practice of structural equation modeling. New York: Guilford Press.

Kotler, J. S., \& McMahon, R. J. (2010). Assessment of Child and Adolescent Psychopathy. In R. T. Salekin \& D. Lynam (Eds.), Handbook of Child \& Adolescent Psychopathy (pp. 79-109). New Yok: Guilford Press.

Kruh, I. P., Frick, P. J., \& Clements, C. B. (2005). Historical and Personality Correlates to the Violence Patterns of Juveniles Tried as Adults. Criminal Justice and Behaviour, 32(1), 69-96.

Lahey, B. B., \& Loeber, R. (1994). Framework for a developmental model of oppositional deviant disorder and conduct disorder. In D. K. Routh (Ed.), Disruptive behaviour disorders in childhood. (pp. 139-180). New York: Plenum Press.

Lee, Z., Vincent, G. M., Hart, S. D., \& Corrado, R. R. (2003). The validity of the Antisocial Process Screening Device as a self-report measure of psychopathy in adolescent offenders. Behavioral Sciences and the Law, 21(6), 771-786.

Loney, B. R., Butler, M. A., Lima, E. N., Counts, C. A., \& Eckel, L. A. (2006). The relation between salivary cortisol, callous-unemotional traits, and conduct problems in an adolescent non-referred sample. Journal of Child Psychology and Psychiatry and Allied Disciplines, 47(1), 30-36.

Loney, B. R., Frick, P. J., Clements, C. B., Ellis, M. L., \& Kerlin, K. (2003). Callous-unemotional traits, impulsivity, and emotional processing in adolescents with antisocial behavior problems. Journal of Clinical Child and Adolescent Psychology, 32(1), 66-80.

Lordos, A., \& Fanti, K. A. (2011). Why CU could stand for 'Callous-Unremorseful': Reconsidering the factor structure of the ICU. Paper presented at the Conference Name|. Retrieved Access Date|. from URL|.

Meesters, C., Muris, P., Bosma, H., Schouten, E., \& Beuving, S. (1996). Psychometric evaluation of the Dutch version of the Aggression Questionnaire. Behaviour Research and Therapy, 34(10), 839-843.

Morren, M., \& Meesters, C. (2002). Validation of the Dutch Version of the Aggression Questionnaire in Adolescent Male Offenders. Aggressive Behaviour, 28, 87-96.

Munoz, L. C., \& Frick, P. J. (2007). The reliability, stability, and predictive utility of the self-report version of the Antisocial Process Screening Device. Scandinavian Journal of Psychology, 48(4), 299-312.

Munoz, L. C., Frick, P. J., Kimonis, E. R., \& Aucoin, K. J. (2008a). Types of aggression, responsiveness to provocation, and callous-unemotional traits in detained adolescents. Journal of Abnormal Child Psychology, $36(1), 15-28$.

Munoz, L. C., Frick, P. J., Kimonis, E. R., \& Aucoin, K. J. (2008b). Verbal ability and delinquency: testing the moderating role of psychopathic traits. Journal of Child Psychology and Psychiatry and Allied Disciplines, 49(4), 414-421.

Patrick, C. J., Hicks, B. M., Nichol, P. E., \& Krueger, R. F. (2007). A bifactor approach to modeling the structure of the psychopathy checklist-revised. Journal of Personality Disorders, 21(2), 118-141.

Raine, A. (2002). Biosocial studies of antisocial and violent behavior in children and adults: a review. Journal of Abnormal Child Psychology, 30(4), 311-326.

Raine, A., Dodge, K., Loeber, R., Gatzke-Kopp, L., Lynam, D., Reynolds, C., et al. (2006). The Reactive-Proactive Aggression Questionnaire: differential correlates of reactive and proactive aggression in adolescent boys. Aggressive Behavior, 32, 159-171.

Raskin, R., \& Terry, H. (1988). A principal-components analysis of the Narcissistic Personality Inventory and further evidence of its construct validity. Journal of Personality and Social Psychology, 54(5), 890-902. 
Roberts, B. W., \& DelVecchio, W. F. (2000). The rank-order consistency of personality traits from childhood to old age: a quantitative review of longitudinal studies. Psychological Bulletin, 126(1), 3-25.

Roose, A., Bijttebier, P., Claes, L., Decoene, S., \& Frick, P. J. (2009). Assessing the Affective Features of Psychopathy in Adolescence: a Further Validation of the Inventory of Callous and Unemotional Traits. Assessment.

Schermelleh-Engel, K., Moosbrugger, H., \& Mueller, H. (2003). Evaluating the fit of structural equation models: Tests of significance and descriptive goodness-of-fit measures. Methods of Psychological Research Online, 8, 23-74.

Schmitt, N., \& Stults, D. M. (1985). Factors defined by negatively keyed items: The result of careless respondents? Applied Psychological Measurement, 9(4), 367-373.

Schumacker, R. E., \& Lomax, R. G. (1996). A beginner's guide to structural equation modeling. Mahwah, NY: Lawrence Erlbaum.

Seagrave, D., \& Grisso, T. (2002). Adolescent development and the measurement of juvenile psychopathy. Law and Human Behavior, 26(2), 219-239.

Shaffer, D., Fisher, P., Lucas, C. P., Dulcan, M. K., \& Schwab-Stone, M. E. (2000). NIMH Diagnostic Interview Schedule for Children Version IV (NIMH DISC-IV): description, differences from previous versions, and reliability of some common diagnoses. Journal of the American Academy of Child and Adolescent Psychiatry, 39(1), 28-38.

Skeem, J. L., \& Cauffman, E. (2003). Views of the downward extension: comparing the Youth Version of the Psychopathy Checklist with the Youth Psychopathic traits Inventory. Behavioral Sciences and the Law, 21(6), 737-770.

Steinberg, L. (2002). The juvenile psychopath: Fads, fictions, and facts. National Institutes of Justice Perspectives on Crime and Justice: 2001 Lecture Series 5, 35-64.

Steinberg, L. (2004). Risk-taking in adolescence: What changes, and why? Annals of the New York Academy of Sciences(1021), 51-58.

Steinberg, L. (2005). Cognitive and affective development in adolescence. TRENDS in Cognitive Sciences, 9(2), 69-74.

Tabachnick, B. G., \& Fidell, L. S. (2007). Using multivariate statistics (5th ed.): Upper Saddle River, NJ: Pearson Allyn \& Bacon.

van de Vijver, F. J. R., \& Hambleton, R. K. (1996). Translating tests: some practical guidelines. European Psychologist, 1(2), 89-99.

Verhulst, F. C., van der Ende, J., Ferdinand, R. F., \& Kasius, M. C. (1997). The prevalence of DSM-III-R diagnoses in a national sample of Dutch adolescents. Archives of General Psychiatry, 54(4), 329-336.

Vitacco, M. J., Rogers, R., \& Neumann, C. S. (2003). The Antisocial Process Screening Device: an examination of its construct and criterion-related validity. Assessment, 10(2), 143-150.

White, S. F., Cruise, K. R., \& Frick, P. J. (2009). Differential correlates to self-report and parent-report of callousunemotional traits in a sample of juvenile sexual offenders. Behavioral Sciences and the Law, 27(6), 910-928. 


\section{Differential associations}

\section{between psychopathy}

dimensions, types

of aggression,

and response inhibition

Based on: Feilhauer, J., Cima, M., Korebrits, A., \& Kunert, H.J. (2012).

Differential associations between psychopathy dimensions, types of aggression, and response inhibition. Aggressive Behavior, 38(1), 77-88. 


\section{ABSTRACT}

Findings on executive functioning in psychopathy are inconsistent. Different associations between psychopathy dimensions and executive functioning might explain contradicting findings. This study examined the role of psychopathy dimensions and types of aggression in response inhibition among 117 male adolescents (53 antisocial delinquents, 64 controls). Participants completed a self-report measure of aggression and a GoNoGo task. Psychopathy dimensions were assessed using the Psychopathy Checklist: Youth Version (PCL:YV). While high scores on the antisocial dimension and reactive aggression were associated with poor response inhibition, the affective/interpersonal dimension, proactive aggression and verbal intelligence (IQ) were related to better response inhibition (two factor model). Associations with the affective/interpersonal dimensions did not reach significance. Exploratory analyses showed that particularly the affective and antisocial facets accounted for the obtained opposing associations of the affective/interpersonal and antisocial psychopathy dimensions with response inhibition. The interpersonal and lifestyle facets (four facet model) were unrelated to response inhibition. Results could not be explained by Attention Deficit Hyperactivity Disorder (ADHD). Findings suggest differential associations between the psychopathy dimensions, types of aggression and response inhibition. Therefore, a dimensional approach to psychopathy and related concepts like aggression might strongly improve diagnostic procedures. Global scores could mask important differential associations. 


\section{INTRODUCTION}

Psychopathy is defined by a constellation of behavioural, interpersonal and affective characteristics. Traditionally, these characteristics were measured by at least two factors constituting the Psychopathy Checklist-Revised (PCL-R; Hare, 1991; e.g., Harpur, Hakstian, \& Hare, 1988). Factor 1 is characterised by a selfish, manipulative predisposition, a lack of remorse, emotional shallowness and callous-unemotional (CU) traits (CU Traits; Cooke \& Michie, 1997), and represents the affective/interpersonal aspects of the disorder. These aspects are related to a profound emotional dysfunction, which underlies the psychopathic disorder (Hare, 2003). Factor 2 consists of an impulsive, irresponsible, poorly planned, antisocial lifestyle (Harpur et al., 1988), resembling the DSM classification of the antisocial personality disorder (APD; APA, 2000). A similar factor structure has been proposed for the Psychopathy Checklist: Youth Version (PCL: YV; Forth, Kosson, \& Hare, 2003). Recently, refinements were suggested for both the adult and youth versions that subdivide the original PCL factor structure even further, with three factor and four factor models (the latter being referred to as four facets in order to distinguish them from the two factor model) being proposed (e.g., Cooke \& Michie, 2001; Forth et al., 2003; Hare, 2003; Neumann, Kosson, Forth, \& Hare, 2006). The four facets separate the original factor into an (1) interpersonal facet reflecting the superficial, manipulative and deceitful characteristics and an (2) affective facet reflecting emotional shallowness and CU-traits. Likewise, the antisocial factor is divided into a (3) lifestyle facet reflecting an impulsive, irresponsible and poorly planned lifestyle, and an (4) antisocial facet, which reflects the criminal and antisocial behavior and poor behavioral control. To date, the validity of the two factor model regarding external criteria is still best documented (Fowles \& Dindo, 2006). However, more recent findings support a more nuanced model (Hare \& Neumann, 2008).

Like most personality disorders, psychopathy is believed to consist of a set of characteristics which have their roots in childhood. Especially, the occurrence of a callous and unemotional temperamental style characterised by fearlessness, a disturbed conscience and socialization development, together with severe behavioural problems seems to go with a particularly high risk of developing psychopathy later in life (Frick \& White, 2008). Recent findings from longitudinal research support the stability of CU-traits (Burke, Loeber, \& Lahey, 2007; Loney, Taylor, Butler, \& lacono, 2007; Lynam, Caspi, Moffitt, Loeber, \& Stouthamer-Loeber, 2007), which contribute to the original affective/interpersonal factor of the psychopathy concept.

Research on youth and adult psychopathy has largely increased over the past few decades. On the neurocognitive level psychopathy has repeatedly been associated with impairments in emotion recognition, decision making, aversive conditioning, extinction and reversal learning in both youths and adults (Blair, 2005b; Finger et al., 2008; O'Brien \& Frick, 1996). However, many questions remain unanswered. One topic that remains controversial concerns the question as to whether psychopathy is associated with a general 
executive dysfunction, including response inhibition deficits. For instance, whereas some studies interpreted their results as indicative of executive, including inhibition, deficits (Gorenstein, 1982; Lapierre, Braun, \& Hodgins, 1995; Roussy \& Toupin, 2000), others found less evidence or even a better performance on certain tasks (Devonshire, Howard, \& Sellars, 1988; Hare, 1984).

Response inhibition, the ability to inhibit inappropriate responding, is fundamental in the processing of goal-directed behavior (Gazzaniga, Ivry, \& Mangun, 2002). While inhibitory problems have long been known to be associated with antisocial, impulsive and criminal behaviour (Blair, 2005a; Ishikawa \& Raine, 2003), findings on inhibition abilities in psychopathy are rare and contradictory (Rogers, 2006). This can in part be explained by the fact that earlier research often considered psychopathy and APD the same, which might have led to an overrepresentation of antisocial behaviour, thus the antisocial factor, in studies. Also, studies often failed to take differences in cognitive ability and possible comorbiditiy (e.g. ADHD or substance abuse) into account. Furthermore, varying methods of defining antisocial and psychopathic groups have added to the confusion (Gorenstein, 1982; Morgan \& Lilienfeld, 2000). For example, Gorenstein (1982) found frontal lobe deficits in adult psychopathic offenders. However, in this study psychopaths differed from the control group mainly on the antisocial and not the affective/interpersonal factor (Hare, 1984). Thus, in these and related early studies participants would not have reached a diagnosis of psychopathy, according to the PCL-R, as their scores were especially elevated on the antisocial factor (Hare, 1984; Rogers, 2006). Also, even where well-defined samples and tools were used (detained youth and adult samples; PCL-R/PCL:YV), earlier research neglected the separate contributions of the psychopathy factors and concentrated on the use of PCL total scores (Rogers, 2006; Roussy \& Toupin, 2000; Toupin, Dery, Pauze, Mercier, \& Fortin, 2000). Likewise, these studies applied a rather taxonic approach, viewing psychopaths as a discrete class and comparing them to non-psychopathic groups. Due to these problems with methods and study design, the question of how the various dimensions of psychopathy, which can be measured by the different PCL factors, contribute to associations with subtypes of aggression and executive control remains unanswered. Taxonic group comparison approaches to psychopathy and the use of total scores only might have masked existing psychopathy subgroups. More recently, a dimensional approach to psychopathy, in which factors (and facets) are viewed as dimensions existing along a continuum, is promoted (Edens, Marcus, Lilienfeld, \& Poythress, 2006; Guay, Ruscio, Knight, \& Hare, 2007; Murrie et al., 2007). Applying dimensional models that take into account the different factors of the concept allow for the characterization of more heterogenicy within the construct of psychopathy (e.g., Cooke \& Michie, 2001; Porter \& Woodworth, 2006; Widiger, Simonsen, Krueger, Livesley, \& Verheul, 2005).

In line with the later approach, different external correlates of the defining characteristics of psychopathy have been found in youths and adults; e.g., the affective/in- 
terpersonal dimension of the disorder is associated with manipulative, proactive aggressive behaviour (Blair, 2004; Frick, Cornell, Barry, Bodin, \& Dane, 2003; Frick \& Morris, 2004; Kruh, Frick, \& Clements, 2005; Meloy, 2006). The antisocial dimension, on the other hand, is characterised by reactive aggression and impulsiveness (Blair, 2004; Frick \& Morris, 2004; Hill, 2002). Thus, whereas findings about response inhibition deficits and psychopathy are rather unclear, associations between psychopathy dimensions and types of aggression are clearer. While reactive aggression is common to many psychiatric conditions, proactive aggression is uniquely related to psychopathy. Different external correlates of these interrelated aggression subtypes have repeatedly been shown (see Cima \& Raine, 2009; for a systematic overview; Crapanzano, Frick, \& Terranova, 2010), although more research is needed to support these findings.

Reactive aggression, usually considered as emotion-driven, unplanned and impulsive behaviour shown in response to a threat, frustration or provocation (Berkowitz, 1993), is associated with intense emotions, affective-physiological arousal and little cognitive processing (Chase, O'Leary, \& Heyman, 2001). Generally, this type of aggression is related to amygdala and frontal lobe functioning. The amygdala evaluates the environmental cues, whereas the orbitofrontal cortex adjusts the reactive aggressive response. In contrast, proactive aggression is controlled, unemotional and used to achieve a particular goal. It is associated with low physiological arousal and requires forethought and planning (Berkowitz, 1993). Proactive aggression depends on cognitive processing, especially the ability to executively control inappropriate responses, i.e., intact response inhibition seems to be important. It is related to a fundamental failure in amygdala functioning and moral socialisation, both of which belong to the core deficits in psychopathy (Blair, Monson, \& Frederickson, 2001; Blair, 2004).

Supporting these concepts, Raine et al. (1998) found evidence of adequate frontal lobe functioning in mainly proactive offenders as compared to controls and mainly reactive offenders, with reactive offenders even showing impaired frontal lobe functioning. In another study (Ishikawa, Raine, Lencz, Bihrle, \& Lacasse, 2001), individuals scoring high on only the affective/interpersonal aspects showed even better executive functioning than did controls. These studies support the dimensional approach to the study of psychopathy. Furthermore, they support the idea that the concept of psychopathy describes a heterogeneous group.

Given that proactive aggression requires good executive control - i.e., response inhibition - and occurs mainly in individuals high on the affective interpersonal factor (e.g. Cima \& Raine, 2009; Woodworth \& Porter, 2002), the idea of a general response inhibition deficit in psychopathy must be cast in doubt (see Rogers, 2006; for a full discussion). Rather, it seems possible that the occurrence and intensity of response inhibition deficits especially relates to the antisocial factor and reactive aggression. Response inhibition deficits are, therefore, expected to be dependent on an individual's position on each psychopathy dimension. 


\section{This Study}

As far as could be determined, no research has been done on the differential relationship of the psychopathy dimensions and types of aggression with response inhibition, particularly not in youths. This study is a first attempt to answer the various questions raised here. The affective/interpersonal dimension and proactive aggression were expected to be positively associated with response inhibition abilities. Furthermore, the antisocial dimension and reactive aggression were expected to show negative associations with response inhibition. These questions will be investigated in a detained youth sample in comparison to a control sample.

\section{METHODS}

\section{Participants}

Two groups of male adolescents were recruited for the present study ( $N=117$, age 15-17

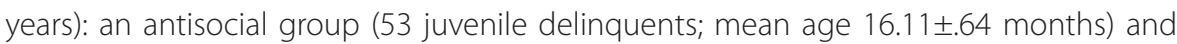
a control group (64 youths from the general population; mean age 15.92 \pm 0.63 months). Psychopathic traits and impulsive behaviour occur naturally during the course of puberty (e.g. Seagrave \& Grisso, 2002). A control group was included to investigate which associations are specific to the antisocial group.

The antisocial group was recruited from youth detention centres and forensic clinics in the Netherlands. Inclusion criteria comprised a primary diagnosis of conduct disorder (CD) according to DSM-IV-TR, age 15-17 and parental consent. Exclusion criteria were insufficient knowledge of the Dutch language, psychiatric disorders other than externalising, neurological disorders, head trauma, organic disorders, total $\mathrm{IQ}<75$, and drug/alcohol use 24 hours prior to testing. The control group was recruited from public schools in the Maastricht area and had to be free of any psychiatric disorder. All participants had to be free of medication at the time of the neuropsychological examination. The antisocial participants underwent regular drug screenings at the detention centres. The study was approved by the local Medical Ethical Committee (MEC), the Dutch Ministry of Justice and the regional Medical Ethical Committee for Mental Health Care Institutions (METIGG Zuid).

\section{Measures}

Intellectual capacity was assessed using two verbal (Information and Vocabulary) and two performance subtests (Picture Completion and Block Design) from the Wechsler Intelligence Scale for Children WISC-IIINL; Dahl, 1986; Wechsler, 2005). 
Response inhibition was measured with a computerised GoNoGo task (Test for Attentional Performance [TAP], 2.0, Psytest). The TAP is a reliable, $r=0.84$ and valid neuropsychological test battery (Földényi, Imhof, \& Steinhausen, 2000; Jakobsen, Sorensen, Rask, Jensen, \& Kondrup, 2011). The task requires an executive response to the Go stimulus, an $\mathbf{x}$, and an inhibitory response to the NoGo stimulus, a $\boldsymbol{+}$. When responding to the Go stimulus, the participant was required to press a button. Task completion took 10-15 minutes. Error rate and choice reaction time (CRT) were recorded. Error rate measures response inhibition, a high error rate indicating poor inhibition. The CRT measures attentional speed (in choice processes).

The psychopathy dimensions were measured using the Psychopathy Checklist: Youth version, $P C L: Y V$, unpublished authorized Dutch research version (de Ruiter, de Vries, \& Das, 2002). Traditionally, the 20 items are divided into two factors: Factor 1 (F1) represents the affective/interpersonal dimension. Factor 2 (F2) measures the antisocial dimension. All items were scored on a three-point scale $(0=$ does not apply; $1=$ applies to a certain extent; 2 = fully applies), yielding a dimensional total score from 0 to 40 . Ratings were based on an interview and collateral information. In the present study the traditional two factor model as well as the more nuanced four facet model were applied (Das, de Ruiter, \& Doreleijers, 2008; Harpur et al., 1988). The PCL:YV has good psychometric qualities (see Das, de Ruiter, Doreleijers, \& Hillege, 2009; Das, de Ruiter, Lodewijks, \& Doreleijers, 2007). In this study, consistency measures were comparable, with $a=0.95$ for the total scale, 0.90 for Factor 1 and 0.91 for Factor 2. Consistency measures of the four facets ranged from $a=0.67$ to 0.81 . The interrater reliability, examined using the interclass correlation coefficient (ICC; two-way random, absolute agreement), was good for Factor 1 (0.66) and excellent for Factor 2 (0.87), with a PCL:YV total of 0.84 (Fleiss, 1986).

The Reactive-Proactive Aggression Questionnaire (RPQ; Raine et al., 2006), is a 23item self-report questionnaire which distinguishes between motivated, proactive aggression (physical and verbal, 12 items) and reactive aggression (in response to external stimuli, 11 items). Items were scored on a three-point scale ( $0=$ never; $1=$ sometimes; $2=$ often). The questionnaire has sufficient internal consistency, $a=0.89-0.91$, and a good validity (Raine et al., 2006). Consistency measures were comparable, with $a=0.90$ for the total scale, 0.82 for the reactive and 0.86 for the proactive subscale. Translation (Cima, Otgaar, \& Merkelbach, in preparation) was done following accepted practical guidelines (van de Vijver \& Hambleton, 1996).

\section{Procedures}

At the time of incarceration, each youth's parents were asked to give permission for their child to participate in a scientific study. Boys who met the criteria for CD (diagnosed by the institutions' child and research psychiatrist or a clinical psychologist) were approached individually. It was made clear that participation would in no way influence 
treatment or legal standing. All participants and parents gave informed consent. Additionally, conduct disorder symptoms at time of testing were measured with the Diagnostic Interview Schedule for Children (DISC; Shaffer, Fisher, Lucas, Dulcan, \& SchwabStone, 2000), a structured clinical evaluation and dossier information (mean lifetime CD symptoms: delinquents $12.4 \pm 4.8$, controls $3.1 \pm 3.4$ ). The control group was approached by either the school counsellor or one of the researchers. Youths and parents had to give informed consent for participation. Each participant received a €20 monetary incentive for their participation.

Tasks were administered during three individual sessions. Sessions and tests were counterbalanced. Tests were administered according to standard procedures and scoring methods. Interviews were conducted by senior clinical and research psychologists or intensively trained psychology master students.

\section{Data Analysis}

Distributions of variables were examined in both groups. Square root transformations were computed for error rate and proactive aggression, yielding skewness and kurtosis values between -1.0 and +1.0. Several missing values occurred ( 3 antisocials: PCL:YV, 3 controls: IQ). Following recommendations from the authors of the test, the median choice reaction time (CRT) of the GoNoGo test was used for analyses as distributions of reaction time measurements were generally expected to be partially skewed.

First, independent-samples t-tests and $x^{2}$-tests on the demographic variables were calculated comparing the antisocial and the control group.

Second, further between-group differences were tested using analysis of covariance (ANCOVA), with the main study variables error rate, $C R T$, proactive and reactive aggression as the dependent variables. The independent variable was group. Verbal and performance IQ were entered as covariates due to their association with impulsiveness (de Wit, Flory, Acheson, McCloskey, \& Manuck, 2007) and neuropsychological measures in general. Bonferroni corrections were applied to the GoNoGo data to prevent type I error. Cohen's $d$ was provided for all group differences. PCL:YV data showed little variability within the control group ( $F 1=0-7, F 2=0-5)$. The affective/interpersonal (F1) and the antisocial dimension (F2) were therefore transformed into dichotomous variables (0/1) for group comparisons only. Participants who scored 0 were assigned a value of 0 , while participants who scored $\geq 1$ were assigned a value of 1 . Group differences on the dichotomous affective/interpersonal (F1) and antisocial (F2) dimensions were analyzed using $\times 2$-tests. Since more than $80 \%$ of the control group scored 0 on the PCL:YV factors, correlational and regression analyses were restricted to the antisocial group only.

Third, within the antisocial group, bivariate and partial correlations, controlling for psychopathy dimensions, were calculated partialling out their common variance. 
Fourth, given our main hypothesis, primary analyses involved multiple regression analyses to test the incremental value of the different key study variables withGoNoGo error rate and CRT as dependent variables. IQ estimates (verbal and performance IQ), ADHD and the main effect variables (reactive aggression, proactive aggression, as well as the original continuous PCL:YV factors, the affective/interpersonal dimension and antisocial dimension) were the predictor variables and were entered simultaneously in the analyses. Additionally, exploratory regression analyses were conducted including the four facet model of the PCL:YV.

All analyses were done using the Statistical Package for Social Sciences (SPSS) 18.0 for Windows (SPSS Inc., Chicago, IL, USA).

\section{RESULTS}

\section{Group differences: Antisocial group vs. controls}

Table 1 shows results of two-tailed independent t-tests and $x^{2}$-tests.

Table 1. Means and standard deviations $[M(S D)]$ of demographic variables (two-tailed)

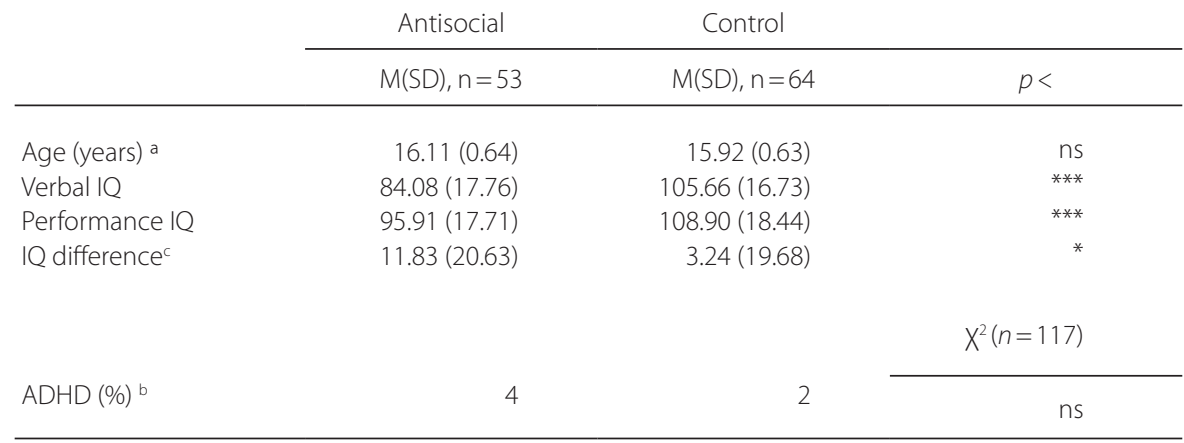

Note: ${ }^{*} p<.05 ;{ }^{* *} p<.01,{ }^{* *} p<.001 ;$ a in years; ${ }^{\text {b }}$ ADHD diagnosis last month before testing; ${ }^{c} \mathrm{PIQ}-\mathrm{VIQ}$, $\mathrm{VIQ}=$ verbal $I \mathrm{Q} ; \mathrm{PIQ}=$ performance $\mathrm{IQ}$

As expected the two groups did not differ in age $(\mathrm{t}(115)=1.63, p=0.106)$. However, comparing intelligence scores, the antisocial group had significantly lower verbal and performance IQ scores $(\mathrm{t}(113)=6.71, p<0.001, d=1.25$ resp. $\mathrm{t}(114)=3.85, p<0.001$, $d=0.72$ ). Both groups had higher performance than verbal IQ scores, indicating comparable ability distributions. Mean difference scores between verbal and performance IQ were significantly greater for the antisocial group $(\mathrm{t}(113)=2.196, p=0.032, d=0.41)$. 
With regard to the ADHD diagnosis no significant group differences were obtained $\left(x^{2}(1)=0.57, p=0.451\right)$. Only $4 \%$ of the antisocial group and $2 \%$ of the control group had a diagnosis of ADHD.

Table 2 contains the results of one-tailed analyses of covariance (ANCOVA) for the main study variables error rate, choice reaction time (CRT), reactive aggression and proactive aggression. For the dichotomous psychopathy dimensions $X^{2}$-tests are given. ANCOVA with error rate as the dependent variable showed significant group differences $(F(1,111)=4.80, p=0.031, d=0.42)$, with the antisocial group making more errors (Table 2$)$. No significant group differences for choice reaction time (cRT) occurred $(F(1,111)=2.17$, $p=0.143, d=0.28)$. The antisocial group consistently had higher mean reactive and proactive aggression scores $(F(1,111)=24.59, p<0.001, d=0.94$, resp. $F(1,111)=38.27, p<0.001$, $d=1.17)$. No significant effect of verbal and performance IQ occurred in any of the ANCOVA comparisons.

With regard to the PCL:YV dimensions results of $X^{2}$-tests showed that $88 \%$ of the antisocial group fell in the high affective/interpersonal category (F1) whereas $91 \%$ of the controls fell in the low affective/interpersonal category $\left(F 1 ; X^{2}(1)=70.47, p<0.001\right)$. All participants (100\%) in the antisocial group fell in the high antisocial category (F2), whereas $86 \%$ of the controls fell in the low category $\left(X^{2}(1)=83.02 ; p<0.001, r=-0.85\right.$, Table 2). Due to the little variability and low scores on the psychopathy dimensions within the control group, the control group was excluded from further analysis.

Table 2. Means and standard deviations $[M(S D)]$ of the main study variables after controlling for verbal and performance $I Q$, with ANCOVA comparisons

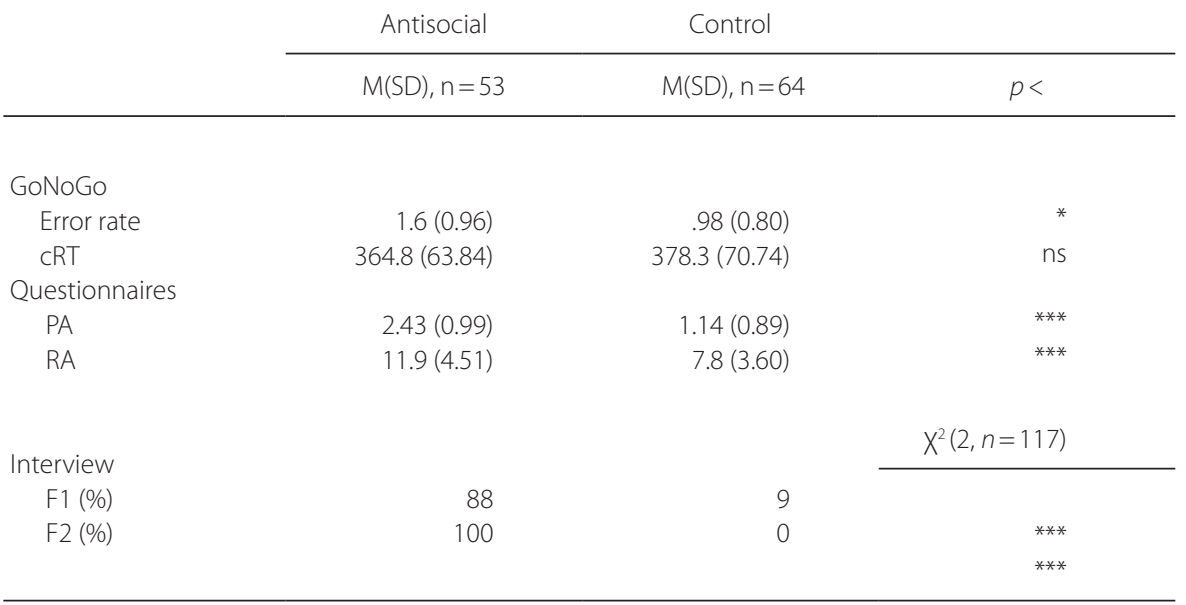

Note: ${ }^{*} p<0.05,{ }^{* *} p<0.01,{ }^{* * *} p<0.001$; Error rate (square root); $\mathrm{CRT}=$ median choice reaction time; $\mathrm{PA}=$ proactive aggression (square root) ; RA = reactive aggression; F1 = Factor 1 (affective-interpersonal dimension); F2 = Factor 2 (antisocial dimension) 
Table 3 and 4 show bivariate and partial correlations for the main study variables.

Table 3. Bivariate correlations amongst study variables (antisocial group only)

\begin{tabular}{lcccccc} 
& 1 & 2 & 3 & 4 & 5 & 6 \\
\hline 1 Error rate & - & & & & & \\
2 CRT & $-0.54^{* *}$ & - & & & & \\
3 PA & -0.12 & -0.12 & - & & & \\
4 RA & 0.19 & -0.14 & $0.64^{* *}$ & - & - & \\
5 F1 & -0.05 & 0.07 & $0.40^{* *}$ & $0.25^{*}$ & $-2^{* *}$ & - \\
6 F2 & $0.28^{*}$ & -0.06 & $0.34^{*}$ & $0.27^{*}$ & $6.2^{*}$ \\
\hline
\end{tabular}

Note: ${ }^{*} p<0.05,{ }^{* *} p<0.01$; one-tailed; $\mathrm{CRT}=$ median choice reaction time; $\mathrm{PA}=$ proactive aggression; $\mathrm{RA}=\mathrm{re}$ active aggression; F1 = Factor 1 (affective-interpersonal dimension); F2=Factor 2 (antisocial dimension)

Table 4. Partial correlations controlling for psychopathy dimensions; (correlations controlling for F2 in parentheses)

\begin{tabular}{|c|c|c|c|c|c|}
\hline & 1 & 2 & 3 & 4 & 5 \\
\hline 1 Error rate & $--(--)$ & & & & \\
\hline $2 \mathrm{cRT}$ & $-0.54^{* * *}\left(-0.55^{* * *}\right)$ & & & & \\
\hline 3 PA & $-0.09(-0.22)$ & $-0.20(-0.14)$ & & & \\
\hline 4 RA & $0.23(0.14)$ & $-0.18(-0.14)$ & $0.60^{* * *}\left(0.59^{* * *}\right)$ & & \\
\hline $5 \mathrm{~F} 1$ & $--\left(-0.29^{*}\right)$ & $--(0.14)$ & $--\left(0.26^{*}\right)$ & $--(0.11)$ & \\
\hline $6 F 2$ & $0.39 * *(--)$ & $-0.13(--)$ & $0.12(--)$ & $0.15(--)$ & $--(--)$ \\
\hline
\end{tabular}

Note: $p<0.05,{ }^{* *} p<0.01,{ }^{* * *} p<0.001$; one-tailed; $C R T=$ median choice reaction time; $P A=$ proactive aggression; $\mathrm{RA}=$ reactive aggression; F1 = Factor 1 (affective-interpersonal dimension); F2=Factor 2 (antisocial dimension)

\section{Prediction of response inhibition from aggression and PCL: YV dimensions}

Multiple regression analysis was conducted for the antisocial group. Analyses aimed to assess the relative impact of the key study variables (reactive aggression, proactive aggression and the continuous affective/interpersonal and antisocial dimensions) on response inhibition. The analysis examined the power of each variable in predicting the error rate. Verbal and performance IQ were entered in the equation due to their influence on all neuropsychological measures. All variables were entered simultaneously (forced entry). Table 5 shows the results of the multiple regression analyses. As hypothesised, the antisocial dimension (F2) and reactive aggression were significantly positive related to error rate (std. $\beta=0.47, p=0.006$; std. $\beta=0.56 p=0.002$ ), with higher levels on the antiso- 
cial dimension and reactive aggression being associated with higher error rates. Proactive aggression, on the other hand, was significantly negative related to error rate (std. $\beta=-0.56, p=0.003$ ). No significant relation between the affective/interpersonal dimension ( $F 1$ ) and error rate was found (std. $\beta=-0.24, p=0.149$ ), but the association described the expected negative form.

Apart from the key study variables a significant negative association between verbal IQ and error rate occurred (std. $B=-0.35, p=0.019$ ). Performance IQ and ADHD did not contribute significantly to the model (std. $\beta=0.15, p=0.303$; std. $\beta=-0.17, p=0.207$ ). Overall, $38 \%$ of the variance in the outcome is accounted for by the predictors. Reactive aggression, proactive aggression and the antisocial dimension (F2) accounted for almost twice as much variance as did verbal IQ and the affective/interpersonal dimension (F1). Performance $I Q$ and ADHD accounted for the least variance. Table 5 also contains results of the second multiple regression analysis for choice reaction time (cRT). Non of the predictors significantly contributed to the variance in choice reaction time.

Table 5. Multiple regression analyses predicting error rate and CRT in the antisocial group

\begin{tabular}{|c|c|c|c|c|c|c|c|c|c|c|}
\hline \multirow[b]{2}{*}{ Model } & \multicolumn{5}{|c|}{ Error rate } & \multicolumn{5}{|l|}{ cRT } \\
\hline & Std. $\beta$ & SE & $\mathrm{t}$ & $p<$ & Part & Std. $\beta$ & SE & $\mathrm{t}$ & $\mathrm{p}<$ & Part \\
\hline Constant & & 0.85 & 1.37 & ns & & & 65.92 & 6.21 & $* * *$ & \\
\hline VIQ & -0.34 & 0.01 & -2.43 & $*$ & -0.30 & 0.19 & 0.61 & 1.11 & ns & 0.16 \\
\hline PIQ & 0.15 & 0.01 & 1.04 & ns & 0.13 & -0.20 & 0.64 & -1.12 & ns & -0.16 \\
\hline PA & -0.56 & 0.04 & -3.12 & $* *$ & -0.38 & -0.04 & 2.98 & -0.18 & ns & -0.03 \\
\hline RA & 0.56 & 0.04 & 3.33 & $* *$ & 0.41 & -0.18 & 2.80 & -0.89 & ns & -0.13 \\
\hline F1 & -0.24 & 0.04 & -1.47 & ns & -0.18 & 0.23 & 3.19 & 1.19 & ns & 0.17 \\
\hline F2 & 0.47 & 0.04 & 2.87 & $* *$ & 0.35 & -0.16 & 3.32 & -0.81 & ns & -0.12 \\
\hline ADHD & -0.17 & 0.33 & -1.28 & ns & -0.16 & 0.16 & 25.75 & 1.02 & ns & 0.15 \\
\hline
\end{tabular}

Note: ${ }^{*} p<0.05,{ }^{* *} p<0.01,{ }^{* *} p<0.001 ; C R T=$ median choice reaction time; $\mathrm{VIQ}=$ verbal IQ; $\mathrm{PIQ}=$ performance $I Q ; R A=$ reactive aggression, $P A=$ proactive aggression; $F 1=$ Factor 1 (affective-interpersonal dimension); F2 = Factor 2 (antisocial dimension); ADHD = Attention-Deficit Hyperactivity Disorder (diagnosis last month before testing)

Additional multiple regression analyses examined the power of the four psychopathy facets in predicting error rate and choice reaction time (cRT). Results are presented in Table 6.

Predicting error rate, associations with IQ measures, types of aggression and ADHD remained stable. Associations with the different psychopathy facets revealed a significant positive association between the antisocial facet and error rate (std. $\beta=0.07$, $p=0.053$ ). Also, the affective facet was significantly negative related to error rate (std. $\beta=0.07, p=0.049$ ). Overall, $42 \%$ of the variance in the outcome is accounted for by the predictors. As with the two factor model no significant associations with choice reac- 
tion time (CRT) were obtained. Results for the four facet model as presented in Table 6 support the two factor findings in the sense that the antisocial dimension (two factor model) and particularly its antisocial facet (four facet model) relate to higher error rates and poorer response inhibition, while associations with the affective/interpersonal dimension (two factor model) seem to be attributable to its affective facet (four facet model). These findings again demonstrate that that the affective/interpersonal dimension of psychopathy relates to good response inhibition, while the antisocial dimension relates to poorer response inhibition.

Table 6. Multiple regression analyses predicting error rate and CRT in the antisocial group (PCL:YV 4 facet model)

\begin{tabular}{|c|c|c|c|c|c|c|c|c|c|c|}
\hline \multirow[b]{2}{*}{ Model } & \multicolumn{5}{|c|}{ Error rate } & \multicolumn{5}{|l|}{ CRT } \\
\hline & Std. $\beta$ & SE & $\mathrm{t}$ & $p<$ & Part & Std. $\beta$ & SE & $t$ & $p<$ & Part \\
\hline Constant & & 0.93 & 1.55 & ns & & & 75.43 & 5.30 & $* * *$ & \\
\hline VIQ & -0.38 & 0.01 & -2.50 & $*$ & -0.31 & 0.19 & 0.69 & 1.03 & ns & 0.16 \\
\hline PIQ & 0.12 & 0.01 & 0.80 & ns & 0.10 & -0.19 & 0.69 & -1.00 & ns & -0.15 \\
\hline PA & -0.54 & 0.04 & -3.00 & $* *$ & -0.37 & -0.03 & 3.18 & -0.13 & ns & -0.02 \\
\hline RA & 0.54 & 0.04 & 3.24 & $* *$ & 0.40 & -0.17 & 2.93 & -0.81 & ns & -0.13 \\
\hline Facet1 & .059 & 0.08 & 0.34 & ns & 0.04 & 0.05 & 6.84 & 0.25 & ns & 0.04 \\
\hline Facet2 & -.35 & 0.07 & -2.04 & * & -0.25 & 0.23 & 5.45 & 1.10 & ns & 0.16 \\
\hline Facet3 & .17 & 0.09 & 0.94 & ns & 0.12 & -0.18 & 7.11 & -0.78 & ns & -0.12 \\
\hline Facet4 & .35 & 0.07 & 2.00 & $*$ & 0.25 & 0.01 & 5.74 & 0.05 & ns & 0.01 \\
\hline ADHD & -0.13 & 0.36 & -.86 & ns & -0.11 & 0.14 & 29.51 & 0.76 & ns & 0.12 \\
\hline
\end{tabular}

$R^{2}$ (error) $=0.42$

$R^{2}(c R T)=0.11$

Note: ${ }^{*} p<0.05,{ }^{* *} p<0.01,{ }^{* *} p<0.001 ; C R T=$ median choice reaction time; $\mathrm{VIQ}=$ verbal IQ; $\mathrm{PIQ}=$ performance IQ; RA = reactive aggression; $P A=$ proactive aggression; Facet1 = interpersonal facet; Facet2 = affective facet; Facet3 = lifestyle facet; Facet4 = antisocial facet; ADHD=Attention-Deficit Hyperactivity Disorder (diagnosis last month before testing)

\section{Discussion}

The exact role of executive functioning deficits in psychopathy remains controversial. Especially, findings on response inhibition deficits are contradictory. This is the first study to examine the relationships between neuropsychological behavioural performance on a response inhibition task, psychopathy factors and types of aggression in a group of detained antisocial youth.

Antisocial youth were compared to a control group on measures of intelligence, ADHD, response inhibition, aggression and psychopathy. Furthermore, partial correlations and multiple regression analyses were conducted in the antisocial group only to 
identify the incremental value of psychopathy factors and types of aggression (Walters, 2003). Results revealed evidence for (a) poorer prefrontal neuropsychological functioning in the antisocial group, and (b) differential relationships between the psychopathy factors and types of aggression with response inhibition. Furthermore, results for the four facet model support the two factor findings.

\section{Group differences}

Groups did not differ in age or ADHD diagnoses, whereas the control group generally achieved higher verbal and performance IQ scores. However, neither verbal nor performance IQ did affect group differences on the key study variables.

With regard to the inhibition task (GoNoGo) antisocial youths made more errors than did the control group. No significant differences in choice reaction time (CRT) occurred, whereas CRT variability was slightly bigger in the control group. High error rates in the antisocial group indicate poor response inhibition (one component of executive control), which in turn indicates impulsiveness. These findings replicated previous work comparing psychopaths with non-psychopaths (based on PCL total scores) on a GoNoGo task. Psychopaths consistently differed from non-psychopaths on the number of errors only (Lapierre et al., 1995; Roussy \& Toupin, 2000). This finding does not seem to be related to an attentional deficit as no difference in CRT occurred, which is a measure of attentional speed in the applied test (Fimm \& Zimmermann, 2006). Additionally, the present findings indicate that the difference in error rate can not be attributed to a diagnosis of ADHD.

As expected, the antisocial group showed significantly higher reactive and proactive aggression scores. Furthermore, boys in the antisocial group had increased scores on the affective/interpersonal and antisocial dimensions, while the controls showed little antisocial behaviour and affective/interpersonal traits.

\section{Psychopathy dimensions, types of aggression and response inhibition}

Results of the regression analyses support the hypothesis of differential associations of the two psychopathy dimensions and types of aggression with response inhibition. The affective/interpersonal dimension was related to better response inhibition. However, this association was not significant, whereas at facet level particularly the affective facet was significantly related to better response inhibition as were proactive aggression and verbal IQ scores. This result agrees with the long tradition of clinical descriptions relating at least some aspects of psychopathy with good executive and cognitive resources (Cleckley, 1941). Specifically, it shows that high scores on the affective/interpersonal dimension do not necessarily have negative cognitive effects. Research in clinical samples found the affective and interpersonal facets of this dimension to be particularly associ- 
ated with verbal abilities, creativity as well as performance related, and analytical thinking in children and adolescents (Loney, Frick, Ellis, \& McCoy, 1998; Salekin, Neumann, Leistico, $\&$ Zalot, 2004). Furthermore, the present results support the hypothesis that proactive aggression, which occurs mainly in psychopaths, is inversely related to poor inhibition. To the contrary, both the antisocial dimension, i.e. its antisocial facet, and reactive aggression were significantly positive associated with poor response inhibition in the present study. This finding is in line with earlier results linking antisocial behaviour to poor response inhibition, reactive aggression and frontal lobe dysfunction (Blair, 2005a; Cima \& Raine, 2009; Ishikawa \& Raine, 2003).

Thus, as expected, high levels on the antisocial dimension and reactive aggression were related to poor response inhibition, whereas poor response inhibition was associated with low levels on the affective/interpersonal dimension and proactive aggression. Additionally, associations with the four facet model support the two factor findings and allow a more nuanced understanding of the obtained results.

The findings refine results of the (rather few) studies on frontal lobe deficits, and particularly those on response inhibition, whose data are from adult and adolescent prison inmates. These studies found psychopaths to be more impulsive than non-psychopaths (Lapierre et al., 1995; Roussy \& Toupin, 2000) based on PCL total scores without taking into account the different influences of the affective/interpersonal and antisocial dimensions (Lapierre et al., 1995; Roussy \& Toupin, 2000). Using groups which differ primarily on the antisocial dimension, or using exclusively total scores, may yield overestimations or no findings, thus masking important differential relationships that could enhance the understanding and further identification of psychopathy subtypes (Gorenstein, 1982; Vitacco, Neumann, \& Wodushek, 2008).

If the findings of the present study represent a general pattern, it should be possible to make similar observations in non-clinical, "highly functional" psychopaths. A study in college students found the affective/interpersonal dimension to be unrelated to response inhibition, but positively associated with other executive functioning tasks. On the other hand, the antisocial dimension correlated negatively with all executive functioning tasks (Sellbom \& Verona, 2007). Accordingly, Ishikawa et al. (2001) showed better executive functioning in individuals high on the affective/interpersonal dimension than in control participants or individuals scoring high on both dimensions.

Thus, together with data from earlier research, the present findings support the importance of the dimensional approach to psychopathy in understanding cognitive deficits, i.e., response inhibition deficits. Particularly, some psychopathic core characteristics like callousness and lack of remorse as well as proactive aggression seem to warrant a certain amount of executive and cognitive skills. Based on the presented evidence, it appears plausible that an individual's position on any of the psychopathy dimensions could be related to large differences on behavioral, structural and psychophysiological levels. For example, so-called successful psychopaths with high affective/interpersonal 
dimension scores and low antisocial dimension scores show more autonomic reactivity than individuals who are high on both dimensions or even controls (Ishikawa et al., 2001), which could possible make them more feasible for emotions in themselves and others. Nevertheless, when elevated scores on the affective/interpersonal dimension (generally associated with amygdala dysfunction) and antisocial dimension (generally associated with prefrontal cortex dysfunction) occur together (e.g. Blair, 2003, , 2004), they constitute a dangerous combination both for the individual and for those around him or her. This might describe the most severe and malevolent phenotype (Sellbom \& Verona, 2007). Concerning the psychopathy facets, future research will have to investigate whether the present findings represent a replicable pattern.

\section{Conclusion}

In conclusion, the present findings provide first evidence of differential associations between response inhibition, types of aggression and the dimensions of psychopathy in an antisocial youth sample. Whereas reactive aggression and the antisocial facet of the original antisocial factor relate to poor response inhibition abilities, proactive aggression and the affective facet of the original affective/interpersonal dimension relate to better response inhibition capacities. Thus, within the highly heterogeneous group of detained youth with psychopathic traits there does not seem to be a simple answer to the question as to whether the disorder is related to poor response inhibition or even response inhibition deficits. This rather seems to depend on an individuals' profile on the psychopathy dimensions. A dimensional approach to psychopathy and related concepts, as recently advanced by the field (e.g.Salekin et al., 2004; Vitacco, Neumann, \& Jackson, 2005; Vitacco et al., 2008; Walsh, Swogger, \& Kosson, 2009), might greatly improve insight in the development of this complex disorder, paving the way for further enhancing diagnostic procedures and improving therapeutic possibilities. Specifically, the identification of unique psychopathy personality subtypes based on an individual's position on the psychopathy dimensions has the potential to clarify the long-standing confusion seen in the literature. Relying on global scores only can mask important differential associations.

\section{Limitations and future directions}

This study had several limitations. First, the sample was restricted to boys. However, recent research in a large community sample obtained no gender differences in predicting cognitive functioning, especially intellectual deficits, from psychopathy dimensions in children (Fontaine, Barker, Salekin, \& Viding, 2008). Likewise, no gender differences in response inhibition were found for CD (Herba, Tranah, Rubia, \& Yule, 2006).

Second, this study relied in part on self-report measures. There is, however, evidence that psychopaths downplay the instrumentality of their offences and present 
them as more reactive than they were (Porter \& Woodworth, 2007). Therefore, the fact that the presented results support the hypothesized relationships does support the findings. Furthermore, differentiating between reactive and proactive aggression remains controversial (Bushman \& Anderson, 2001). However, research indicates partly differential correlates for reactive and proactive aggression (see Cima \& Raine, 2009, for a systematic overview). Therefore, the evidence from this and from other studies supports a dimensional model of aggression.

Third, partialling together with multiple regression analysis can have its pitfalls (Lynam, Hoyle, \& Newman, 2006). In the context of intercorrelated concepts like types of aggression and psychopathy dimensions, interpretations must be stated with caution. In this study, reactive and proactive aggression were correlated moderately with $r=0.64$ and $40 \%$ shared variance, thereby allowing for differential associations and their interpretation. Similar results were obtained for associations between psychopathy dimensions with $r=0.62$. Given the relatively small sample size, the statistical power of the results from this study could be cast into doubt. However, the results and corresponding effect sizes lend support to the validity of these findings.

Fourth, only a few inhibitory tests were used. This makes it impossible to determine what effect the tool had on the absence of significant associations. Furthermore, in a laboratory setting, adolescents might show better cognitive control abilities than in real life. Emotional states, social influences and skills can greatly influence performance under real-life conditions (e.g., Steinberg, 2004). Future research should also include other measures of prefrontal executive functioning as well as tasks that indicate amygdala functioning to further investigate the issues raised here and elsewhere (Sellbom \&Verona, 2007)

Fifth, the lack of clinical norms (concerning good, poor and deficient response inhibition) for the present study population does not allow us to speak of a response inhibition deficit in the antisocial group, but rather poor inhibition as compared to the control group. Nevertheless, the aim of the present study was less the specific clinical investigation of the dependent variable, i.e. response inhibition, but rather the study of associations between the independent variables and neurocognitive performance, i.e. response inhibition ability. Future studies should aim at the identification of clinical norms, which would add to the ecological validity of this type of research.

Sixth, this was not a longitudinal study, allowing only statistical predictions. The results neither address the temporal order of variables nor causal relationships amongst variables. However, according to Sellbom and Verona (2007), a strength of this study is that it presents a conservative test of the main study variables by controlling for intellectual abilities and ADHD, which would make the findings more reliable.

Seventh and last, we are aware that youth is a neurologically vulnerable period. Large parts of the frontal lobe and reciprocal connections with the limbic system are still maturating, as is cell myelination. On the other hand it is possible that the amygdala dysfunction, 
which can already be observed in adolescents (Marsh et al., 2008), and the related poor lifestyle only later in the development severely affect prefrontal functioning. It would, therefore, be important to also replicate the present findings in adult clinical or detained samples.

For now, the present findings support the dimensional approach to youth psychopathy and the incorporation of the affective/interpersonal dimension in the conceptualisation of youth and adult antisocial behaviour subtypes in future diagnostic manuals.

\section{ACKNOWLEDGEMENTS}

We kindly thank all participants and detention centers (St. Joseph Foundation, Cadier en Keer; De Catamaran, Eindhoven; De Leij, Vught) for their participation. 


\section{REFERENCES}

APA. (2000). Diagnostic and statistic manual of mental disorder (4th ed., text revision) Washington, DC: American Psychological Association.

Berkowitz, L. (1993). Aggression: Its causes, consequences, and control. Philadelphia: Temple University Press.

Blair, J., Monson, J., \& Frederickson, N. (2001). Moral reasoning and conduct problems in children with emotional and behavioural difficulties. Personality and Individual Differences, 31, 799-811.

Blair, R. J. (2003). Neurobiological basis of psychopathy. British Journal of Psychiatry, 182, 5-7.

Blair, R. J. (2004). The roles of orbital frontal cortex in the modulation of antisocial behavior. Brain and Cognition, 55(1), 198-208.

Blair, R. J. (2005a). Applying a cognitive neuroscience perspective to the disorder of psychopathy. Development and Psychopathology, 17(3), 865-891.

Blair, R. J. (2005b). Responding to the emotions of others: dissociating forms of empathy through the study of typical and psychiatric populations. Consciousness and Cognition, 14(4), 698-718.

Burke, J. D., Loeber, R., \& Lahey, B. B. (2007). Adolescent conduct disorder and interpersonal callousness as predictors of psychopathy in young adults. Journal of Clinical Child and Adolescent Psychology, 36(3), 334-346.

Bushman, B. J., \& Anderson, C. A. (2001). Is it time to pull the plug on the hostile versus instrumental aggression dichotomy? Psychological Review, 108(1), 273-279.

Chase, K. A., O'Leary, K. D., \& Heyman, R. E. (2001). Categorizing partner-violent men within the reactiveproactive typology model. Journal of Consulting and Clinical Psychology, 69(3), 567-572.

Cima, \& Raine, A. (2009). Distinct characteristics of psychopathy relate to different subtypes of aggression. Personality and Individual Differences, 47(8), 835-840.

Cima, M., Otgaar, H., \& Merkelbach, H. (in preparation). Development and validation of a psychpathic inventory for children.

Cleckley, H. (1941). The mask of sanity. St. Louis, MO: C.V. Mosby.

Cooke, D. J., \& Michie, C. (1997). An item response theory analysis of the Hare Psychopathy Checklist. Psychological Assessment, 9, 3-14.

Cooke, D. J., \& Michie, C. (2001). Refining the construct of psychopathy: towards a hierarchical model. Psychological Assessment, 13(2), 171-188.

Crapanzano, A. M., Frick, P. J., \& Terranova, A. M. (2010). Patterns of physical and relational aggression in a school-based sample of boys and girls. Journal of Abnormal Child Psychology, 38(4), 433-445.

Dahl, G. (1986). Handbuch zum Reduzierten Wechsler-Intelligenztest Koenigstein-Traunstein, Germany: Hain Verlag.

Das, J., de Ruiter, C., \& Doreleijers, T. (2008). Reliability and validity of the Psychopathy Checklist: Youth Version in Dutch female adolescents. International Journal of Law and Psychiatry, 31(3), 219-228.

Das, J., de Ruiter, C., Doreleijers, T., \& Hillege, S. (2009). Reliability and construct validity of the Dutch psychopathy checklist: youth version: findings from a sample of male adolescents in a juvenile justice treatment institution. Assessment, 16(1), 88-102. 
Das, J., de Ruiter, C., Lodewijks, H., \& Doreleijers, T. (2007). Predictive validity of the Dutch PCL:YV for institutional disruptive behavior: findings from two samples of male adolescents in a juvenile justice treatment institution. Behavioral Sciences and the Law, 25(5), 739-755.

de Ruiter, C., de Vries, J. K., \& Das, J. (2002). Psychopathie Checklist: Jeugd Versie:Geautoriseerde Nederlandse vertaling [Psychopathy Checklist: Youth Version: Authorized Dutch translation]: Unpublished research version.

de Wit, H., Flory, J. D., Acheson, A., McCloskey, M., \& Manuck, S. B. (2007). IQ and nonplanning impulsivity are independently associated with delay discounting in middle-aged adults. Personality and Individual Differences, 42(1), 111-121.

Devonshire, P. A., Howard, R. C., \& Sellars, C. (1988). Frontal lobe function and personlaity in mentally abnormal offenders. Personality and Individual Differences, 9(2), 339-344.

Edens, J. F., Marcus, D. K., Lilienfeld, S. O., \& Poythress, N. G., Jr. (2006). Psychopathic, not psychopath: taxometric evidence for the dimensional structure of psychopathy. Journal of Abnormal Psychology, 115(1), 131-144.

Fimm, B., \& Zimmermann, P. (2006). Testbatterie zur Aufmerksamkeitsprüfung, (TAP)-Version 2.0. Herzogenrath, Germany: Psytest.

Finger, E. C., Marsh, A. A., Mitchell, D. G., Reid, M. E., Sims, C., Budhani, S., et al. (2008). Abnormal ventromedial prefrontal cortex function in children with psychopathic traits during reversal learning. Archives of General Psychiatry, 65(5), 586-594.

Fleiss, J. L. (1986). The design and analysis of clinical experiments. NY: Wiley.

Földényi, M., Imhof, K., \& Steinhausen, H.-C. (2000). Klinische Validität der computerunterstützten TAP bei Kindern mit Aufmerksamkeits-/ Hyperaktivitätsstörungen. Zeitschrift für Neuropsychologie, 11(3), 154167.

Fontaine, N., Barker, E. D., Salekin, R. T., \& Viding, E. (2008). Dimensions of psychopathy and their relationships to cognitive functioning in children. Journal of Clinical Child and Adolescent Psychology, 37(3), 690-696.

Forth, A. E., Kosson, D. S., \& Hare, R. D. (2003). Hare Psychopathy Checklist: Youth Version. Toronto, Ontario: Multi-Heath Systems.

Fowles, D. C., \& Dindo, L. (2006). A Dual-Deficit Model of Psychopathy. In C. J. Patrick (Ed.), Handbook of Psychopathy (pp. 14-34). NY: Guilford Press.

Frick, P. J., Cornell, A. H., Barry, C. T., Bodin, S. D., \& Dane, H. E. (2003). Callous-unemotional traits and conduct problems in the prediction of conduct problem severity, aggression, and self-report of delinquency. Journal of Abnormal Child Psychology, 31(4), 457-470.

Frick, P. J., \& Morris, A. S. (2004). Temperament and developmental pathways to conduct problems. Journal of Clinical Child and Adolescent Psychology, 33(1), 54-68.

Frick, P. J., \& White, S. F. (2008). Research review: the importance of callous-unemotional traits for developmental models of aggressive and antisocial behavior. Journal of Child Psychology and Psychiatry and Allied Disciplines, 49(4), 359-375.

Gazzaniga, M. S., Ivry, R. B., \& Mangun, G. R. (2002). Executive Functions and Frontal Lobes. In M. S. Gazzaniga, R. B. Ivry \& G. R. Mangun (Eds.), Cognitive Neuroscience (2nd ed., pp. 499-535). New York: Norton \& Company, Inc. 
Gorenstein, E. E. (1982). Frontal lobe functions in psychopaths. Journal of Abnormal Psychology, 91(5), 368379.

Guay, J. P., Ruscio, J., Knight, R. A., \& Hare, R. D. (2007). A taxometric analysis of the latent structure of psychopathy: evidence for dimensionality. Journal of Abnormal Psychology, 116(4), 701-716.

Hare, R. D. (1984). Performance of psychopaths on cognitive tasks related to frontal lobe function. Journal of Abnormal Psychology, 93(2), 133-140.

Hare, R. D. (1991). The Psychopathy Checklist-Revised. Toronto, Ontario: Multi-Health Publishers.

Hare, R. D. (2003). The Psychopathy Checklist-Revised technical manual (2nd ed.). Toronto: Multi-Health Systems.

Hare, R. D., \& Neumann, C. S. (2008). Psychopathy as a clinical and empirical construct. Annu Rev Clin Psychol, 4, 217-246.

Harpur, T. J., Hakstian, A. R., \& Hare, R. D. (1988). Factor structure of the Psychopathy Checklist. Journal of Consulting and Clinical Psychology, 56(5), 741-747.

Herba, C. M., Tranah, T., Rubia, K., \& Yule, W. (2006). Conduct problems in adolescence: three domains of inhibition and effect of gender. Dev Neuropsychol, 30(2), 659-695.

Hill, J. (2002). Biological, psychological and social processes in the conduct disorders. Journal of Child Psychology and Psychiatry and Allied Disciplines, 43(1), 133-164.

Ishikawa, S. S., \& Raine, A. (2003). Prefrontal Deficits and Antisocial Behaviour. In B. B. Lahey, T. Moffitt \& A. Caspi (Eds.), Causes of Conduct Disorder and Juvenile Delinquency (pp. 277-304). London, New York: The Guilford Press.

Ishikawa, S. S., Raine, A., Lencz, T., Bihrle, S., \& Lacasse, L. (2001). Autonomic stress reactivity and executive functions in successful and unsuccessful criminal psychopaths from the community. Journal of Abnormal Psychology, 110(3), 423-432.

Jakobsen, L. H., Sorensen, J. M., Rask, I. K., Jensen, B. S., \& Kondrup, J. (2011). Validation of reaction time as a measure of cognitive function and quality of life in healthy subjects and patients. Nutrition, 27(5), 561-570.

Kruh, I. P., Frick, P. J., \& Clements, C. B. (2005). Historical and Personality Correlates to the Violence Patterns of Juveniles Tried as Adults. Criminal Justice and Behaviour, 32(1), 69-96.

Lapierre, D., Braun, C. M., \& Hodgins, S. (1995). Ventral frontal deficits in psychopathy: neuropsychological test findings. Neuropsychologia, 33(2), 139-151.

Loney, B. R., Frick, P. J., Ellis, M., \& McCoy, M. G. (1998). Intelligence, callous-unemotional traits, and antisocial behaviour. Journal of Psychopathology and Behavioural Assessment, 20(3), 231-247.

Loney, B. R., Taylor, J., Butler, M. A., \& lacono, W. G. (2007). Adolescent psychopathy features: 6-year temporal stability and the prediction of externalizing symptoms during the transition to adulthood. Aggress Behav, 33(3), 242-252.

Lynam, D. R., Caspi, A., Moffitt, T. E., Loeber, R., \& Stouthamer-Loeber, M. (2007). Longitudinal evidence that psychopathy scores in early adolescence predict adult psychopathy. Journal of Abnormal Psychology, 116(1), 155-165.

Lynam, D. R., Hoyle, R. H., \& Newman, J. P. (2006). The perils of partialling: cautionary tales from aggression and psychopathy. Assessment, 13(3), 328-341. 
Marsh, A. A., Finger, E. C., Mitchell, D. G., Reid, M. E., Sims, C., Kosson, D. S., et al. (2008). Reduced amygdala response to fearful expressions in children and adolescents with callous-unemotional traits and disruptive behavior disorders. American Journal of Psychiatry, 165(6), 712-720.

Meloy, J. R. (2006). Empirical basis and forensic application of affective and predatory violence. Australian and New Zealand Journal of Psychiatry, 40(6-7), 539-547.

Morgan, A. B., \& Lilienfeld, S. O. (2000). A meta-analytic review of the relation between antisocial behavior and neuropsychological measures of executive function. Clinical Psychology Review, 20(1), 113-136.

Murrie, D. C., Marcus, D. K., Douglas, K. S., Lee, Z., Salekin, R. T., \& Vincent, G. (2007). Youth with psychopathy features are not a discrete class: a taxometric analysis. Journal of Child Psychology and Psychiatry and Allied Disciplines, 48(7), 714-723.

Neumann, C. S., Kosson, D. S., Forth, A. E., \& Hare, R. D. (2006). Factor structure of the Hare Psychopathy Checklist: Youth Version (PCL: YV) in incarcerated adolescents. Psychological Assessment, 18(2), $142-$ 154.

O'Brien, B. S., \& Frick, P. J. (1996). Reward dominance: associations with anxiety, conduct problems, and psychopathy in children. Journal of Abnormal Child Psychology, 24(2), 223-240.

Porter, S., \&Woodworth, M. (2006). Psychopathy and aggression. In C. J. Patrick (Ed.), Handbook of Psychopathy. New York: The Guilford Press.

Porter, S., \& Woodworth, M. (2007). "I'm sorry I did it... but he started it": a comparison of the official and self-reported homicide descriptions of psychopaths and non-psychopaths. Law and Human Behavior, 31(1), 91-107

Raine, A., Meloy, J. R., Bihrle, S., Stoddard, J., LaCasse, L., \& Buchsbaum, M. S. (1998). Reduced prefrontal and increased subcortical brain functioning assessed using positronemission tomography in predatory and affective murderers. Behavioural Sciences and the Law, 16, 319-332.

Raine, A., Dodge, K., Loeber, R., Gatzke-Kopp, L., Lynam, D., Reynolds, C., et al. (2006). The Reactive-Proactive Aggression Questionnaire: differential correlates of reactive and proactive aggression in adolescent boys. Aggressive Behavior, 32, 159-171.

Rogers, R. D. (2006). The functional architecture of the frontal lobes: Implications for research with psychopathic offenders. In C. J. Patrick (Ed.), Handbook of Psychopathy (pp. 313-334). London: The Guilford Press.

Roussy, S., \& Toupin, J. (2000). Behavioural Inhibition Deficits in Juvenile Psychopaths. Aggressive Behaviour, 26, 413-424.

Salekin, R. T., Neumann, C. S., Leistico, A. M., \& Zalot, A. A. (2004). Psychopathy in youth and intelligence: an investigation of Cleckley's hypothesis. Journal of Clinical Child and Adolescent Psychology, 33(4), 731 742.

Seagrave, D., \& Grisso, T. (2002). Adolescent development and the measurement of juvenile psychopathy. Law and Human Behavior, 26(2), 219-239.

Sellbom, M., \& Verona, E. (2007). Neuropsychological correlates of psychopathic traits in a non-incarcernated sample. Journal of Research in Personality, 41, 276-294. 
Shaffer, D., Fisher, P., Lucas, C. P., Dulcan, M. K., \& Schwab-Stone, M. E. (2000). NIMH Diagnostic Interview Schedule for Children Version IV (NIMH DISC-IV): description, differences from previous versions, and reliability of some common diagnoses. Journal of the American Academy of Child and Adolescent Psychiatry, 39(1), 28-38.

Steinberg, L. (2004). Risk-taking in adolescence: What changes, and why? Annals of the New York Academy of Sciences(1021), 51-58.

Toupin, J., Dery, M., Pauze, R., Mercier, H., \& Fortin, L. (2000). Cognitive and familial contributions to conduct disorder in children. Journal of Child Psychology and Psychiatry and Allied Disciplines, 41(3), 333-344.

van de Vijver, F. J. R., \& Hambleton, R. K. (1996). Translating tests: some practical guidelines. European Psychologist, 1(2), 89-99.

Vitacco, M. J., Neumann, C. S., \& Jackson, R. L. (2005). Testing a four-factor model of psychopathy and its association with ethnicity, gender, intelligence, and violence. Journal of Consulting and Clinical Psychology, 73(3), 466-476.

Vitacco, M. J., Neumann, C. S., \& Wodushek, T. (2008). Differential relationships between the dimensions of psychopathy and intelligence: Replication with adult jail inmates. Criminal Justice and Behavior, 35(1), 48-55.

Walsh, Z., Swogger, M. T., \& Kosson, D. S. (2009). Psychopathy and Instrumental Violence: Facet Level Relationships. Journal of Personality Disorders, 23(4), 416-424.

Walters, G. D. (2003). Predicting institutional adjustment and recidivism with the psychopathy checklist factor scores: a meta-analysis. Law and Human Behavior, 27(5), 541-558.

Wechsler, D. (2005). Wechsler Intelligence Scale for Children-Third Edition-NL (WISC-III-NL): Dutch version: NIP Dienstencentrum, Amsterdam.

Widiger, T. A., Simonsen, E., Krueger, R., Livesley, W. J., \& Verheul, R. (2005). Personality disorder research agenda for the DSM-V. J Pers Disord, 19(3), 315-338.

Woodworth, M., \& Porter, S. (2002). In cold blood: characteristics of criminal homicides as a function of psychopathy. Journal of Abnormal Psychology, 111(3), 436-445. 



\section{Salivary cortisol and psychopathy dimensions in detained antisocial adolscents}




\section{ABSTRACT}

Previous research revealed hypothalamic-pituitary-adrenal (HPA) axis abnormalities in relation to antisocial and aggressive behavior. Some evidence suggests that low cortisol levels may serve as a biological marker for a severe antisocial subgroup with pronounced callous-unemotional (CU) traits. Children displaying the combination of severe antisocial behavior and CU traits appear to be particularly at risk of developing adult psychopathy. Given the lack of studies on the relationship between cortisol levels and CU traits in antisocial adolescents, the current study investigates whether cortisol levels are uniquely associated with $\mathrm{CU}$ traits as compared to other psychopathy dimensions (i.e., narcissism and impulsivity). Detained antisocial adolescents ( $n=63)$ and a community comparison group ( $n=62)$ completed diaries and collected three saliva samples daily on two days, with compliance monitored electronically. Psychopathy dimensions were assessed through self-report questionnaires. Externalizing symptoms were assessed by structured clinical interview. Multilevel regression analyses indicated no differences in cortisol levels or diurnal slopes between the two groups. Overall, cortisol levels were not significantly related to psychopathy dimensions. However, greater impulsivity was associated with lower cortisol levels in the community sample, but not in the antisocial group. Conclusion: Results cast doubt on the notion of low cortisol levels as a biological marker for CU traits. Low basal cortisol levels appear to be more closely related to a general deficit in behavioral regulation. Implications for future research are discussed. 


\section{INTRODUCTION}

Childhood behavioral disorders are the most common diagnoses in child and adolescent psychiatric settings. Among these, conduct disorder (CD) describes the most severe form of antisocial and aggressive behavior, causing the highest mental health and public expenditures of all problem behaviors (Foster \& Jones, 2005; Schmeck \& Poustka, 2000). Aside from the environmental risk factors that play a role in the development of severe antisocial and aggressive behavior, certain neurobiological factors may be of importance. The hypothalamic-pituitary-adrenal (HPA) axis and its end product, the stress hormone cortisol, are of particular interest in this respect (McBurnett, Lahey, Rathouz, \& Loeber, 2000; van Goozen et al., 1998). It is theorized that low levels of arousal in the central nervous system are causally related to the development and maintenance of antisocial and aggressive behavior (van Goozen, Matthys, Cohen-Kettenis, Buitelaar, \& van Engeland 2000). According to this line of thought, low HPA axis activity, as reflected in low cortisol levels, may be a neurobiological marker of underarousal and thus of predisposition toward aggressive and antisocial behavior. The mechanisms through which underarousal and low cortisol contribute to antisocial behavior have been conceptualized in terms of two largely compatible theories.

First, according to the fearlessness theory, the neurobiological systems that normally process threat information, including the amygdala and the prefrontal cortex, are believed to be compromised in highly antisocial and aggressive individuals (van Goozen \& Fairchild, 2008). Fearless individuals are thus physiologically underaroused and less sensitive to stress (Raine, 1996). Being less afraid of negative consequences of their actions and less sensitive to punishment, they do not experience normal inhibitions against engaging in aggressive and antisocial behavior (Raine, 1993).

Second, the stimulation-seeking theory suggests that a certain level of arousal or stress is needed in order to feel pleasant; underarousal thus represents an aversive condition. Chronically underaroused individuals are believed to seek physiological stimulation through aggressive and antisocial behavior in order to counteract this negative state (Zuckerman, 1979).

In adults, studies have repeatedly found associations between antisocial, aggressive behavior and low cortisol levels (Virkkunen, 1985; Woodman, Hinton, \& O'Neill, 1978). Several studies in children and adolescents have also reported negative associations between CD symptoms and basal cortisol levels. For example, children with antisocial fathers showed both more CD symptoms and lower cortisol levels (Vanyukov et al., 1993). In particular, the severity and persistence of aggressive, antisocial behavior has been linked to low cortisol (Matthys, van Goozen, Snoek, \& van Engeland, 2004; McBurnett, Lahey, Capasso, \& Loeber, 1996; McBurnett et al., 2000; Popma et al., 2006; van de Wiel, van Goozen, Matthys, Snoek, \& van Engeland 2004). However, patterns appear to be less consistent than in adults, as a number of carefully conducted studies have 
reported mixed findings (Azar et al., 2004; McBurnett et al., 2005; van Bokhoven et al., 2005; van Goozen et al., 2000). For example, van Bokhoven et al. (2005) reported that reactive aggression was positively associated with cortisol levels, whereas Azar et al. (2004) found no association of aggression or CD with cortisol. Sondeijker and colleagues (2007) found no evidence that disruptive behavior was associated with low basal cortisol levels in a community sample. They concluded that this aspect of HPA axis activity might not be a useful biological marker of disruptive, antisocial, aggressive behavior (Sondeijker et al., 2007). The same research group also investigated whether low cortisol levels might predict the development of disruptive behavior in pre-adolescent youth from the general population (Sondeijker et al., 2008). Interestingly, their longitudinal data suggest that low cortisol, although not a good predictor of future disruptive behavior, might help identify a severe subgroup among those children who already show disruptive behavior problems (Sondeijker et al., 2008).

A recent meta-analysis of 82 studies in child and adolescent samples found a significant but small ( $d=-0.10)$ relationship between antisocial behavior and low cortisol levels; no association was found between antisocial behavior and cortisol reactivity (Alink et al., 2008). Thus, despite inconsistent findings, the leading hypothesis - in line with underarousal theory - still postulates a negative relationship between aggressive, antisocial behavior and basal cortisol (Shirtcliff et al., 2009; van Goozen , Fairchild, Snoek, \& Harold, 2007). At the same time, it is clear that this relationship is less strong and more complex than originally thought.

Differences in sample characteristics and other methodological aspects have likely contributed to the observed inconsistencies. First, heterogeneity arises from divergent operationalizations of antisocial behavior, which include delinquency, covert and overt aggressive, oppositional behavior, and psychiatric externalizing disorders like CD or ADHD. Second, the research population and settings have varied widely, with participants drawn from healthy community samples, at-risk community samples, clinically-referred samples with diverse diagnoses, and samples of incarcerated offenders. Third, the samples have differed in age and gender (see Alink et al., 2008, for a more detailed discussion). Fourth, studies have differed in how cortisol was assessed: most importantly, some investigated basal cortisol levels, whereas others measured cortisol reactivity to experimental stressors. Furthermore, the timing, frequency, and method of cortisol assessment as well as the applied statistical analyses need to be taken into account. These methodological differences, which occur not only between studies conducted by different research groups but also within large research consortia, complicate the comparison of findings (Rosmalen \& Oldehinkel, 2011).

Inconsistent findings may also be due to heterogeneity within aggressive, antisocial samples. Low cortisol might not be related to all types of aggression and antisocial behavior, but particularly to severe forms associated with stimulation seeking, reward dominance, fearlessness, and insensitivity to punishment (Mitchell, Colledge, Leonard, \& Blair, 
2002; O'Brien \& Frick, 1996; van Honk, Schutter, Hermans, \& Putman, 2003). O'Brien and Frick (1996) found the strongest evidence for a reward-dominant response style, in which behavior is stimulated by the gain of quickly available short-term rewards, rather than by the avoidance of punishment, in children with conduct problems and psychopathic traits. At present, research suggests that the combination of severe aggressive, antisocial and impulsive behavior, as often seen in youth with a diagnosis of $C D$, together with callousunemotional (CU) traits delineates a highly severe behavioral group, with a close resemblance to the adult picture of psychopathy (e.g. Barry et al., 2000; Frick \& White, 2008).

In addition to severe antisocial and aggressive behavior, the construct of psychopathy includes deviant personality features (Porter \& Woodworth, 2006). There is still substantial debate about how many dimensions best capture the construct (e.g., Cooke, Michie, \& Skeem, 2007), but at least three dimensions consistently emerge. In adults, these are (1) an affective deficient dimension comprising CU traits (including a lack of empathy, emotion, and guilt), believed to be at the core of the disorder, (2) an interpersonal, arrogant, deceitful, and narcissistic behavior dimension, and (3) an irresponsible, impulsive, and aggressive behavior dimension. In children and adolescents, similar dimensions are often described as CU traits, narcissism, and impulsivity (Frick \& White, 2008; Salekin, Neumann, Leistico, \& Zalot, 2004). Understanding the causes and correlates of psychopathic traits in children and adolescents has become an increasingly important research topic.

In this regard, the role of HPA axis abnormalities in psychopathy remains to be clarified. In studies of incarcerated individuals, initial evidence indicated low cortisol levels in psychopathic offenders as compared to non-psychopathic offenders (Cima, Smeets, \& Jelicic, 2008). In adolescent males, there is evidence that low cortisol levels as well as an attenuated cortisol response to stress may be biological markers for CU traits: low cortisol was related to higher CU traits, even after controlling for conduct problems (Loney, Butler, Lima, Counts, \& Eckel, 2006). The same study found no significant associations between the narcissistic or impulsive psychopathy dimensions with cortisol levels.

However, in clinically referred boys with behavioral problems, low cortisol predicted the combined CU traits/narcissistic dimension later in life (Burke, Loeber, \& Lahey, 2007). Similarly, in young adult offenders high scores on the combined callous/narcissistic dimension were associated with low cortisol levels (Holi, Auvinen-Lintunen, Lindberg, Tani, \& Virkkunen, 2006). In contrast, recent community findings showed no relationship between CU traits and basal cortisol in youth (Poustka et al., 2010). Although findings are still sparse, research to date thus suggests that low basal cortisol levels might play a more important role in the etiology of psychopathy through a particularly severe and aggressive antisocial pathway than in the etiology of aggressive, antisocial behavior in general (Hawes, Brennan, \& Dadds, 2009). If cortisol abnormalities can be clearly linked to the development of antisocial behavior and psychopathy, the HPA axis might be a promising target for pharmacological interventions, as raising low cortisol levels might increase sensitivity to behavioral treatments (Glenn, 2009; Stadler, Poustka, \& Sterzer, 2010). 
A number of questions still need to be addressed. As mentioned above, metaanalytic evidence supports the association between youth antisocial behavior and low cortisol levels. Nevertheless, those studies that included relevant control samples found no differences in basal cortisol between antisocial youths and controls (Fairchild et al., 2008; Popma et al., 2007). These studies did not, however, investigate the possible association of different psychopathy dimensions with cortisol. The few studies that did examine the psychopathy dimensions did so predominantly in small, non-clinical samples (Loney et al., 2006), thereby failing to consider those youths who are most at risk for developing psychopathy. Thus, whereas there are at least preliminary findings concerning CU traits, the role of the remaining psychopathy dimensions, narcissism and impulsivity, in relation to cortisol is as yet largely unknown.

The present study aimed to bridge this gap in knowledge by investigating the associations of all three psychopathy dimensions (CU traits, narcissism and impulsivity) with cortisol levels. Given the lack of studies on the relationship between diurnal cortisol patterns and psychopathy dimensions in antisocial youth, the design incorporated a detained antisocial group and a comparison group from the community. We addressed the following questions:

1) Do detained antisocial adolescents differ from a healthy comparison group in patterns of basal cortisol secretion and diurnal slopes?

2) Do the three psychopathy dimensions (CU traits, narcissism, and impulsivity) show different patterns of association with cortisol?

\section{METHODS}

\section{Participants}

Participants were 125 male adolescents. Inclusion criteria were age 15-17, sufficient fluency in Dutch, total IQ $\geq 75$ (assessed using two verbal and two performance subtests of the Wechsler Intelligence Scale for Children, WISC-III (Dahl, 1986; Wechsler, 2005), and consent from parent or legal guardian. Detained youth underwent medical exams and extensive psychiatric diagnostic procedures at the time of incarceration. For inclusion in the antisocial group, detained boys had to meet DSM-IV-TR criteria for conduct disorder (CD) as primary diagnosis. Exclusion criteria were psychiatric symptoms other than externalizing, neurological disorders, head trauma, or organic disorders. Participants in the comparison group were screened to exclude those with a chronic illness or any known psychiatric disorder (see also Clinical evaluation, below).

The antisocial group consisted of 63 adolescents, mean age $16.2 \pm 0.6$ years, recruited from the secure sections of three youth detention centers/forensic clinics that admit adolescents from all over the Netherlands. Boys were sentenced by the court to 
detention via either a supervision or a mandatory treatment order. The duration of a mandatory treatment order varies from 2 to 6 years, depending on the seriousness of the offence, whether a mental disorder was present at the time of the offence, and on whether the parenting situation was seriously compromised. A supervision order is a civil measure, which can be imposed when a child's development is threatened because of incompetent parenting and/or behavioral problems of the child. Offences included repeated serious property crimes, drug-related crimes, and violent crimes.

At the time of incarceration, parents were asked to give permission for their child's participation in scientific research. Boys who met criteria for $C D$, diagnosed by the institutions' psychiatrist or a clinical psychologist, were individually approached for participation. We made clear that participation would not influence the adolescents' treatment or legal standing, as all information would be treated as strictly confidential. A total of 72 boys were approached (10 from Den Hey-Acker, 5 from GGzE Catamaran, 57 from St. Joseph Stichting). Five boys refused to participate; in three additional cases parents refused their consent. The total refusal rate was thus $11 \%$. One volunteer was moved to a different detention center before data collection began.

The community comparison group comprised 62 healthy volunteers, mean age $16.0 \pm 0.7$, recruited from two different high schools. In order to match the groups as closely as possible on education', over half of the comparison group was recruited from classes at the vocational level. All 75 boys in the relevant age range (15-17) were invited to participate: 46 from St. Maartens College in Maastricht and 29 from Stella Maris College in Valkenburg). Each boy was approached individually, either by the school's contact person or by one of the researchers, and also received written information. Of those invited, only 12 boys (16\%) refused participation, without giving further reasons.

The study was approved by the Maastricht University Medical Center Ethical Committee, the Dutch Ministry of Justice, and the Medical Ethical Committee for Mental Health Care Institutions (METIGG Zuid). All participants and parents/legal guardians gave informed consent and were informed that they could stop at any time. Participants received $20 €$ for completing the study.

\section{Clinical evaluation}

We used the National Institute of Mental Health Diagnostic Interview Schedule for Children (DISC; Fisher, Wicks, Shaffer, Piacentini, \& Lapkin, 1992), module E of the child form, to assess symptoms of attention deficit disorder (ADD), hyperactivity (HY), oppositional defiant disorder (ODD), and conduct disorder in all participants. The DISC displays adequate reliability and validity (Shaffer, Fisher, Lucas, Dulcan, \& Schwab-Stone, 2000). As most of

\footnotetext{
1 Before incarceration, antisocial youth often either attended schools below their actual educational level or did not attend school regularly, due to their behavioral problems.
} 
the participants in the antisocial group had already been in detention for much of the last 12 months, the number of lifetime CD symptoms was used as an index for CD. Indices for $A D D, H Y$ and ODD refer to symptoms in the last 12 months. In the current sample, reliability estimates for symptom measures were good for ADD, ODD, and CD (Cronbach's alphas of .77, .93, and .90, respectively); alpha for $\mathrm{HY}$ was .34, reflecting the low frequency of hyperactivity symptoms in this group.

\section{Psychopathy dimensions}

We used the total score of the Inventory of Callous-Unemotional Traits (ICU; Frick, 2003) as an index of the callous-unemotional (CU) psychopathy dimension. This 24-item selfreport instrument measures the occurrence and intensity of CU traits on 4-point Likert scales, ranging from 0 not at all true to 3 definitely true. Items describe callous, unemotional and uncaring attitudes, for example, "I don't care who I hurt to get what I want" or "I don't feel remorseful when I do something wrong". In the present sample the internal consistency of the total score was good (Cronbach's alpha $=0.82$ ). Although factor analyses have revealed three subscales, in detained and community samples the reliability of the ICU appears to be highest for the original, unidimensional scale (Essau, Sasagawa, \& Frick, 2006; Feilhauer, Cima, \& Arntz, 2012)

We used the reactive (impulsive) aggression subscale of the Reactive-Proactive Aggression Questionnaire (RPQ; Raine et al., 2006) as a measure of the impulsivity dimension of psychopathy. The RPQ is a 23-item self-report questionnaire that distinguishes between reactive aggression (impulsive behavior in response to external stimuli like threat or frustration, 11 items) and motivated, proactive aggression (physical and verbal controlled behavior used to achieve a desired goal, 12 items). In the present sample internal reliability was good, with Cronbach's a of 0.90 for the total scale, 0.81 for the reactive, and 0.86 for the proactive subscale. Examples of items describing impulsive aggression are "How often have you ... damaged things because you felt mad" or "...felt better after hitting or yelling at someone". The choice of this instrument was based not only on pragmatic (short length, good reliability) but also on theoretical considerations: the RPQ reactive aggression items closely resemble the impulsive behaviors associated with the impulsivity factor of psychopathy. Furthermore, this RPQ subscale correlates with the general impulsivity concept as measured by the Impulsivitiy and Sensation-Seeking Personality subscales of the Zuckerman-Kuhlman Personality Questionnaire (Raine et al., 2006). The proactive subscale was not used in the current analyses.

We used the total score on the Narcissistic Personality Inventory for Children (NPIC) as a measure of the narcissistic psychopathy dimension (Barry, Frick, \& Killian, 2003). The NPIC is a 40-item forced-choice questionnaire (Raskin \& Terry, 1988). Items are derived from the adult NPI, reformulated to be developmentally appropriate. Respondents must 
endorse one of two statements, e.g., "I am jealous when good things happen to other people" versus "I am happy when good things happen to other people". The endorsed statement is rated as being either sort of true or really true, thereby creating a 4-point scale. The internal consistency of the total scale was good $(a=0.88)$ in this sample.

All tests were administered and scored according to standard procedures by senior clinical and research psychologists or intensively trained psychology master students.

\section{Salivary cortisol}

Saliva samples were collected at three predefined time points (10h, 16h, and 21h) on two different days. In both groups, recorded wake-up times were between 0700h and 0730h a.m. Participants received oral and written sampling instructions, including a request not to smoke or to drink alcohol or coffee during the two sampling days. After each saliva sample, participants completed diary reports on the actual sampling time as well as information on stressful events, smoking, eating, drinking, tooth brushing, sport activities, medication, recreational drug and alcohol use. If a participant reported a highly stressful or unusual event (e.g., got into a fight that led to a time-out or more severe punishment, had to attend court, or participated in a soccer competition), he was asked to repeat the saliva sampling on a different day.

For the saliva collection, participants chewed on a cotton swab (salivette; Sarstedt Inc., Rommelsdorf, Germany) for 1-2 minutes and then returned the saturated swab to its tube. Participants recorded the actual collection time on the tube and stored samples either in their home or the institutional unit freezer at the end of the day. To monitor compliance, participants received all necessary cotton swabs in a 100cc bottle with an electronic monitoring cap (MEMS 6, Aardex Ltd., Switzerland) that registered all opening times. They were told to open the storage bottle only at the designated sampling times and to remove only one swab each time. When participants are aware that their performance is being monitored, compliance is substantially improved (Broderick, Arnold, Kudielka, \& Kirschbaum, 2004).

Of the 750 samples, 16 had insufficient saliva for the assay. Of the remaining 734 samples, 695 (94.7\%) had both a self-reported collection time on the tube and an electronic time registration via the MEMS cap. After exclusion of 131 (18.8\%) samples with tube-cap and tube-target time differences of more than 60 minutes, 603 accurately timed samples (detained: 304; controls: 299 ) remained in the analyses. No participants had to be excluded due to poor sampling compliance.

Salivary free cortisol concentrations were determined with a commercially available chemiluminescence-immuno-assay (CLIA; IBL, Hamburg, Germany; TU Dresden, Germany). The mean intra-assay and inter-assay coefficients of variation were under $8 \%$. All samples from an individual were analyzed in the same assay to reduce sources of variability. 


\section{STATISTICAL ANALYSES}

\section{Multilevel modeling approach}

Multilevel regression is a variant of linear regression that is appropriate for hierarchically clustered data (Snijders \& Bosker, 1999). In the present analysis, the model used to estimate effects on cortisol had three levels: (1) data were collected three times a day (measurement level), (2) on two different days (day level), (3) clustered within participants (person level). Stata 11 (Stata Corporation, College Station, Texas) was used to estimate multilevel models (XTMIXED) with maximum likelihood estimation. Fixed effects are expressed as unstandardized b coefficients; $b$ divided by the standard error (SE) is approximately Z-distributed. Statistical tests were two-tailed, with $a=.05$. When significant interactions were found, stratified analyses were conducted to clarify group differences, using the Stata LINCOM command to calculate the appropriate linear combinations.

Cortisol values were natural-log transformed to correct positive skew in their distribution. All independent variables were centered around the grand mean. To model the cortisol diurnal curve, the variables time (in hours) and time ${ }^{2}$ were included as predictors in all analyses. Modeling random slopes for time did not improve the model fit. We tested the effects of the following potential measurement-level confounders for all models: recent smoking, strenuous exercise, alcohol/drugs, food intake, and tooth brushing before sampling. At the person-level, we investigated effects of being a smoker, attention deficit disorder, hyperactivity disorder, and prescription medication (stimulants and antihistamines). No significant effects on cortisol were found (all $p>$.10). To test our main hypotheses, we included the following independent variables: group ( 0 if comparison, 1 if antisocial), CU traits, narcissism, and impulsive aggression (further referred to as impulsivity).

\section{Cortisol levels and diurnal slope: group differences}

First, to answer the question whether cortisol levels differed between antisocial and healthy comparison groups, a multilevel model was estimated with log-cortisol as the dependent variable and the categorical variable group as independent variable. Second, adding a Group by Time interaction term to the model tested whether the antisocial group had a steeper or flatter diurnal cortisol slope. 


\section{Cortisol and psychopathy dimensions}

To examine the relationship between cortisol and psychopathy dimensions, separate multilevel regression analyses, with log-cortisol as the dependent variable and either CU traits, narcissism or impulsivity as the continuous independent variable, were conducted. We also estimated a multilevel model with all three continuous psychopathy dimensions as independent variables to account for intercorrelations among these measures.

Next, to examine whether the relationship between psychopathy dimensions and cortisol varied as a function of group membership (antisocial vs. comparison), we estimated separate multilevel models for the interaction between group and each psychopathy dimension. As above, all three interaction terms were also estimated in a single multilevel model, to account for intercorrelations among these measures.

\section{RESULTS}

\section{Sample characteristics}

All 125 participants complied adequately with the protocol. Descriptive statistics for clinical characteristics are presented in Table 1. As expected, antisocial and comparison groups differed significantly in the severity of CD symptoms and on all three psychopathy dimensions (CU traits, narcissism, impulsivity). Large and medium effect sizes could be shown for group differences in impulsivity $(d=1.18)$ and $C U$ traits $(d=-.67)$, respectively. The effect size for differences in narcissism was small ( $d=-.37)$.

Table 1. Descriptives: conduct disorder symptoms and psychopathy dimensions

\begin{tabular}{|c|c|c|c|c|c|c|}
\hline & \multirow{2}{*}{$\begin{array}{c}\begin{array}{c}\text { Comparison } \\
(n=62)\end{array} \\
M(S D)\end{array}$} & \multicolumn{2}{|l|}{$\begin{array}{c}\text { Antisocial } \\
(n=63)\end{array}$} & \multicolumn{3}{|c|}{$\begin{array}{l}\text { Pearson correlations, } r \\
\qquad(n=125)\end{array}$} \\
\hline & & $M(S D)$ & $t$ & CU traits & Narcissism & Impulsivity \\
\hline $\mathrm{CD}_{\text {symptoms }}{ }^{\mathrm{a}}$ & $2.56(2.60)$ & $13.29(4.90)$ & $15.30^{* * *}$ & $.35^{* * *}$ & .16 & $.61^{* * *}$ \\
\hline CU traits & $22.31(7.70)$ & 28.10 (9.38) & $3.75^{* * *}$ & - & .05 & $.35 * * *$ \\
\hline Narcissism & $48.05(12.41)$ & $52.20(10.19)$ & $2.01^{*}$ & - & - & $.32 * * *$ \\
\hline Impulsivity & $7.44(3.40)$ & $11.90(4.11)$ & $6.63^{* * *}$ & - & - & - \\
\hline
\end{tabular}

Note: anumber of lifetime symptoms, $C U=$ callous-unemotional. ${ }^{*} p<.05,{ }^{* * *} p<.001$ 


\section{Cortisol levels and diurnal slope: group differences}

To address our first question, we examined whether the antisocial and comparison groups differed in cortisol levels. Although cortisol levels in the antisocial group appeared to be lower, this difference was not significant (see Table 2, Model 1). The two groups also showed similar patterns of diurnal decline in cortisol secretion, as indicated by the non-significant Group by Time interaction (Table 2, Model 2). Thus, basal cortisol levels and slopes did not differ significantly between the antisocial group and the healthy comparison group.

Table 2. Multilevel regression coefficients for effects of group (antisocial vs. healthy comparison) on cortisol level and diurnal slope

\begin{tabular}{lll} 
& \multicolumn{2}{c}{ Coefficient B (SE) } \\
\cline { 2 - 3 } & Model 1 & Model 2 \\
\hline Intercept & $1.200(0.083)^{* * *}$ & $1.200(0.083)^{* * *}$ \\
Group & $0.029(0.101)$ & $0.028(0.101)$ \\
Time of day (diurnal slope) & $-0.124(0.006)^{* * *}$ & $-0.114(0.009)^{* * *}$ \\
Group by Time & & $-0.020(0.013)$ \\
\hline
\end{tabular}

Note: The dependent variable is log-cortisol. In preliminary analyses, the possible confounders smoking, recent strenuous exercise, alcohol/drug use, food intake or tooth brushing, medication (any, stimulants, antihistamines), and symptoms of attention deficit disorder (ADD) or hyperactivity (HY) had no significant effect and were excluded from the final model (all $p>$.10). None of the participants took corticosteroids in any form. Group is coded 1 for the antisocial group and 0 for the comparison group. The variable time of day, expressed in hours, is centered around the grand mean. Time² was also a significant predictor of logcortisol $(p<.01)$ and is controlled for in all analyses. $\mathrm{b}=$ unstandardized regression coefficient; $S E=$ standard error. ${ }^{* *} p<.001$.

\section{Cortisol in relation to psychopathy dimensions}

Separate multilevel models for each of the different psychopathy dimensions indicated no significant main effects on cortisol levels (all $p>0.3$ ). Results were also non-significant when all three dimensions were tested in the same model $(p>0.358)$. Thus, in the entire sample none of the three psychopathy dimensions was associated with cortisol levels.

In a second step we examined whether the relationship between psychopathy dimensions and cortisol varied as a function of group membership. Again separate multilevel models were estimated (Table 3, models 1, 2, and 3). No significant interaction effects for group and CU traits or group and narcissism on cortisol levels were obtained (Table 3, Models 1 and 2). However, group moderated the effect of impulsivity on cortisol (Table 3 , Model 3). Because cortisol values were log-transformed in the analysis, the unstandard- 
ized regression coefficients can be interpreted as follows: \% change in raw cortisol per unit change in predictor $=[\exp (\beta)]-1$. In Model 3, the Group by Impulsivity coefficient (0.079) thus signifies that log-cortisol was $2 \%$ higher (on average) in the antisocial group for each one-point increase in Impulsivity. This apparent increase has to be interpreted in light of the general decrease in cortisol levels in relation to Impulsivity scores in the comparison group (coefficient -0.059 for Impulsivity in Model $3=6 \%$ lower cortisol for each one-point increase in Impulsivity). Thus, a one-point increment in Impulsivity score would be associated with an estimated 8\% difference in cortisol levels between the two groups, whereas a two-point increment would be associated with an almost 17\% difference in cortisol levels. Stratifying showed that higher impulsivity was associated with lower cortisol levels in the healthy comparison group ( $B=-0.059, S E=.020, p=.003)$, but not in the antisocial group ( $\beta=-0.020$, $S E=.017, p=.220$ ). Similarly, in a combined model that included as predictors group, all three psychopathy dimensions, and their interactions with group, only the Group by Impulsivity interaction was significant (Table 3, Model 4), with higher impulsivity predicting lower cortisol in the comparison group only. In summary, findings support the association of lower cortisol with higher impulsivity, but only in the healthy comparison sample.

\section{Associations of impulsivity and CU traits with cortisol}

The combination of severe aggressive, antisocial behavior (as often seen in antisocial youth with $C D$ ) with $C U$ traits is thought to delineate a highly severe behavioral group, with a close resemblance to the adult picture of psychopathy. However, the analyses reported above revealed no association between cortisol and CU traits in either antisocial or comparison group. To further explore the significant finding for impulsivity, we developed a third research question. In a final multilevel model, we investigated whether specifically the combination of antisocial behavior with high impulsivity and high CU traits would be associated with low cortisol levels, by testing the three-way Group by Impulsivity by CU traits interaction. No significant main or interaction effects were obtained (Table 3, Model 5). Thus, in the present study CU traits were not significantly associated with cortisol levels and had no effect on the association between impulsivity and cortisol in either the antisocial group or the comparison group.

\section{Discussion}

To our knowledge, this is the first study to investigate the relationship between cortisol and psychopathy dimensions in antisocial youth as compared to a healthy community comparison group. Three main questions were addressed.

Regarding our first research question, cortisol levels were slightly lower in the antisocial group than in the healthy comparison group, but these differences were not sig- 


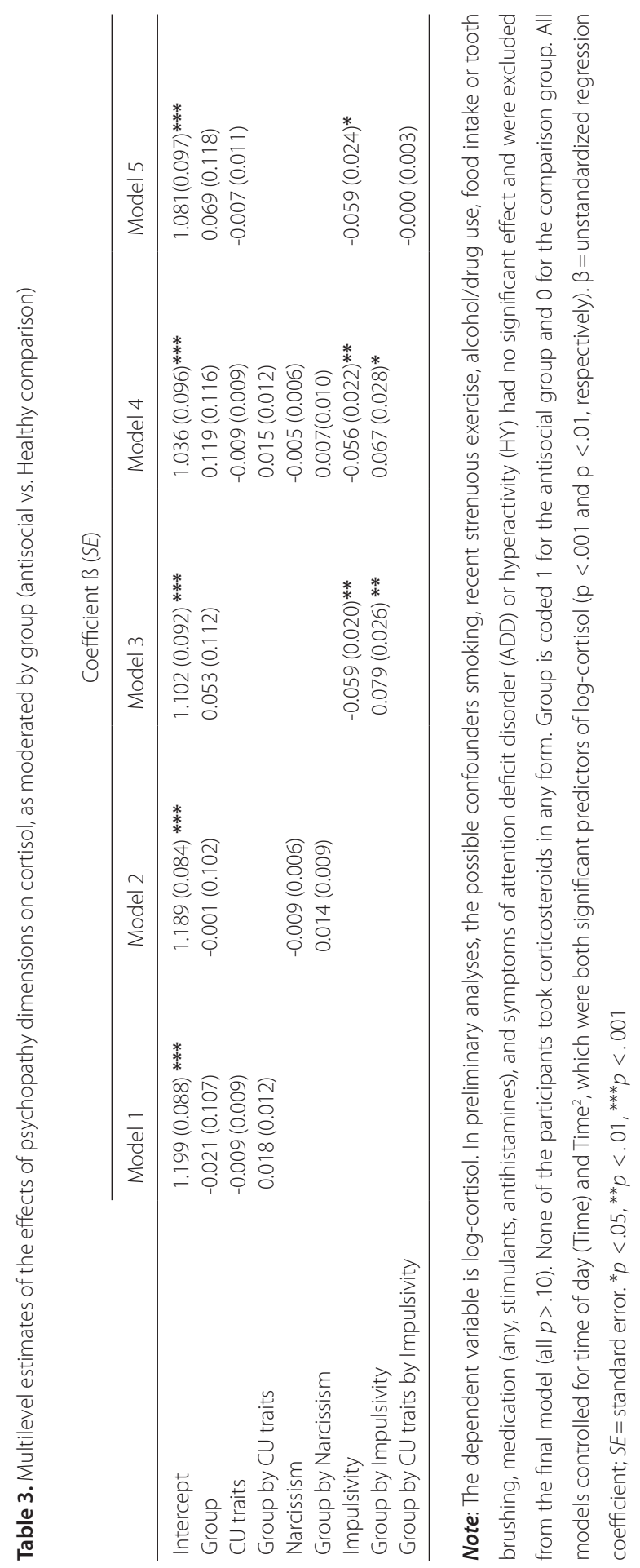


nificant. The two groups also showed similar slopes of diurnal decline in cortisol secretion. Our findings replicate and extend the few studies that have compared male antisocial youth with healthy controls with respect to cortisol secretion in everyday life. Two recent studies comparing adolescents with CD/ODD and healthy controls found no significant group differences in diurnal cortisol slopes (Fairchild et al., 2008; Popma et al., 2007). Taken together with these and other recent findings, the current data suggest a more or less intact basal HPA axis functioning across different groups of antisocial youth and across the range of pubertal development. The current results do not support the notion of low basal cortisol as a general correlate of antisocial behavior or CD.

With regard to the second research question, no psychopathy dimension was significantly associated with basal cortisol levels over the entire sample. This finding casts doubt on the hypothesis of earlier studies that CU traits, among the psychopathy dimensions, have the most specific association with low basal cortisol. Whereas associations have been found in CD-risk community samples, college students, and detained young adults (Burke et al., 2007; Holi et al., 2006; Loney et al., 2006; O'Leary, Loney, \& Eckel, 2007; O'Leary, Taylor, \& Eckel, 2010), in the present study CU traits were not related to cortisol levels in either antisocial or healthy comparison participants. These results are in line with the recent finding of no association between CU traits and cortisol levels in an adolescent community sample (Poustka et al., 2010).

The relationship between narcissism and cortisol has been relatively understudied in the past. As part of the combined CU/narcissistic dimension, narcissism has been linked to lower basal cortisol (Burke et al., 2007; Holi et al., 2006), whereas a study in an at-risk community sample found no association between the narcissistic dimension and basal cortisol (Loney et al., 2006). Likewise, the present study found no association between basal cortisol and the narcissistic dimension in either the antisocial or the healthy comparison group. More research on external correlates of the narcissistic dimension is warranted in order to identify possible differing psychopathy subtypes and their developmental pathways.

We did, however, find a significant interaction between group and impulsivity in relation to basal cortisol. In the comparison group, but not in the antisocial group, impulsivity was associated with lower cortisol levels. This finding is consistent with recent results from another adolescent community sample, in which low cortisol was related to impulsive aggression and low impulse control (Poustka et al., 2010). These different lines of evidence thus suggest that low basal cortisol is associated with impulsive aggressive behavior. It is unclear why this pattern, which was robust enough to be biologically meaningful as well as statistically significant, was seen only in the comparison group. Future research will have to investigate whether this finding can be generalized beyond the current sample.

Regarding our third, exploratory research question, the reviewed literature suggests that it is specifically the group of antisocial youth with severe aggressive behavior 
combined with CU traits that is at greatest risk of developing psychopathy (Frick \& White, 2008). Given our findings of a specific association between impulsivity and cortisol levels, we hypothesized that for CU traits it might specifically be the combination with high impulsivity that is associated with low cortisol levels. However, we found no support for this hypothesis: CU traits did not appear to moderate the relationship between impulsivity and basal cortisol in either the antisocial or the comparison group.

Taken together, the present results question the notion of low basal cortisol levels as a biological marker for CU traits. To date the strongest evidence linking CU traits to low cortisol comes from the original study, in a community sample, by Loney and colleagues (2006), in which boys (but not girls) with high CU traits displayed lower cortisol levels, regardless of the presence or absence of CD symptoms. However, that study contrasted small groups ( 9 to 16 boys per subgroup) at the extreme ends of the CU continuum, thereby increasing the chance of a type 1 error. Moreover, results were based on only a single cortisol measure, collected at 9 a.m. Our findings suggest that low basal cortisol levels may be more closely related to general deficits in behavioral regulation, such as poor impulse control and aggressive impulsive behavior, than to CU traits in particular.

Differences between the current results and previous findings could also reflect the way psychopathy dimensions were assessed. As in earlier research, the current study applied self-report measures to assess psychopathy dimensions. However, in contrast to earlier studies, all three psychopathy dimensions were assessed by separate questionnaires. This was done because of the low internal consistency of the Antisocial Process Screening Device (APSD), the instrument used in the first study on the topic (Loney et al., 2006). The APSD contains fewer than seven items for each of the three dimensions. Moreover, although construct validity of the APSD is considered satisfactory, Cohen's alpha for the impulsivity subscale is low, and relevant items are missing (Vitacco, Rogers, \& Neumann, 2003)

In addition to the relatively large sample size, strengths of the current study include recruitment of a severe, more homogenous study group and a comparison sample; timing, frequency and method of cortisol assessment; monitoring of sampling compliance; and advanced statistical analyses by applying a multilevel approach, thereby allowing simultaneously modeling of between- and within-individual variation in diurnal cortisol levels, without using crude averages (Hruschka, Kohrt, \&Worthman, 2005). The study also has some limitations. Ethical, logistical, and financial considerations forced us to focus on a subset of variables that would potentially have been informative. This applies to the assessment of psychological as well as neuroendocrine measures. The participating institutions, in particular, set limits on the number and length of questionnaires. Concerning the impulsivity dimensions and additional, more general measure of the construct would have been eligible. Although cortisol samples from days with high reported stress were excluded from the analysis, we had no measure of perceived stress and therefore cannot rule out possible differences between detained and community groups in stress 
levels ${ }^{2}$. Similarly, no direct measures of anxiety or depression were included in the present study. Previous research has reported low anxiety in association with severe antisocial behavior and psychopathic traits, but results have not always been straightforward (Kubak \& Salekin, 2009; O'Brien \& Frick, 1996). Moreover, internalizing symptoms (i.e., anxiety and depression) are thought to moderate the association between antisocial behavior and cortisol, and this is another important issue we were unable to explore.

The current study assessed cortisol levels and diurnal slopes, two central features of HPA secretory patterns. Other features, which are often uncorrelated with each other and probably under different regulatory control systems, include cortisol reactivity to stressful stimuli and the cortisol response to awakening (CAR). Even though meta-analyses showed stronger associations, in relation to aggression and externalizing behavior, for cortisol levels than for cortisol responses to stress, cortisol reactivity remains an important outcome measure for future research, especially in relation to CU traits. There is evidence that the cortisol response to stress may be blunted in antisocial adolescents (Fairchild et al., 2008), and this would also be the expected pattern in youths with high CU traits. CAR abnormalities have also been reported in antisocial adolescents (Popma et al., 2007). Ideally, all of these aspects of diurnal cortisol secretion would be assessed in the same study, but this has very rarely if ever been the case. Collecting multiple saliva samples each day is expensive and burdensome for the participants. For this reason, we restricted sampling to three measures a day on two days. Nevertheless, this sampling frequency combined with electronic monitoring of sampling compliance provided a more reliable assessment of cortisol patterns than achieved in earlier studies.

In future studies, maturational changes in HPA axis functioning during the transition from childhood to adulthood, in particular pubertal development, deserve more attention. Age appears to be an important moderator of the association of externalizing and aggressive behavior with cortisol (Alink et al., 2008). Although we found no effect of age on cortisol in the current study, the sample had a limited age range. Studies over a larger age range could clarify whether age might moderate the association between psychopathy dimensions and cortisol. Finally, cortisol is only one aspect of the neurobiology of antisocial behavior and psychopathy. Because hormone systems are highly interconnected, it may be important to examine multiple hormone systems and their interplay with different brain areas simultaneously (Shirtcliff et al., 2009). For example,

\footnotetext{
2 Being incarcerated might be stressful in itself, in which case one might expect increased cortisol levels in the detained sample. But it is also conceivable that perceived stress during detainment may be lower than it would be living dangerous and illegal lives outside; spending a few hours alone in the cell each day might be more boring than stressful. Being part of a regimented social unit might also give detained boys the structure and predictability they miss outside. In this case, cortisol might even be lower inside than it would have been outside the youth prison.
} 
recent research found that an increased testosterone (baseline) to cortisol (reactivity) ratio was specifically associated with psychopathy symptoms (Glenn, Raine, Schug, Gao, \& Granger, 2011).

The current study, while shedding light on some previously understudied dimensions of psychopathy in relation to the HPA axis, focused on only a subset of the variables that are thought to contribute to the heterogeneity in pathways to CD and psychopathy. As Hawes et al. (2009) have pointed out, a testable theory of the role of cortisol in these disorders will need to go beyond this, incorporating influences of genetics, adverse experiences in early childhood, anxiety and other psychological aspects. The possibility that interventions targeting the HPA axis can help prevent or treat antisocial behavior awaits a more complete understanding of the underlying mechanisms and developmental pathways. Seen in this light, negative findings are also important.

In conclusion, considering antisocial youth as a homogenous, underaroused group, with diminished HPA output as suggested by the stimulation-seeking theory (Zuckerman, 1979), may be an oversimplification. Although a meta-analysis provided support for an association between low cortisol levels and risk for childhood antisocial behavior (Alink et al., 2008), this pattern was not replicated by the present findings. Furthermore, our results lend no support to the hypothesis that low cortisol is a biological marker for CU traits. Of the three dimensions of psychopathy investigated (CU traits, narcissism, impulsivity), only impulsivity showed a significant association with cortisol, but only in the community comparison group. Because it is not yet clear whether these results can be generalized to other populations, we believe it would be premature to draw broad conclusions about the importance or unimportance of the HPA axis in relation to antisocial behavior and psychopathic traits. Future research should build further, with attention to the theoretical and methodological issues raised.

\section{ACKNOWLEDGMENTS}

The authors kindly thank Professor Robert Hare and the Society for the Scientific Study of Psychopathy (SSSP) for rewarding the presented study with the Cheryl Wayne Hare Memorial Award. We also thank the participants, schools and legal/forensic institutions for their participation, and all graduate students for their help with the data collection. 


\section{REFERENCES}

Alink, L. R. A., van ljzendoorn, M. H., Bakermans-Kranenburg, M. J., Mesman, J., Juffer, F., \& Koot, H. M. (2008). Cortisol and externalizing behavior in children and adolescents: mixed meta-analytic evidence for the inverse relation of basal cortisol and cortisol reactivity with externalizing behavior. Developmental Psychobiology, 50(5), 427-450.

Azar, R., Zoccolillo, M., Paquette, D., Quiros, E., Baltzer, F., \& Tremblay, R. E. (2004). Cortisol levels and conduct disorder in adolescent mothers. Journal of the American Academy of Child and Adolescent Psychiatry, 43(4), 461-472.

Barry, C. T., Frick, P. J., DeShazo, T. M., McCoy, M. G., Ellis, M., \& Loney, B. R. (2000). The importance of callousunemotional traits for extending the concept of psychopathy to children. Journal of Abnormal Psychology, 109(2), 335-340.

Barry, C. T., Frick, P. J., \& Killian, A. L. (2003). The relation of narcissism and self-esteem to conduct problems in children: a preliminary investigation. Journal of Clinical Child and Adolescent Psychology, 32(1), 139-152.

Broderick, J. E., Arnold, D., Kudielka, B. M., \& Kirschbaum, C. (2004). Salivary cortisol sampling compliance: comparison of patients and healthy volunteers. Psychoneuroendocrinology, 29(5), 636-650.

Burke, J. D., Loeber, R., \& Lahey, B. B. (2007). Adolescent conduct disorder and interpersonal callousness as predictors of psychopathy in young adults. Journal of Clinical Child and Adolescent Psychology, 36(3), 334-346.

Cima, M., Smeets, T., \& Jelicic, M. (2008). Self-reported trauma, cortisol levels, and aggression in psychopathic and non-psychopathic prison inmates. Biological Psychology, 78(1), 75-86.

Cooke, D. J., Michie, C., \& Skeem, J. (2007). Understanding the structure of the Psychopathy Checklist-Revised: an exploration of methodological confusion. British Journal of Psychiatry, 190(Suppl 49), 39-50.

Dahl, G. (1986). Handbuch zum Reduzierten Wechsler-Intelligenztest Koenigstein-Traunstein, Germany: Hain Verlag.

Essau, C. A., Sasagawa, S., \& Frick, P. J. (2006). Callous-unemotional traits in a community sample of adolescents. Assessment, 13(4), 454-469.

Fairchild, G., van Goozen, S. H., Stollery, S. J., Brown, J., Gardiner, J., Herbert, J., et al. (2008). Cortisol diurnal rhythm and stress reactivity in male adolescents with early-onset or adolescence-onset conduct disorder. Biological Psychiatry, 64(7), 599-606.

Feilhauer, J., Cima, M., \& Arntz, A. (2012). Assessing callous-unemotional traits across different groups of youths: further cross-cultural validation of the Inventory of Callous-Unemotional Traits. International Journal of Law and Psychiatry, 35, 251-262.

Fisher, P., Wicks, J., Shaffer, D., Piacentini, J., \& Lapkin, J. (1992). Diagnostic Interview Schedule for Children: User's Manual, version 2.3. New York: Division of Child and Adolescent Psychiatry, Columbia University.

Foster, E. M., \& Jones, D. E. (2005). The high costs of aggression: public expenditures resulting from conduct disorder. American Journal of Public Health, 95(10), 1767-1772.

Frick, P. J. (2003). The Inventory of Callous-Unemotional Traits. University of New Orleans. 
Frick, P. J., \& White, S. F. (2008). Research review: the importance of callous-unemotional traits for developmental models of aggressive and antisocial behavior. Journal of Child Psychology and Psychiatry and Allied Disciplines, 49(4), 359-375.

Glenn, A. L. (2009). Neuroendocrine markers of psychopathy. In M. S. Ritsner (Ed.), The Handbook of Neuropsychiatric Biomarkers, Endophenotypes, and Genes (Vol. 3). Dordrecht, The Netherlands: Springer.

Glenn, A. L., Raine, A., Schug, R. A., Gao, Y., \& Granger, D. A. (2011). Increased testosterone-to-cortisol ratio in psychopathy. Journal of Abnormal Psychology, 120(2), 389-399.

Hawes, D. J., Brennan, J., \& Dadds, M. R. (2009). Cortisol, callous-unemotional traits, and pathways to antisocial behavior. Current Opinion in Psychiatry, 22(4), 357-362.

Holi, M., Auvinen-Lintunen, L., Lindberg, N., Tani, P., \& Virkkunen, M. (2006). Inverse correlation between severity of psychopathic traits and serum cortisol levels in young adult violent male offenders. Psychopathology, 39(2), 102-104.

Hruschka, D. J., Kohrt, B. A., \& Worthman, C. M. (2005). Estimating between- and within-individual variation in cortisol levels using multilevel models. Psychoneuroendocrinology, 30(7), 698-714.

Kubak, F. A., \& Salekin, R. T. (2009). Psychopathy and anxiety in children and adolescents: new insights on developmental pathways to offending. Journal of Psychopathology and Behavioral Assessment, 31(4), 271-284.

Loney, B. R., Butler, M. A., Lima, E. N., Counts, C. A., \& Eckel, L. A. (2006). The relation between salivary cortisol, callous-unemotional traits, and conduct problems in an adolescent non-referred sample. Journal of Child Psychology and Psychiatry and Allied Disciplines, 47(1), 30-36.

Matthys, W., van Goozen, S. H., Snoek, H., \& van Engeland, H. (2004). Response perseveration and sensitivity to reward and punishment in boys with oppositional defiant disorder. European Child and Adolescent Psychiatry, 13(6), 362-364.

McBurnett, K., Lahey, B. B., Capasso, L., \& Loeber, R. (1996). Aggressive symptoms and salivary cortisol in clinic-referred boys with conduct disorder. Annals of the New York Academy of Sciences, 794, 169-178.

McBurnett, K., Lahey, B. B., Rathouz, P. J., \& Loeber, R. (2000). Low salivary cortisol and persistent aggression in boys referred for disruptive behavior. Archives of General Psychiatry, 57(1), 38-43.

McBurnett, K., Raine, A., Stouthamer-Loeber, M., Loeber, R., Kumar, A. M., Kumar, M., et al. (2005). Mood and hormone responses to psychological challenge in adolescent males with conduct problems. Biological Psychiatry, 57(10), 1109-1116.

Mitchell, D. G., Colledge, E., Leonard, A., \& Blair, R. J. (2002). Risky decisions and response reversal: is there evidence of orbitofrontal cortex dysfunction in psychopathic individuals? Neuropsychologia, 40(12), 2013-2022.

O'Brien, B. S., \& Frick, P. J. (1996). Reward dominance: associations with anxiety, conduct problems, and psychopathy in children. Journal of Abnormal Child Psychology, 24(2), 223-240.

O'Leary, M. M., Loney, B. R., \& Eckel, L. A. (2007). Gender differences in the association between psychopathic personality traits and cortisol response to induced stress. Psychoneuroendocrinology, 32(2), 183-191.

O'Leary, M. M., Taylor, J., \& Eckel, L. (2010). Psychopathic personality traits and cortisol response to stress: the role of sex, type of stressor, and menstrual phase. Hormones and Behavior, 58(2), 250-256. 
Popma, A., Doreleijers, T. A., Jansen, L. M., Goozen van, S. H., Engeland van, H., \& Vermeiren, R. (2007). The diurnal cortisol cycle in delinquent male adolescents and normal controls. Neuropsychopharmacology, 32(7), 1622-1628.

Popma, A., Jansen, L. M., Vermeiren, R., Steiner, H., Raine, A., Goozen van, S. H., et al. (2006). Hypothalamus pituitary adrenal axis and autonomic activity during stress in delinquent male adolescents and controls. Psychoneuroendocrinology, 31(8), 948-957.

Porter, S., \&Woodworth, M. (2006). Psychopathy and aggression. In C. J. Patrick (Ed.), Handbook of Psychopathy. New York: The Guilford Press.

Poustka, L., Maras, A., Hohm, E., Fellinger, J., Holtmann, M., Banaschewski, T., et al. (2010). Negative association between plasma cortisol levels and aggression in a high-risk community sample of adolescents. Journal of Neural Transmission, 117(5), 621-627.

Raine, A. (1993). The Psychopathology of Crime: Criminal Behavior as a Clinical Disorder. San Diego, CA, USA: Academic Press, Inc

Raine, A. (1996). Autonomic nervous system activity and violence. In D. M. C. Stoff, R.B. (Ed.), Aggression and Violence (pp. 145-168). Mahwah,NJ: Erlbaum.

Raine, A., Dodge, K., Loeber, R., Gatzke-Kopp, L., Lynam, D., Reynolds, C., et al. (2006). The Reactive-Proactive Aggression Questionnaire: differential correlates of reactive and proactive aggression in adolescent boys. Aggressive Behavior, 32, 159-171.

Raskin, R., \& Terry, H. (1988). A principal-components analysis of the Narcissistic Personality Inventory and further evidence of its construct validity. Journal of Personality and Social Psychology, 54(5), 890-902.

Rosmalen, J. G., \& Oldehinkel, A. J. (2011). The role of group dynamics in scientific inconsistencies: a case study of a research consortium. PLoS Medicine, 8(12), e1001143.

Salekin, R. T., Neumann, C. S., Leistico, A. M., \& Zalot, A. A. (2004). Psychopathy in youth and intelligence: an investigation of Cleckley's hypothesis. Journal of Clinical Child and Adolescent Psychology, 33(4), 731 742.

Schmeck, K., \& Poustka, F. (2000). Biologische Grundlagen von impulsiv-aggressivem Verhalten/Biological foundations of impulsive-aggressive behaviour. Kindheit und Entwicklung, 9(1), 3-13.

Shaffer, D., Fisher, P., Lucas, C. P., Dulcan, M. K., \& Schwab-Stone, M. E. (2000). NIMH Diagnostic Interview Schedule for Children Version IV (NIMH DISC-IV): description, differences from previous versions, and reliability of some common diagnoses. Journal of the American Academy of Child and Adolescent Psychiatry, 39(1), 28-38.

Shirtcliff, E. A., Vitacco, M. J., Graf, A. R., Gostisha, A. J., Merz, J. L., \& Zahn-Waxler, C. (2009). Neurobiology of empathy and callousness: implications for the development of antisocial behavior. Behavioral Sciences and the Law, 27(2), 137-171.

Snijders, T. A. B., \& Bosker, R. (1999). Multilevel Analysis: an Introduction to basic and advanced multilevel modeling. London: Sage

Sondeijker, F., Ferdinand, R. F., Oldehinkel, A. J., Tiemeier, H., Ormel, J., \& Verhulst, F. C. (2008). HPA-axis activity as a predictor of future disruptive behaviors in young adolescents. Psychophysiology, 45(3), 398-404. 
Sondeijker, F., Ferdinand, R. F., Oldehinkel, A. J., Veenstra, R., Tiemeier, H., Ormel, J., et al. (2007). Disruptive behaviors and HPA-axis activity in young adolescent boys and girls from the general population. Journal of Psychiatric Research, 41(7), 570-578.

Stadler, C., Poustka, F., \& Sterzer, P. (2010). The heterogeneity of disruptive behavior disorders-implications for neurobiological research and treatment. Frontiers in Psychiatry | Child and Neurodevelopmental Psychiatry, 1(1-12)

van Bokhoven, I., van Goozen, S. H., van Engeland, H., Schaal, B., Arseneault, L., Seguin, J. R., et al. (2005). Salivary cortisol and aggression in a population-based longitudinal study of adolescent males. Journal of Neural Transmission, 112(8), 1083-1096.

van de Wiel , N. M., van Goozen, S. H., Matthys, W., Snoek, H., \& van Engeland , H. (2004). Cortisol and treatment effect in children with disruptive behavior disorders: a preliminary study. Journal of the American Academy of Child and Adolescent Psychiatry, 43(8), 1011-1018.

van Goozen, S. H., \& Fairchild, G. (2008). How can the study of biological processes help design new interventions for children with severe antisocial behavior? Development and Psychopathology, 20(3), 941-973.

van Goozen, S. H., Fairchild, G., Snoek, H., \& Harold, G. T. (2007). The evidence for a neurobiological model of childhood antisocial behavior. Psychological Bulletin, 133(1), 149-182.

van Goozen, S. H., Matthys, W., Cohen-Kettenis, P.T., Buitelaar, J. K., \& van Engeland, H. (2000). Hypothalamicpituitary-adrenal axis and autonomic nervous system activity in disruptive children and matched controls. Journal of the American Academy of Child and Adolescent Psychiatry, 39(11), 1438-1445.

van Goozen, S. H., Matthys, W., Cohen-Kettenis, P. T., Gispen-de Wied, C., Wiegant, V. M., \& van Engeland, H. (1998). Salivary cortisol and cardiovascular activity during stress in oppositional-defiant disorder boys and normal controls. Biological Psychiatry, 43(7), 531-539.

van Honk, J., Schutter, D. J., Hermans, E. J., \& Putman, P. (2003). Low cortisol levels and the balance between punishment sensitivity and reward dependency. Neuroreport, 14(15), 1993-1996.

Vanyukov, M. M., Moss, H. B., Plail, J. A., Blackson, T., Mezzich, A. C., \& Tarter, R. E. (1993). Antisocial symptoms in preadolescent boys and in their parents: associations with cortisol. Psychiatry Research, 46(1), 9-17.

Virkkunen, M. (1985). Urinary free cortisol secretion in habitually violent offenders. Acta Psychiatry,Scand, $72(1), 40-44$.

Vitacco, M. J., Rogers, R., \& Neumann, C. S. (2003). The Antisocial Process Screening Device: an examination of its construct and criterion-related validity. Assessment, 10(2), 143-150.

Wechsler, D. (2005). Wechsler Intelligence Scale for Children-Third Edition-NL (WISC-III-NL): Dutch version: NIP Dienstencentrum, Amsterdam.

Woodman, D. D., Hinton, J. W., \& O'Neill, M. T. (1978). Cortisol secretion and stress in maximum security hospital patients. Journal of Psychosomatic Research, 22(2), 133-136.

Zuckerman, M. (1979). Sensation Seeking: Beyond the Optimum Level of Arousal. Hillsdale, NJ: Erlbaum. 


\section{Knowing right from}

wrong, but just not always feeling it: relations among

callous-unemotional traits, psychopathological symptoms, and cognitive and affective

\section{morality in 8- to 12-year-old boys}

Based on: Feilhauer, J., Cima, M., Benjamins, C. \& Muris, P. (2013). Knowing right from wrong, but just not always feeling it: Relations among callous-unemotional traits, psychopathological symptoms, and cognitive and affective morality judgments in 8- to 12-year-old boys. Journal of Child Psychiatry and Human Development, DOI 10.1007/ s10578-013-0363-0. 


\section{ABSTRACT}

The present research expands our understanding of cognitive and affective morality by exploring associations with callous-unemotional (CU) traits and externalizing symptoms. Participants were 46 8- to 12-year-old boys from the community who completed the Affective Morality Index, the Youth Self-Report, and the Inventory of Callous-Unemotional Traits. A pattern of results was found indicating that in particular the combination of high CU traits and high externalizing symptoms was associated with lack of affective morality, and an increased perceived likelihood of recommitting antisocial acts (recidivism). The implications of these findings and suggestions for future research are discussed. 


\section{INTRODUCTION}

Aggressive and criminal antisocial behavior is widely acknowledged as a major problem for society. In particular the rates of violence and criminal behavior in youth with conduct disorder (CD) are high (Devine, Gilligan, Miczek, Shaikh, \& Pfaff, 2004), which signals an urgent need for developing early preventive interventions and effective treatment programs. A better understanding of the associations between temperamental characteristics, behavioral problems, and moral development might help to identify children at risk for a deviant social development early in life.

Morality is a key component of human social behavior (Cimbora \& Mclntosh, 2005). Disturbed social development has been linked to severe criminal and antisocial behavior, and particularly the disorder of psychopathy (Blair, Mitchell, \& Blair, 2005). Psychopathy is characterized by a profound affective deficit, such as a lack of experiencing shame and guilt, which lies at the core of the disorder. Psychopaths thus do not seem to care about the emotions of others (Blair et al., 2005; Hare, 2003). In children and adolescents these affective deficits are called callous-unemotional (CU) traits (Christian, Frick, Hill, Tyler, \& Frazer, 1997). The combination of CD and CU traits predicts particularly severe behavioral and morally deviant outcomes and seems to put children most at risk to develop extreme antisocial and violent behavior later in life, including psychopathy (Frick, Cornell, Bodin et al., 2003).

Morality is a multidimensional concept that manifests itself in at least two important modalities: 1. cognitive morality - how an individual thinks about rules of ethical conduct; and 2. affective morality - how an individual feels about moral issues (Koops, Brugman, \& Ferguson, 2010; Smetana, Killen, \& Turiel, 2000). Past research has mainly focused on the relation between antisocial behavior in youth and cognitive morality, i.e., moral reasoning to determine right from wrong based on rules and laws (Cimbora \& Mclntosh, 2005). Cognitive morality also refers to the ability of cognitive perspective taking, which enables a person to identify what somebody feels without actually 'sympathizing/feeling' the other's emotional state. Although not all the results are univocal, they have generally shown that antisocial behavior in children and adolescents is associated with deficits in cognitive morality judgments and higher levels of self-serving cognitive distortions (Barriga, SullivanCosetti, \& Gibbs, 2009; Blair, 1997; Nas, Brugman, \& Koops, 2008; Stams et al., 2006).

Research in adults has indicated that psychopathic individuals display no deficits in cognitive morality (Blair et al., 1996; Dolan \& Fullam, 2004; Richell et al., 2003). This is in line with the clinical observation that psychopaths are known as true manipulators, who generally possess good perspective taking abilities and exactly know what implications their acts have for other people (Hare, 1996). Meanwhile, there is clear evidence showing that psychopathy, at least in adults, is associated with inadequacies in affective morality. For example, a recent study found that at a cognitive level the judgments about moral dilemmas of psychopathic offenders did not differ from those of non-psychopathic offenders and 
healthy control subjects (Cima, Tonnaer, \& Hauser, 2011). At the same time, the offenders with psychopathic traits appeared to largely ignore the feelings of others, thereby showing little compassion and empathy for other persons. This seems to justify the conclusion that psychopaths seem to understand the distinction between right and wrong, but just do not care about it (Cima et al., 2011). In other words, they seem to lack the human tendency to feel what others feel and to care about others, i.e. affective morality.

Affective morality describes moral emotions that can direct a person's behavior without a moral reasoning process, purely based on how a situation feels, thereby leading to moral outcomes (Cimbora \& Mclntosh, 2005). Guilt, shame, and empathy are typically described as being the most important emotions in this regard (Eisenberg, 2000). Deficits in affective morality may be particularly present in youths with high levels of CU traits, which can be defined as a persistent temperamental pattern that reflects a lack of empathy, guilt, remorse, and a disregard of others (Christian et al., 1997). Consequently, CU traits and affective morality can be viewed as two sides of the same coin. It has been shown that CU traits especially in combination with externalizing problems put children at risk of developing extreme antisocial and violent behavior, including psychopathy, in later life (Frick, Cornell, Bodin et al., 2003). So far, research on the relationship between CU traits, externalizing problems, and the development of moral feelings is sparse, and most of these studies have focused on empathy as an indicator of affective morality. For example, Anastassiou-Hadjicharalambous and Warden (2008) compared affective and cognitive perspective taking across three groups of children with an age range of 7 to 11 years: a CD/CU group, a CD only group and a nonclinical comparison group. The results indicated that cognitive perspective taking deficits were only present in the CD only group, whereas affective perspective taking deficits were found in both the CD/CU and CD only groups (Anastassiou-Hadjicharalambous \& Warden, 2008a). Another study by Jones, Happé, Gilbert, Burnett and Viding (2010) compared a sample of 96 boys, 9 to 16 year-old, with CU traits and CD, autism spectrum disorder (ASD), CD only, and a non-clinical control group with regard to affective empathy and cognitive perspective taking. Comparisons with the non-clinical control group indicated that boys with CU traits reported to experience less empathy for victims of aggression, although they showed sufficient capacity for perspective taking. In contrast, boys with ASD displayed the appropriate affective reactions, but had problems with cognitive perspective taking. Interestingly, boys with CD did not differ from the normative comparison group on any of the measures, which suggests that the affective empathy deficit would be specific to the boys with CU traits, rather than being common to all boys with externalizing problems. In line with this, a similar investigation by Schwenck et al. (2012), conducted in a sample of 192 boys aged 6-17 years, showed cognitive empathy impairments in boys with ASD, while boys with CD and CU traits were impaired in affective empathy. Again boys with CD only did not differ 
from the comparison group (Schwenck et al., 2012). In another investigation by Dadds et al. (2009), parents of a large community sample of 3- to 13-year-old children were asked to indicate how much their child identified with and cared about the feelings of others. Across all age groups, boys with high levels of CU traits displayed clear deficits in affective morality, whereas such a relation was not found in girls. Interestingly, high levels of CU traits were also positively linked to deficits in cognitive morality in both genders, although this association disappeared as children became older. Altogether, the available evidence suggests that CU traits, in youths have a specific link to deficits in affective morality, and that this is particularly true for boys.

Taken together, the presented literature on morality in childhood suggests that youths high on CU traits at a cognitive level are well aware of what is right and what is wrong, but at an affective level do not always display the appropriate feelings, which seems particularly true for boys. Moreover, as mentioned before, children high on CU traits who also suffer from severe externalizing problems constitute a high risk group for persistent antisocial and aggressive behavior in later life (Frick, Cornell, Barry, Bodin, \& Dane, 2003).

However, certain levels of psychopathology and self-centered callousness are evident during puberty, even in non-clinical children and adolescents (Seagrave \& Grisso, 2002; Steinberg, 2002). To be able to invent successful prevention programs it seems essential to identify when these symptoms become pathological (Salekin, Rosenbaum, Lee, \& Lester, 2009). Therefore, the present study assesses psychopathic traits (CU traits), various aspects of morality (cognitive and affective morality), and psychopathological symptoms (externalizing and internalizing symptoms) in a community sample. The sample was restricted to boys as research suggests that deviant moral processes are particularly relevant for this gender (Dadds et al., 2009; Zahn-Waxler, Cole, Richardson, \& Friedman, 1994). It was expected that especially children with a combination of high CU traits and externalizing problems will show the most clear-cut deficits in their (affective) morality judgments. To explore the specificity of this effect, the combination of CU traits and internalizing problems in relation to affective morality judgments was also investigated.

\section{METHOD}

\section{Participants}

The sample consisted of 46 boys, aged 8-12 years, from the community. Children with known ADHD, autism spectrum problems, and neurological problems were excluded from the study, and this was also true for those with insufficient mastery of the Dutch language and/or too low intelligence. 


\section{Procedure}

We contacted a school in the Dutch speaking part of Belgium in the vicinity of Maastricht University to ask whether they were willing to cooperate with the researchers. Next, all 52 boys between 8 and 12 years of age and their parents received written information about the study. They were also provided with a consent form that had to be signed by both the parents and the boys. Six boys and/or parents refused participation without giving reasons. Participation was on a voluntary basis, and children were allowed to end their participation at any time. The study was approved by the Ethical Committee of Psychology of Maastricht University.

Participants were tested individually, mostly during school hours. Testing took approximately 40 minutes. The researcher administered the vignette task (see below) by reading the vignettes and questions to the child. Following this, children completed the questionnaires, with the experimenter being present to explain difficult words if necessary.

\section{Materials}

Morality was measured with the Affective Morality Index (AMl; Cimbora \& Mclntosh, 2003), which consists of 10 short vignettes describing boys committing antisocial acts. In the original AMI, children are asked three questions about each vignette. First, they have to indicate how happy, excited, afraid, guilty, and an "other" emotion the protagonist would feel after committing the described delinquent act. In this way, multiple emotions are assessed in response to each of the hypothetical events. Second, the AMI also asks children to indicate on a 4-point scale how likely the protagonist will commit the antisocial act again ( 1 =definitely not, 4 =definitely yes). Third and finally, children also have to rate on a 4-point scale how they think most people would feel after acting as described in each vignette ( 1 =absolutely not okay, $1=$ absolutely okay). Since the questions of the original AMI actually assess cognitive morality (by asking how others would feel after committing these antisocial acts), two additional questions were added (after consulting the authors of the original AMI) in order to also measure affective morality (by asking how the participants would feel themselves after having conducted such antisocial acts). Thus, participants were asked how happy, excited, afraid, guilty, and an "other" emotion they would feel themselves after having committed various acts, and how likely it would be for them to act in this way again, using similar 4-point scales as described above. Examples of the antisocial acts presented in the 10 vignettes were stealing a CD from a record store, starting a serious fight, kicking a dog to stop him barking, swearing at the teacher and calling him dirty names, and changing a bad grade in the teacher's note book. Levels of emotional responses to the vignettes were computed using proportion scores. For each emotion, the scores from all 10 vignettes were summed and then divided by the sum of all emotion scores combined (Cimbora \& Mclntosh, 2003). 
In the present study, Cronbach's alphas of the AMI OTHER and SELF scales were respectively .86 and .92 for guilt, .89 and .92 for fear, .87 and .94 for excitement, .84 and .72 for happiness, .88 and .94 for anger. For 'recidivism' (would the protagonist/you do it again?), internal consistency coefficients were .90 and .77.

The Youth Self-Report (YSR; Achenbach, 1991) was included as an index of children's externalizing and internalizing number of psychopathological problems. Items described behavioral (e.g., aggression or delinquent behavior) and emotional (e.g. depression or anxiety) symptoms for which children have to indicate the frequency of experience on a 3-point scale, with $0=$ not true, $1=$ somewhat or sometimes true, and $2=$ very true or often true. The YSR is a highly reliable and valid index of child psychopathology (Achenbach, 1991; Ebesutani, Bernstein, Martinez, Chorpita, \& Weisz, 2011) and this is also true for the Dutch translation of the scale (De Groot, Koot, \& Verhulst, 1994; Verhulst, Van der Ende, \& Koot, 1996). In the present study, Cronbach's alphas were 89 for the externalizing and .88 for the internalizing scale of the YSR.

The Inventory of Callous-Unemotional Traits (ICU; Frick, 2003) consists of 24 items that are scored on a 4-point scale (ranging from $0=$ not at all true to $3=$ definitely true). Half of the items are positively worded and must be reversed before calculating the total and subscales (see Essau, Sasagawa, \& Frick, 2006). Previous research has yielded diverging results about the exact number of factors of the $\mathrm{CU}$ construct, but the use of the total score as an indication of these traits is generally supported to be valid (Essau et al., 2006; Feilhauer, Cima, \& Arntz, 2012; Kimonis et al., 2008). Therefore, the original single factor model of the ICU (represented by the ICU total score) was used in this study as a general index of CU traits. In the present study, the Cronbach's alpha of the total scale was.73.

\section{RESULTS}

\section{Correlational analysis}

Table 1 shows correlations among various YSR, ICU, and AMI scales. The externalizing and internalizing YSR subscales were substantially and positively associated in the present sample, which means that higher levels of behavioral problems were generally accompanied by higher levels of emotional symptoms. Further, both externalizing and internalizing were significantly and positively associated with the ICU total score, which suggests that higher levels of both types of problems to some extent were associated with higher levels of CU traits. However, a partial correlation analysis which controlled for the shared variance across both types of problems, showed that internalizing and externalizing were both not significantly related to CU traits, (partial $r=.03, p=.86$; partial $r=.26, p=.09$ ), although it should be noted that the partial correlation between CU traits and externalizing approached significance. 
Table 1. Mean scores (standard deviations) on various instruments and the most relevant correlations among these variables

\begin{tabular}{|c|c|c|c|c|c|c|}
\hline & & & $M(S D)$ & 1 & 2 & 3 \\
\hline \multirow{2}{*}{ 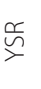 } & 1 & Externalizing & $7.98(6.22)$ & & & \\
\hline & 2 & Internalizing & $12.37(7.27)$ & $0.76^{* *}$ & & \\
\hline \multirow[t]{3}{*}{$\underline{己}$} & 3 & CU traits & & $0.41^{* *}$ & $0.33^{*}$ & \\
\hline & & & $20.30(7.23)$ & & & \\
\hline & 4 & Anger & $0.20(0.05)$ & 0.01 & 0.01 & -0.07 \\
\hline \multirow{5}{*}{ 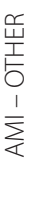 } & 5 & Happy & $0.15(0.05)$ & -0.06 & -0.08 & 0.02 \\
\hline & 6 & Guilt & $0.25(0.05)$ & 0.13 & -0.06 & 0.11 \\
\hline & 7 & Excitement & $0.16(0.05)$ & -0.03 & 0.13 & 0.12 \\
\hline & 8 & Fear & $0.23(0.04)$ & 0.07 & 0.12 & -0.20 \\
\hline & 9 & 'Would you do it again?' & $1.84(0.53)$ & 0.07 & 0.20 & 0.17 \\
\hline \multirow{6}{*}{ 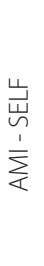 } & 10 & Anger & $0.25(0.05)$ & -0.21 & -0.03 & -0.12 \\
\hline & 11 & Happy & $0.10(0.03)$ & $0.35^{*}$ & -0.00 & $0.34^{*}$ \\
\hline & 12 & Guilt & $0.28(0.04)$ & -0.23 & -0.26 & $-0.36^{*}$ \\
\hline & 13 & Excitement & $0.13(0.05)$ & 0.17 & 0.14 & $0.32^{*}$ \\
\hline & 14 & Fear & $0.23(0.04)$ & 0.02 & 0.17 & -0.15 \\
\hline & 15 & 'Would you do it again?' & $1.20(0.27)$ & $0.35^{*}$ & $0.31^{*}$ & $0.43^{* *}$ \\
\hline
\end{tabular}

Note: YSR = Child Behavior Checklist ; ICU = Inventory of Callous Unemotional traits, AMI = Affective Morality Index; CU traits = Callous-Unemotional Traits; ${ }^{*} p<.05,{ }^{* *} p<.01$

Neither YSR internalizing and externalizing nor CU traits scores were significantly related to indexes of cognitive morality as assessed by the questions of the AMI vignettes referring to an OTHER person. However, the externalizing problems scale of the YSR was significantly linked to affective morality as measured with the questions of the AMI referring to the SELF. In particular, externalizing symptoms were related to the experience of happiness after committing antisocial acts and an increased likelihood of committing such acts again. The internalizing scale was unrelated to affective morality except from also being related to an increased likelihood of committing antisocial acts again.

CU traits were also significantly associated with indices of affective morality, i.e., estimations of the one's own emotional responses following imagined antisocial acts. In particular, higher levels of CU traits were associated with experiencing less guilt and stronger feelings of happiness and excitement. In addition, higher levels of CU traits were significantly related to an increased likelihood of committing delinquent acts again. 


\section{Regression analyses}

As the previous analyses only revealed temperamental and psychopathological correlates in the case of affective morality, we conducted four hierarchical regression analyses examining the unique and interactive effects of CU traits, internalizing and externalizing symptoms on children's responses to the SELF-referent responses as obtained with the AMI. On step 1, main effects were examined by entering CU traits and either YSR internalizing or externalizing into the equation, while on step 2 the interaction effects of CU traits and one of the two YSR scales were added.

Table 2. Results of hierarchical regression analyses predicting feelings of happiness and recidivism (as assessed with a modified version of the Affective Morality Index) from CU traits, externalizing/internalizing symptoms, and their interaction terms

\begin{tabular}{|c|c|c|c|c|}
\hline & $B$ & SEB & $b$ & $R^{2}$ change \\
\hline \multicolumn{5}{|l|}{ Happy } \\
\hline Step 1 & & & & $.17^{*}$ \\
\hline CUTraits & .01 & .01 & .23 & \\
\hline Externalizing (EXT) & .01 & .01 & .26 & \\
\hline Step 2 & & & & $.08^{*}$ \\
\hline Interaction EXT x CU & .01 & .01 & $.30^{*}$ & \\
\hline \multicolumn{5}{|l|}{ Happy } \\
\hline Step 1 & & & & .13 \\
\hline CU traits & .02 & .00 & $.38^{*}$ & \\
\hline Internalizing (INT) & -.00 & .00 & -.13 & \\
\hline Step 2 & & & & .00 \\
\hline Interaction INT x CU & .00 & .00 & .04 & \\
\hline \multicolumn{5}{|l|}{ Would you do it again? } \\
\hline Step 1 & & & & $.22^{* *}$ \\
\hline CU traits & .09 & .04 & $.35^{*}$ & \\
\hline Externalizing (EXT) & .05 & .04 & .21 & \\
\hline Step 2 & & & & $.12^{*}$ \\
\hline Interaction EXT x CU & .12 & .04 & $.36^{*}$ & \\
\hline \multicolumn{5}{|l|}{ Would you do it again? } \\
\hline Step1 & & & & $.22^{* *}$ \\
\hline CU traits & .10 & .04 & $.37^{* *}$ & \\
\hline Internalizing (INT) & .05 & .04 & .19 & \\
\hline Step 2 & & & & .05 \\
\hline Interaction INT x CU & .06 & .04 & .22 & \\
\hline
\end{tabular}

Note: $N=46$. CU traits=Callous Unemotional traits; Externalizing and Internalizing symptoms were assessed by means of the Youth Self-Report. ${ }^{*} p<.05,{ }^{* *} p<.01,{ }^{* * *} p<.001$ 
Analyses were conducted for happiness and the willingness to commit the antisocial act again, as these emotions showed the strongest associations with the predictor variables. As can be seen in Table 2, CU traits and externalizing symptoms together accounted for a significant proportion in feelings of happiness scores (17\%), although due to the control of statistical overlap their unique contributions were not significant. On step 2, a significant interaction effect of externalizing symptoms and CU traits was found that accounted for an additional 8\% of the variance. Inspection of the regression plot revealed that in particular boys with a combination of high CU traits and high externalizing symptoms reported the highest level of happy feelings while imagining to commit antisocial acts (see Figure 1).

The second regression analysis examined CU traits, internalizing symptoms, and their interaction term as predictors of feelings of happiness. On step 1, only CU traits made a significant positive contribution, explaining on its own $13 \%$ of the variance. On step 2, no significant interaction effect was found.

The third regression analysis predicted the boys' willingness to commit antisocial acts again (recidivism) from CU, externalizing symptoms, and their interaction term On step 1, CU traits emerged as a unique and significant predictor, even when controlling for the overlap with externalizing (with a joint explained variance of 22\%). On step 2 the interaction of CU traits and externalizing symptoms also made a significant contribution, explaining an additional 12\% of the variance (see Table 2). Again, inspection of the plot of this interaction effect revealed that in particular boys with a combination of high CU traits and high externalizing symptoms reported the highest level of willingness to commit antisocial acts again (see Figure 2).

A fourth and final regression analyses predicting the boys' willingness to commit antisocial acts from CU traits, internalizing symptoms, and their interaction again identified CU traits as a unique and significant predictor on step 1. No significant contributions of internalizing symptoms or the interaction of CU traits and internalizing symptoms were found.

\section{Discussion}

The present study examined unique and interactive effects of CU traits and externalizing behavioral symptoms on cognitive and affective morality judgments in response to hypothetical antisocial acts in a preadolescent community sample of boys.

First, CU traits, externalizing and internalizing symptoms were not related to the participants' cognitive morality scores. Second, significant associations were obtained with participants' affective morality scores. That is, externalizing symptoms and CU traits were related to feelings of happiness when imagining having committed antisocial acts. CU traits were further related to lower feelings of guilt and higher feelings of excitement when thinking of having committed antisocial acts. CU traits, externalizing and internalizing symptoms 


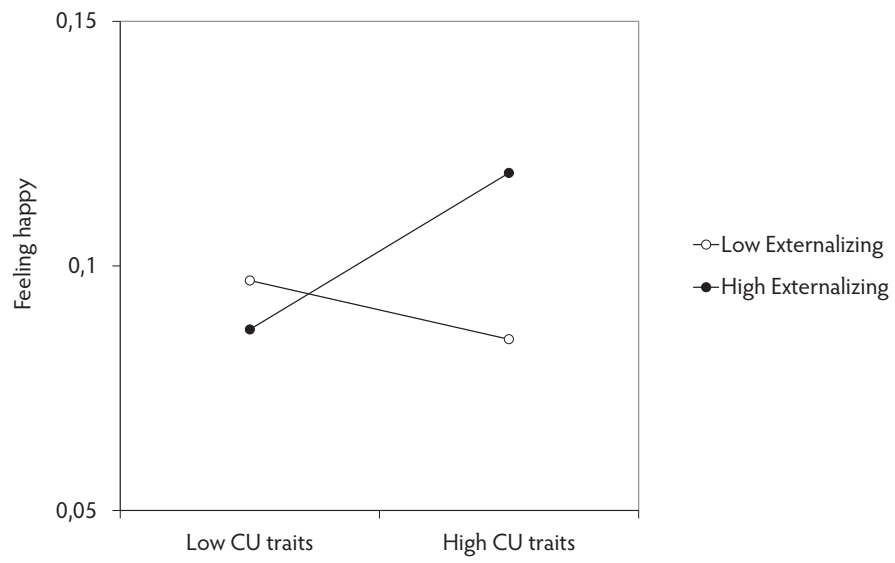

Figure 1. Interaction effects of CU traits and externalizing symptoms predicting feelings of happiness after an antisocial act. Note: Happiness scores had a possible range of 1-4.

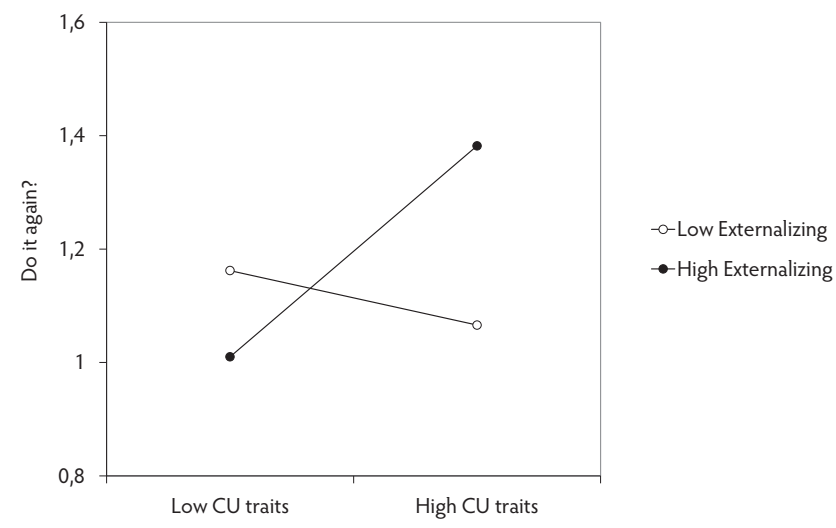

Figure 2. Interaction effects of CU traits and externalizing symptoms predicting willingness to commit again after an antisocial act. Note: Willingness to commit again had a possible range of 1-4.

were also linked to an increased willingness to commit these antisocial acts again. Third, regression analyses conducted to explore unique main and interaction effects showed that CU traits were a robust predictor of feelings of happiness after committing an antisocial act, although when controlling for externalizing symptoms it unique contribution was no longer significant. Further, CU traits also emerged as a significant, positive predictor of the willingness to commit antisocial acts again. The combination of CU traits and externalizing symptoms was related to increased feelings of happiness after committing antisocial acts 
and to an increased willingness to commit these acts again. In contrast, neither internalizing symptoms on their own nor the combination of CU traits and internalizing were related to feelings of happiness or the willingness to commit again after such acts.

Taken together, the present study has three main findings. First, no deficits in cognitive morality occurred. That is, ratings of another persons' feelings after having committed an antisocial act were in line with the general norms and values of the society and were unrelated to the participants' psychopathological symptoms and CU traits. This finding supports earlier research suggesting that perspective taking and cognitive moral competence are no particular problem of children with CU traits and adults with psychopathic traits (Cima et al., 2011; Jones, Happe, Gilbert, Burnett, \& Viding, 2010; Richell et al., 2003). Second, the combination of externalizing symptoms and CU traits designates a group that feels less guilt and instead more happiness and excitement after committing antisocial acts, which indicates deficits in affective morality. Whereas the obtained interaction effects are small, results are generally in line with findings in the field and with the concept of the reward dominance theory (O'Brien \& Frick, 1996). This theory describes a style in which behavior is more driven by the gain of quickly available positive short term rewards than by the avoidance of punishment. Generally, individuals with externalizing symptoms, particularly those with externalizing and antisocial symptoms were believed to be most likely to persist in a former rewarding response style. Interestingly, O'Brien and Frick (1996) found the strongest evidence for a reward dominant response style in nonanxious children highest on CU traits.

Given the results of the current study, one could speculate that the positive emotional experience in response to the antisocial act (feeling happy and excited and less guilty), which was experienced by those children high on CU traits and on externalizing symptoms might enhance their vulnerability for this reward dominance response style. The combination of happiness and low guilt is generally associated with profound deficits of conscience, which indicates that individuals with these characteristics do not seem to care about their actions (Koops et al., 2010) rather than not knowing the difference between right or wrong (Cima et al., 2011).In line with this, (Pardini, Lochman, \& Frick, 2003) observed that detained adolescents with CU traits were confident that aggression would result in positive outcomes and would not have negative consequences. These youths appear to place more value on the positive short term consequences of their aggressive behavior (i.e., dominance, revenge) and seem to care relatively little about the negative consequences of their actions (punishment and victim suffering. Similar patterns were obtained within community children with CU traits (Pardini \& Byrd, 2012)..

Third, results also suggest that the group high on CU traits and externalizing symptoms has the highest chance for recidivism, which is also in line with the reward dominance theory. The quickly available positive short term rewards (feeling happy, excited and less guilty) after committing an antisocial act will probably rather enhance the wish to do it again than motivate the individual to think about the avoidance of punishment in the long run. 
This combination makes them a highly severe and dangerous group and generally supports research in the field suggesting that the combination of CU traits and particularly severe antisocial behavior designates a group that is at high risk for negative future outcomes (see Frick \& White, 2008 for an overview).

Admittedly, the current study suffers from a number of limitations that need to be considered when generating interpretations from the present data. First and foremost, the question rises whether the added question concerning the participants' own emotional responses (SELF) does indicate affective morality or whether it measures cognitive morality. Measurement of affective morality often actually taps on cognitive morality by asking participants how they 'think' (cognitively) about for instance the emotions of a protagonist or victim. Although the applied modified questionnaire is unique in its ability to distinguish between cognitive morality and affective morality, evidence about its psychometric qualities is currently lacking. Although the current study provides some support for its reliability and findings with the measure were generally in line with results from related studies, it is clear that further validation of the Affective Morality Index (AMI) is needed. Methods involving experimental research, that actually put subjects in antisocial situations, might be more appropriate to elicit moral emotions. In addition, the assessment of physiological responses in such situations could be helpful. However, in clinical/forensic practice, such experiments would raise ethical problems, be rather time-consuming and difficult to conduct. There is however evidence suggesting that antisocial children with CU traits show lower baseline heart rates and are physiologically less aroused by emotion evocative film material (AnastassiouHadjicharalambous \& Warden, 2008b).

A further problem when measuring affective morality concerns the different methodologies that are currently applied, including questions about the emotional states of protagonists and victims (perspective taking) as well as making decisions in moral dilemmas (tapping more empathy than all moral emotions). Furthermore, the obtained data generally vary from self-report till informant measures. These differences make it difficult to compare findings across studies.

Second, the present study comprised a community sample of boys. Relevant emotional processes might differ in comparison to clinical/detained samples. However, CU traits are known to also occur in normal youths (Seagrave \& Grisso, 2002; Steinberg, 2002). Further, psychopathic traits, including CU traits, have been identified to exist on a continuum rather than presenting a dichotomy (e.g. Edens, Marcus, Lilienfeld, \& Poythress, 2006; Murrie et al., 2007), thereby suggesting comparable underlying processes in the general community. Future research will have to investigate whether the present findings can be generalized to other behaviorally deviant populations.

Third, the present study consists of a small sample. Although the study investigated clearly formulated hypotheses, conducting multiple regression might have increased the change of a type 1 error. 
Fourth, the ICU in its current form has recently been shown to have problems in differentiating between different groups of youth, thereby raising the question whether self-report is the optimal measure of these traits in children and adolescents (Feilhauer et al., 2012). Furthermore, the psychopathy construct in children and adolescents consists of additional important dimensions, i.e. narcissism and impulsivity (e.g. Frick \& White, 2008). As far as we know, at present the ICU is the only instrument that measures particularly CU traits in close detail. We therefore utilized this instrument. Moreover, as this was the first study that investigated CU traits in relation to the multidimensional concepts of psychopathology and morality, we concentrated on the psychopathy dimension that has been most of all related to affective deficits (e.g. Frick \& White, 2008). Future research should however include additional instruments that also tap the other psychopathy dimensions to build further on the results presented here and elsewhere.

\section{SUMMARY}

The recent study investigated the association of CU traits and externalizing problems with cognitive and affective morality judgments. We found particularly the combination of CU traits and externalizing symptoms to be related to atypical emotional responses in relation to hypothesized antisocial acts (stronger feelings of happiness and excitement and lower feelings of guilt), and also to an increased perceived likelihood of committing the acts again (recidivism). Interestingly, estimations of a protagonists' emotional responses (OTHER) to a delinquent act were in line with the societies norms and values, thereby indicating that children high on CU traits do have general knowledge of right and wrong (cognitive morality), but do not experience the moral emotions typically associated with immoral behavior (affective morality). The present findings thus underscore the need to develop programs to assist children and youth in empathy and emotional-social development early in life to guard these children against those serious consequences as the development of the antisocial personality disorder and psychopathy (Salekin, 2002; Salekin, Worley, \& Grimes, 2010). Treatment should therefore focus less on explaining the difference between good and bad (cognitive morality), but more on experiencing guilt, remorse and empathy (affective morality). 


\section{REFERENCES}

Achenbach, T. M. (1991). Manual of the Child Behavior Checklist/4-18 and 1991 profile. Burlington: University of Vermont, Department of Psychiatry.

Anastassiou-Hadjicharalambous, X., \& Warden, D. (2008a). Cognitive and affective perspective-taking in conduct-disordered children high and low on callous-unemotional traits. Child and Adolescent Psychiatry and Mental Health, 2(Jul).

Anastassiou-Hadjicharalambous, X., \& Warden, D. (2008b). Physiologically-indexed and self-perceived affective empathy in conduct-disordered children high and low on callous-unemotional traits. Child Psychiatry and Human Development, 39(4), 503-517.

Barriga, A. Q., Sullivan-Cosetti, M., \& Gibbs, J. C. (2009). Moral cognitive correlates of empathy in juvenile delinquents. Crim Behav Ment Health, 19(4), 253-264.

Blair, J. (1997). Moral reasoning and the child with psychopathic tendencies. Personality and Individual Differences, 22(5), 731-739.

Blair, J., Mitchell, D., \& Blair, K. (2005). The psychopath: emotion and the brain. Oxford, UK: Blackwell

Blair, J., Sellars, C., Strickland, I., Clark, F., Williams, A., Smith, M., et al. (1996). Theory of mind in the psychopath. Journal of Forensic Psychiatry, 7(1), 15-25.

Christian, R. E., Frick, P. J., Hill, N. L., Tyler, L., \& Frazer, D. R. (1997). Psychopathy and conduct problems in children: II. Implications for subtyping children with conduct problems. Journal of the American Academy of Child and Adolescent Psychiatry, 36(2), 233-241.

Cima, M., Tonnaer, F., \& Hauser, M. D. (2011). Psychopaths know right from wrong but don't care. Social Cognitive and Affective Neuroscience, 5(1), 59-67.

Cimbora, D. M., \& McIntosh, D. N. (2003). Emotional responses to antisocial acts in adolescent males with conduct disorder: a link to affective morality. Journal of Clinical Child and Adolescent Psychology, 32(2), 296-301.

Cimbora, D. M., \& McIntosh, D. N. (2005). Understanding the link between moral emotions and behaviour. In A. V. Clark (Ed.), Psychology of Moods. New York: Nova Science

Dadds, M. R., Hawes, D. J., Frost, A. D., Vassallo, S., Bunn, P., Hunter, K., et al. (2009). Learning to 'talk the talk: the relationship of psychopathic traits to deficits in empathy across childhood. Journal of Child Psychology and Psychiatry and Allied Disciplines, 50(5), 599-606.

De Groot, A., Koot, H. M., \&Verhulst, F. C. (1994). Cross-cultural generalizability of the Child Behavior Checklist cross-informant symptoms. Psychological Assessment, 6, 225-230.

Devine, J., Gilligan, J., Miczek, K. A., Shaikh, R., \& Pfaff, D. (2004). Youth violence. Scientific approaches to prevention. Prologue. Annals of the New York Academy of Sciences, 1036, ix-xii.

Dolan, M., \& Fullam, R. (2004). Theory of mind and mentalizing ability in antisocial personality disorders with and without psychopathy. Psychological Medicine, 34(6), 1093-1102.

Ebesutani, C., Bernstein, A., Martinez, J. I., Chorpita, B. F., \&Weisz, J. R. (2011). The Youth Self Report: Applicability and Validity Across Younger and Older Youths. Journal of Clinical Child and Adolescent Psychology, 40(2), 338-346. 
Edens, J. F., Marcus, D. K., Lilienfeld, S. O., \& Poythress, N. G., Jr. (2006). Psychopathic, not psychopath: taxometric evidence for the dimensional structure of psychopathy. Journal of Abnormal Psychology, 115(1), 131-144.

Eisenberg, N. (2000). Emotion, regulation, and moral development. Annual Review of Psychology, 51, 665-697.

Essau, C. A., Sasagawa, S., \& Frick, P. J. (2006). Callous-unemotional traits in a community sample of adolescents. Assessment, 13(4), 454-469.

Feilhauer, J., Cima, M., \& Arntz, A. (2012). Assessing callous-unemotional traits across different groups of youths: further cross-cultural validation of the Inventory of Callous-Unemotional Traits. International Journal of Law and Psychiatry, 35, 251-262.

Frick, P. J. (2003). The Inventory of Callous-Unemotional Traits. University of New Orleans.

Frick, P. J., Cornell, A. H., Barry, C. T., Bodin, S. D., \& Dane, H. E. (2003). Callous-unemotional traits and conduct problems in the prediction of conduct problem severity, aggression, and self-report of delinquency. Journal of Abnormal Child Psychology, $37(4), 457-470$.

Frick, P. J., Cornell, A. H., Bodin, S. D., Dane, H. E., Barry, C. T., \& Loney, B. R. (2003). Callous-unemotional traits and developmental pathways to severe conduct problems. Developmental Psychology, 39(2), 246-260.

Frick, P. J., \& White, S. F. (2008). Research review: the importance of callous-unemotional traits for developmental models of aggressive and antisocial behavior. Journal of Child Psychology and Psychiatry and Allied Disciplines, 49(4), 359-375.

Hare, R. D. (1996). Psychopathy and antisocial personality disorder: a case of diagnostic confusion. Psychiatric times, 13, 39-40.

Hare, R. D. (2003). The Psychopathy Checklist-Revised technical manual (2nd ed.). Toronto: Multi-Health Systems.

Jones, A. P., Happe, F. G., Gilbert, F., Burnett, S., \& Viding, E. (2010). Feeling, caring, knowing: different types of empathy deficit in boys with psychopathic tendencies and autism spectrum disorder. Journal of Child Psychology and Psychiatry and Allied Disciplines, 51(11), 1188-1197.

Kimonis, E. R., Frick, P. J., Skeem, J. L., Marsee, M. A., Cruise, K., Munoz, L. C., et al. (2008). Assessing callousunemotional traits in adolescent offenders: validation of the Inventory of Callous-Unemotional Traits. International Journal of Law and Psychiatry, 31(3), 241-252.

Koops, W., Brugman, D., \& Ferguson, T. J. (2010). The development of conscience: Concepts and theoretical and empirical approaches. An introduction. In W. Koops, D. Brugman, T. J. Ferguson \& A. F. Sanders (Eds.), The Development and Structure of Conscience (pp. 1-22). Hove: Psychology Press.

Murrie, D. C., Marcus, D. K., Douglas, K. S., Lee, Z., Salekin, R. T., \& Vincent, G. (2007). Youth with psychopathy features are not a discrete class: a taxometric analysis. Journal of Child Psychology and Psychiatry and Allied Disciplines, 48(7), 714-723.

Nas, C. N., Brugman, D., \& Koops, W. (2008). Measuring self-serving cognitive distortions with the How IThink Questionnaire. European Journal of Psychological Assessment, 24, 181-189.

O'Brien, B. S., \& Frick, P. J. (1996). Reward dominance: associations with anxiety, conduct problems, and psychopathy in children. Journal of Abnormal Child Psychology, 24(2), 223-240. 
Pardini, D. A., \& Byrd, A. L. (2012). Perceptions of aggressive conflicts and others' distress in children with callous-unemotional traits: I'll show you who's boss, even if you suffer and I get in trouble'. Journal of Child Psychology and Psychiatry, 53(3), 283-291.

Pardini, D. A., Lochman, J. E., \& Frick, P. J. (2003). Callous/unemotional traits and social-cognitive processes in adjudicated youths. Journal of the American Academy of Child and Adolescent Psychiatry, 42(3), 364-371.

Richell, R. A., Mitchell, D. G. V., Newman, C., Leonard, A., Baron-Cohen, S., \& Blair, R. J. R. (2003). Theory of mind and psychopathy: can psychopathic individuals read the 'language of the eyes'? Neuropsychologia, 41(5), 523-526.

Salekin, R. T. (2002). Psychopathy and therapeutic pessimism. Clinical lore or clinical reality? Clinical Psychology Review, 22(1), 79-112.

Salekin, R. T., Rosenbaum, J., Lee, Z., \& Lester, W. S. (2009). Child and adolescent psychopathy like a painting by Monet. Youth Violence and Juvenile Justice, 7(3), 239-255.

Salekin, R. T., Worley, C., \& Grimes, R. D. (2010). Treatment of psychopathy: a review and brief introduction to the mental model approach for psychopathy. Behavioral Sciences and the Law, 28(2), 235-266.

Schwenck, C., Mergenthaler, J., Keller, K., Zech, J., Salehi, S., Taurines, R., et al. (2012). Empathy in children with autism and conduct disorder: Group specific profiles and developmental aspects. Journal of Child Psychology and Psychiatry, 53(6), 651-659.

Seagrave, D., \& Grisso, T. (2002). Adolescent development and the measurement of juvenile psychopathy. Law and Human Behavior, 26(2), 219-239.

Smetana, J. G., Killen, M., \& Turiel, E. (2000). Moral reasoning. In W. Craig (Ed.), Childhood social development. The essential readings (pp. 273-304). Oxford: Blackwell

Stams, G. J., Brugman, D., Dekovic, M., van Rosmalen, L., van der Laan, P., \& Gibbs, J. C. (2006). The moral judgment of juvenile delinquents: a meta-analysis. Journal of Abnormal Child Psychology, 34(5), 692-708.

Steinberg, L. (2002). The juvenile psychopath: Fads, fictions, and facts. National Institutes of Justice Perspectives on Crime and Justice: 2001 Lecture Series 5, 35-64.

Verhulst, F. C., Van der Ende, J., \& Koot, H. M. (1996). Handleiding voor de CBCL/4-18.

Zahn-Waxler, C., Cole, P. M., Richardson, D. T., \& Friedman, R. J. (1994). Social problem solving in disruptive preschool children: reactions to hypothethical situations of conflict and distress. Merrill-Palmer Quarterly, 40, 98-119. 

Summary

and general discussion 
The present dissertation comprises two parts. Part I started with the presentation of the theoretical framework for the conducted studies. It described the current state of research concerning cognitive, behavioral and affective correlates of different psychopathy dimensions in detained antisocial youths. Within this framework, different empirical research questions were defined (chapter $\mathbf{1}$ ) and tested in the presented studies. In chapter $\mathbf{2}$ the psychometric qualities of the Dutch translation of the Inventory of Callous Unemotional Traits (ICU) were investigated. The second part of this dissertation comprised the study of cognitive, behavioral and affective correlates of different psychopathy dimensions (chapter 3, 4 and 5). Viewing the traditional psychopathy factors as existing on a continuum, we aimed to further elucidate differential functional correlates, thereby allowing for the characterization of more heterogeneity within the construct of (youth) psychopathy. This final chapter will give a summary of the main findings, followed by a general discussion, including limitations, possible avenues for future research, and clinical implications of the presented findings.

\section{RESEARCH QUESTIONS AND SUMMARY OF MAIN FINDINGS}

Part I in chapter $\mathbf{2}$ the psychometric qualities of the Inventory of Callous-Unemotional Traits (ICU; Frick, 2003), the only (self-report) measure that focuses on CU traits in such close detail, were tested. It was administered to young clinical offenders (detained, NS=127), healthy controls (community, NS=172), non-clinical offenders (not detained, NS=42) and an externalizing non-offender group (under treatment for behavioral problems, NS $=42$ ). The age range for all groups was 13-20 years. First, it was investigated whether CU traits can reliably and validly be measured by use of a self-report questionnaire, i.e., the Inventory of Callous-Unemotional Traits.

Confirmatory and exploratory factor analyses were conducted. Confirmatory analyses revealed some shortcomings eventually leading to an alternative five factor structure (Lack of Conscience, Uncaring, Unemotional, Callousness and Lack of Empathy). For these scales modest internal consistencies were achieved. Test-retest stability was adequate particularly for the total scale. Furthermore, the study assessed the convergent, and criterion validity of the ICU. CU traits correlated well with measures of conduct problems and proactive as well as reactive aggression, indicating a good criterion and convergent validity. Weak associations were obtained in relation to expert (Psychopathy Checklist: Youth Version, PCL:YV) and informant (Antisocial Process Screening Device, APSD) measures of psychopathic traits. This result suggests a restricted conceptual overlap between self-report, informant and expert ratings of psychopathic traits. Taken together, present results question the hypothesized ICU factor structure, but lend some support to the ICU's convergent and criterion validity.

Second, as the occurrence of CU traits is regarded to be highly important in the development of psychopathy the question whether a measure of CU traits would be able 
to distinguish between antisocial and healthy control samples was investigated. High levels of CU traits have been shown to characterize youths showing severe antisocial tendencies. On the other hand, it is also known that certain degrees of CU traits are normal with a peak during puberty (Seagrave \& Grisso, 2002; Steinberg, 2002). The reason to measure CU traits across different groups of youths thus was to examine whether the ICU would be able to discriminate between youths with CU traits and severe behavioral problems and those with more normal levels of CU traits. Statistically significant group differences were only found when differentiating the healthy controls from the externalizing and the two offender groups. However, the mean ICU scores were rather low with a narrow range (21-29; total score 72) suggesting no clinically meaningful distinction based on CU traits alone. The conducted meta-analyses comparing results from community vs. detained samples support this result. Thus, in its present form, the ICU does not sufficiently discriminate between pathological occurrences of CU traits versus puberty related normal levels of CU traits.

Part II The studies presented in the second part of the dissertation (chapter 3, $\mathbf{4}$ and 5) investigated some of the existing controversies on cognitive, behavioral and affective correlates of the different psychopathy dimensions, beyond the assessment of CU traits, in those currently believed to be particularly at risk to develop adult psychopathy.

The question whether psychopathy is associated with response inhibition problems is not yet clarified. Research often included mainly antisocial participants and concentrated on the use of total psychopathy scores (Rogers, 2006; Roussy \& Toupin, 2000; Toupin, Dery, Pauze, Mercier, \& Fortin, 2000), thereby neglecting possible differential associations between psychopathy dimensions and response inhibition abilities. Given that proactive aggression requires good executive control, i.e., response inhibition, and is associated particularly with the callous/narcissistic dimension (e.g., Blair, 2004), the idea of a general response inhibition deficit in psychopathy is questionable. The study described in chapter $\mathbf{3}$ therefore examined the question whether psychopathy in youths is associated with a general inhibition problem or whether mutually contradictory past research findings could be related to the fact that most research did not take the role of the different psychopathy dimensions into account. The relationship between different psychopathy dimensions, types of aggression and response inhibition was examined among 53 detained antisocial youth and 64 controls from a community comparison group. Psychopathy dimensions were assessed with the PCL:YV. Response inhibition was assessed through neuropsychological testing (GoNoGo). Types of aggression were assessed through self-report (RPQ). Within the antisocial group the callous/narcissistic dimension of the PCL:YV was related to better response inhibition (two factor model). This was particularly true for the callous dimension (PCL: YV four facet model). On the other hand, both the PCL:YV impulsive/antisocial dimension (two factor model) and its antisocial facet (four facet model) were associated with poorer response inhibition. Furthermore, it was examined whether reactive 
and proactive forms of aggression are differently associated with response inhibition. As hypothesized, proactive aggression (together with verbal IQ) was related to better response inhibition, whereas reactive aggression was associated with poorer response inhibition. The present findings thus plead against a general inhibition problem in youth psychopathy. Whether psychopathic traits relate to poor response inhibition or even response inhibition deficits seems to depend on an individuals' profile on the different psychopathy dimensions and levels of reactive and proactive aggression.

The study in chapter $\mathbf{4}$ examined the question how different psychopathy dimensions are related to basal cortisol in antisocial youth as compared to a comparison sample. Recent research suggested that low cortisol levels serve as a biological marker for affective deficits as they particularly occur in the disorder of psychopathy, i.e., CU traits (Loney, Butler, Lima, Counts, \& Eckel, 2006). However, the role of the remaining psychopathy dimensions in relation to cortisol is as yet largely unknown. Furthermore, the question whether there is support for the notion of cortisol as a biological marker for the callous dimension, has been explicitly addressed by only one study so far, therefore an independent replication was necessary. Psychopathy dimensions (callousness, narcissism and impulsivity; three factor model) were assessed through different self-report questionnaires (ICU, NPIC and RPQ). Cortisol was extracted from saliva samples. The sample consisted of detained antisocial adolescents ( $n S=63$ ) and a community comparison group ( $n S=62$ ). Overall, no group differences in basal cortisol secretion and diurnal slopes were found, indicating a more or less intact basal HPA axis functioning in detained antisocial youth and across the range of pubertal development, which supports and extends earlier findings (Fairchild et al., 2008; Popma et al., 2007). Of the three dimensions of psychopathy investigated (CU traits, narcissism, impulsivity), only impulsivity showed a significant association with low cortisol, but only in the community comparison group. The findings of this study, therefore, question the notion of low cortisol as a biological marker for the callous dimension, at least for basal cortisol. Interestingly, cortisol appeared to be more significantly related to a general deficit in behavioral regulation, impulsivity, but only in the comparison group.

It is suggested that adult psychopaths, and children high on the callous dimension, are well aware of what is right and what is wrong at a cognitive level, but at an affective level do not always display the appropriate feelings (Dadds et al., 2009; Jones, Happe, Gilbert, Burnett, \& Viding, 2010). However, research on the associations with cognitive and affective morality in children is sparse. Chapter $\mathbf{5}$ explored the question whether the combination of the callous dimension, i.e., CU traits and externalizing symptoms would be differently related to cognitive and affective morality. Participants were 46 pre-adolescent community boys. Cognitive and affective morality (AMI), psychopathological symptoms (YSR) and $\mathrm{CU}$ traits (ICU) were assessed. A pattern of results was found indicating that in particular the combination of high CU traits and high externalizing symptoms was associated with 
a lack of affective morality (feeling less guilt and instead more happiness and excitement after imagining committing an antisocial act), but not cognitive morality (being able to describe what and how another person feels). Furthermore, this combination was related to an increased perceived likelihood of recommitting antisocial acts (recidivism). Thus, children high on CU traits and externalizing symptoms seem to have general knowledge of what is right and wrong (cognitive morality), but do not experience the moral emotions typically associated with immoral behavior.

\section{GENERAL DISCUSSION OF THE MAIN FINDINGS}

Apart from the traditional two-factor model of psychopathy, three and four factor models (see Figure 1, p. 14 for an overview) have been applied in the presented studies. Results will be discussed in relation to each separate factor. Accordingly, we will talk about the callous/narcissistic and impulsive/antisocial dimensions (two factor model), the callous, narcissistic and impulsive dimensions (three factor model), and the callous, narcissistic, impulsive and antisocial dimensions (four facet model).

\section{The callous dimension}

Three main findings occurred across the different studies of the present dissertation. The first conceptually interesting finding was that no meaningful differences in self-reported levels on the callous dimension could be shown between youths with severe behavioral problems and a community sample (Chapter 2). In its current form, therefore, the Inventory of Callous-Unemotional Traits (ICU) is not able to distinguish those who show normal levels of CU traits that naturally occur during adolescence from truly callous individuals. This finding supports concerns raised by the field that psychopathic traits might be overrepresented in child and particularly youth samples. During puberty elevated levels of psychopathic traits, including CU traits, naturally occur with youths being, e.g., uncaring and self-centered, prone to boredom, unconcerned about their own performance, goalless, irresponsible, impulsive and less empathic (Steinberg, 2002, 2004, 2005). CU traits might thus not be as stable in youth as they seem in adults (Seagrave \& Grisso, 2002). The fact that elevated scores on the callous dimension occur naturally during puberty creates difficulties for the discriminating power of the ICU. More research is needed to test whether self-report instruments are at all capable to distinguish normal from pathological CU traits in youth samples.

In the light of the proposed new specifier within the diagnosis of Conduct Disorder (with and without CU traits) for the DSM-5, an instrument that assesses these traits in more depth and assists clinicians in diagnosing is highly warranted. Frick and Moffitt (2010) suggest that self-report would be the best way to infer about personality charac- 
teristics during youth. We question this notion. It is of course true that during puberty parents and other informants lose insight into the internal cognitive and emotional processes that occur within the adolescent. Therefore, self-report generally seems a more promising method to infer about inner states (Kamphaus \& Frick, 2005). However, from our own experience we believe that, given the complexity of personality and psychopathic traits, these concepts are difficult to assess using self-report in youth. Reliably filling in a questionnaire on these concepts may require a level of self-reflection that might not be developed sufficiently during puberty. Also, youth may misinterpret contents as describing less serious behaviors or by overrating the resemblance of the described behavior with their own behavior, a problem that is well-known by clinicians working with clinical personality interviews. In line with this idea a recent review on the utility of youth psychopathy self-report measures casts doubt on the reliability of particularly the callous and narcissistic dimensions of the disorder (Sharp \& Kine, 2008). As with the ICU, statements like, e.g.:"I do not show my emotions to others"; "I hide my feelings from others"; "I do not care about doing things well"; "I do not let my feelings control me" or "I do not care about being on time" in our opinion describe attitudes that are common to many adolescents and may thus lead to an overrepresentation of psychopathic traits in youth when measured this way. Furthermore, those who are truly callous and unemotional could easily downplay these attitudes. We thus view the findings of our validation study and metaanalysis on the ICU in line with Seagrave and Grissos' (2002) notion that self-report might not be able to tap the differences between normal and clinical levels of CU traits leading to a possible overrepresentation of psychopathy in youth samples.

Based on assessment through expert ratings ( $P C L-R$ and $P C L: Y V$ ) prevalence scores of psychopathy seem to be similar in youth and adult samples (Salekin, Worley, \& Grimes, 2010). This finding supports our belief that these complex personality traits can best be diagnosed and studied through thorough clinical interviews. However, different assessment methods might tap on different aspects of a construct. We therefore generally agree with Frick and Moffitt that psychopathic traits can best be assessed through a multi-method, multi-informant approach.

The second finding was that the callous/narcissistic dimension (two factor model), and particularly the callous dimension (four facet model), were related to better response inhibition in a detained adolescent sample, as were proactive aggression and verbal IQ (chapter 3). This finding can be linked to the long tradition of clinical descriptions relating at least some aspects of psychopathy with good executive and cognitive resources (Cleckley, 1941). Specifically, it shows that high scores on the callous dimension are not necessarily related to negative cognitive effects. Analyses beyond the use of global psychopathy scores thus questions the notion of a general inhibition problem in psychopathy and could lead the way to answer the long standing controversy in the literature.

Third, we found particularly the combination of the callous dimension together with externalizing symptoms to be related to deficits in affective morality (showing an 
adequate emotional reaction themselves), but intact cognitive morality (being able to describe what and how another person feels; Chapter 5). Albeit the literature on this topic is sparse, similar findings have been obtained with adult psychopaths who seem to cognitively understand the distinction between right and wrong, but just do not seem to care about it (Cima, Tonnaer, \& Hauser, 2011). They seem thus to lack the human tendency to feel what others feel, i.e., sympathizing, and to care about others, i.e., affective morality. The obtained associations might, in pronounced forms, therefore predispose a child to develop severe, aggressive and antisocial behavior and are in line with developmental models of psychopathy suggesting a particular risk for children with this combination to develop the most severe forms of antisocial and delinquent behavior, including psychopathy, in adulthood (e.g., Frick \& White, 2008). In these children the lack in affective morality might contribute to the vulnerability for a reward dominance response style that is more driven by the gain of quickly available positive short-term rewards than by the avoidance of punishment (O'Brien \& Frick, 1996), which might also explain the elevated recidivism estimations.

\section{The narcissistic dimension}

The presented studies did not obtain any specific associations of narcissism with response inhibition or cortisol levels (three and four factor model of psychopathy; Chapters 3 and 4). Whereas the two factor model suggested an association between the callous/narcissistic dimension and response inhibition abilities, the four facet model showed that this association held for the callous dimension only. These findings do not take away the possibility of specific functional correlates of the narcissistic dimension, which were beyond the scope of the current dissertation. For example, some studies suggest a possible relation between aggression and the narcissistic dimension (Barry, Chaplin, \& Grafeman, 2006; Barry et al., 2007). Future research could also investigate the role of narcissism in relation to problems in emotion regulation and stress reactivity. In sum, our findings support the dimensional concept of psychopathy with the different psychopathy dimensions having different functional correlates. Applying the four facet model allowed for the most nuanced view on psychopathy profiles.

\section{The impulsive and antisocial dimensions}

Findings concerning the impulsive and antisocial dimensions were twofold. First, in line with predictions the impulsive/antisocial dimension (two factor model) was related to poor response inhibition, i.e., impulsivity (Chapter 3). It could however be shown that response inhibition deficits were particularly related to the antisocial dimension (four facet model), i.e., antisocial behavior, whereas (as discussed earlier) the callous dimension was related to better response inhibition. Applying the four facet model therefore allowed 
the most nuanced understanding of the obtained results. Moreover, these findings support the notion of different psychopathy subtypes. As has been put forward by Karpman (1948):"... the true psychopath is in a sense the least impulsive of them all...(p.527)". What Karpman suggested was a difference between primary and secondary psychopaths with primary psychopaths being less antisocial, i.e., more 'successfully adapted' to normative societal functioning, but without guilt and conscience, whereas the secondary psychopath was described as impulsive and antisocial due to poor parenting and environmental influences (Karpman, 1948; Poythress \& Hall, 2011). In summary, our finding of differential associations between psychopathy dimensions and response inhibition, first, supports the dimensional approach to psychopathy as similar patterns of results occurred across different kinds of samples (Sellbom \& Verona, 2007; Snowden \& Gray, 2011). Second, it supports the notion that the callous/narcissistic dimension and the impulsive/antisocial dimension of psychopathy might be rough indicators of the primary and secondary psychopathy subtypes (Skeem, Poythress, Edens, Lilienfeld, \& Cale, 2003), thereby also supporting the idea of different psychopathy profiles based on an individuals' position on each psychopathy dimension.

The second finding in relation to the impulsive dimension (three factor model) was an exclusive association of this dimension with low basal cortisol in the community comparison sample only (Chapter 4). No associations with basal cortisol were found in the antisocial sample. It might thus be an oversimplification to treat antisocial youth as a homogenous, underaroused group, with diminished HPA output as suggested by the stimulation-seeking theory. This finding was interesting for two reasons. First, it questions the notion of low cortisol levels as a biological marker for the callous dimension in particular. To date the strongest evidence linking CU traits to low cortisol comes from the original study, in a community sample, by Loney and colleagues (2006), in which boys (but not girls) with high CU traits displayed lower cortisol levels, regardless of the presence or absence of CD symptoms. However, that study contrasted small groups ( 9 to 16 boys per subgroup) at the extreme ends of the CU continuum, thereby increasing the chance of a type 1 error. Moreover, results were based on only a single cortisol measure, collected at 9 a.m. Second, it suggests that low basal cortisol might rather be a biological marker for a general deficit in behavior regulation at least in community samples. Although the finding of the study reported in chapter 4 was somewhat unexpected, it is in line with recent findings, in which low cortisol was related to impulsive aggression and low impulse control in a community sample (Poustka et al., 2010). The simulation-seeking theory offers a possible underlying explanation for this finding. It suggests that a certain level of arousal or stress is needed in order to feel pleasant; underarousal, which is believed to be indicated by low basal cortisol levels, thus represents an aversive, undesirable state. According to this theory chronically underaroused individuals are believed to seek physiological stimulation through impulsive, aggressive and antisocial behavior in order to counteract this negative state (Zuckerman, 1979). 
It is however unclear why this pattern, which was robust enough to be biologically meaningful as well as statistically significant, was only seen in the comparison group and not the detained antisocial youths. Future research will have to investigate whether this finding was sample specific.

\section{CONCLUSION}

The findings from the first part of the present doctoral dissertation lend some support to the psychometric validity of the ICU. However, results also support the cautions raised by Seagrave and Grisso (2002) and therefore question the usefulness of self-report in the assessment of psychopathic traits in children and youths in general and the ICU in particular. Moreover, the obtained differential functional correlates of the psychopathy dimensions described in the second part of the dissertation support the idea of different psychopathy profiles and the usefulness of assessing all psychopathy dimensions beyond the use of global psychopathy scores.

The position on each dimension seems thus to be important for the expression of psychopathy related cognitive, behavioral and affective problems. Extreme levels on all three dimensions describe the most malevolent phenotype (Sellbom \& Verona, 2007). Identifying different psychopathic profiles through associations with external correlates might be able to redraw the impressionist unidimensional painting of youth psychopathy into a more naturalistic pluralistic picture.

\section{METHODOLOGICAL ISSUES}

The findings of the present dissertation provide an important extension to the concept of youth psychopathy particularly in those youths believed to be at increased risk to develop severe antisocial or psychopathic tendencies until adulthood. Nevertheless, a number of limitations need to be acknowledged.

\section{Design}

First, the studies in the present dissertation applied a cross-sectional design. The obtained findings can thus give no indication about the causal direction of the described associations. Studies with a longitudinal design and well-designed experimental studies are warranted to explore cause-effect associations between psychopathy dimensions and external correlates. Moreover, more longitudinal research is needed to disentangle stable traits of psychopathy from more normative psychopathic characteristics that occur during the transition from adolescence to adulthood. More specifically, in relation to 
our findings concerning the discriminant validity on the ICU, it would have been interesting to follow participants into adulthood to gain more insight into the development and stability of psychopathic traits or CU traits in particular, in this group.

Second, in chapter $\mathbf{3}$ only few inhibitory tests were used. However, although our results confirmed expectations, response inhibition and impulsivity are multidimensional concepts with a broad range of possible assessments. Future research should incorporate different aspects of these concepts to test whether the present findings suggest a general pattern of associations or whether they are specific to this kind of inhibition.

Third, the study in chapter $\mathbf{4}$ assessed cortisol levels and diurnal slopes, two central features of HPA secretory patterns. Other features, which are often uncorrelated with each other and probably under different regulatory control systems, include cortisol reactivity to stressful stimuli and the cortisol response to awakening (CAR). Even though meta-analyses showed the strongest associations between aggression, antisocial behavior and basal cortisol levels, our results do not exclude the possibility that other features of the HPA-axis, e.g., cortisol reactivity might be related to psychopathy dimensions, i.e., CU traits. At least one study has found a blunted cortisol response to stress in antisocial adolescents compared to a healthy comparison group (Fairchild et al., 2008). This would also be the expected pattern in youths with high CU traits, particularly in relation to psychological stressors.

\section{Samples}

First, the fact that the detained antisocial samples of the present studies (chapter $\mathbf{2}, \mathbf{3}$ and 4) were rather homogeneous groups could be interpreted as a limitation. A comparison with results from community samples or samples with overall behavioral problems is difficult. In the presented studies, reviewing file information together with information from clinical practitioners and our own diagnostic assessments (DISC) yielded a detained antisocial CD group with no comorbid externalizing diagnosis. Overall sampling differences might thus explain possible differences between findings presented here and elsewhere. We, however, chose this severe behavioral study group as it is particularly this group that is described in the literature as being at an increased risk to develop severe aggressive, antisocial behavior and even psychopathy later in life (Frick \& Marsee, 2006). Furthermore, as it is proposed that this group should receive a special diagnosis in the upcoming DSM-5 (Frick \& Moffitt, 2010), we strongly believe that research concentrating on this particular group and external correlates of their psychopathic symptoms is highly warranted. We therefore see the specific sampling strategy applied in the presented studies as strength rather than a limitation.

Second, the study described in chapter $\mathbf{5}$ comprised a community sample. It would therefore be possible that relevant emotional processes might differ in comparison to clinical/detained samples. However, psychopathic traits have been identified to be 
dimensional existing on a continuum varying in degree rather than in kind (e.g., Edens, Marcus, Lilienfeld, \& Poythress, 2006; Murrie et al., 2007). This would suggest comparable outcomes in the general community. The present findings, which are in line with the sparse literature from forensic research, support this idea. Nevertheless, future research will have to investigate whether the present findings can be generalized to other behavioral deviant populations.

\section{Instruments}

The studies described in chapters $\mathbf{4}$ and $\mathbf{5}$ relied solely on self-report measures which, as discussed at length above, has its pitfalls. However, in chapter $\mathbf{4}$ the reason we did so was straight forward. The study assessed psychopathy dimensions and basal cortisol across a detained antisocial sample and a community comparison group. Unfortunately, to date no structured (clinical) interview exists that is able to assess psychopathy dimensions in both clinical/detained and community samples. We therefore had to rely on self-report measures. Furthermore, the available self-report questionnaires that measure the whole youth psychopathy construct show several psychometric shortcomings and comprise only very few items concerning CU traits (Feilhauer, Cima, \& Arntz, 2012; Sharp \& Kine, 2008). We therefore decided to assess each psychopathy dimension through a separate self-report questionnaire. In chapter $\mathbf{5}$ the ICU and the YSR were administered in interview form to ensure that the participating children would understand the content of the questions. Despite the discussed difficulties with the ICU we used this instrument, since to date no alternative instrument exists that solely measures $C U$ traits.

A final limitation concerns the fact that the studies presented here and elsewhere applied different operationalizations, i.e., different dimensional models of psychopathy. We believe that different factor models may be useful in research, as different correlates across dimensions occur. Though, research should aim at the identification of a general model that adequately covers all critical domains and proves useful to clinicians in the identification of differing psychopathic profiles and their real life expressions. The triarchic model of psychopathy as recently proposed by Patrick and colleagues suggests a promising alternative that integrates the existing conceptualizations of psychopathy as well as empirical findings (Patrick, Fowles, \& Krueger, 2009). According to the triarchic model, psychopathy can best be described by three distinct dimensions/phenotypic expressions: disinhibition, boldness and meanness. Disinhibition generally captures problems with behavioral and emotional impulse control; boldness is viewed as the nexus of high dominance, venturesomeness, and fearlessness in social, emotional, and behavioral domains; meanness reflects social and emotional detachment, callousness, and exploitativeness with no regard for others (Patrick et al., 2009). A combination of boldness and meanness would reflect the callous, goal-oriented and fearless primary psychopath. According to Patrick 
(2009) the PCL:YV and APSD do index disinhibition and meanness, but only to a lesser extent boldness. The Triarchic Psychopathy Measure (TriPM) systematically covers these three dimensions and presents a promising framework for guiding and integrating future research on psychopathy dimensions.

\section{THEORETICAL IMPLICATIONS}

First, the obtained differential associations are important in the ongoing debate about how many dimensions best describe the psychopathy concept. Evidence for the four facet model emerged. The use of a single global psychopathy score or concentrating on CU traits only, overshadows many facets, and specific correlates, that might be important in the identification of different psychopathy profiles and specific treatment interventions.

Second, the presented studies support the dimensional approach to psychopathy and personality features in general by showing that the obtained pattern of associations, particularly in relation to response inhibition, was similar with findings obtained in community samples. This suggests differences in degree of different psychopathic traits rather than kind per se (Edens, Marcus, \& Vaughn, 2011). Furthermore, the results provide some support for the proposed hybrid dimensional-categorical organization of personality disorders for the DSM-5 (APA, 2012).

Third, the present findings lend some support to the proposed specifier of the Conduct Disorder Diagnosis for the DSM-5 by showing that of all externalizing disorders (ADD, HY, ODD, CD), self-reported CU traits showed the strongest associations with a diagnosis of conduct disorder. Also, showing a specific association between CU traits and psychopathy linked behaviors like proactive aggression and affective morality lend further support. At the same time our findings raise some important warnings. Sharp and Kine (2008) studied the psychometric and clinical utility of self-report questionnaires that measure the youth psychopathy construct. They concluded that at present self-report instruments on youth psychopathy can only fulfill the use of screening instruments that may lead to a more comprehensive clinical interview, including the thorough gathering of collateral information. This finding is in line with our findings concerning the ICU. Taken together, more research is required before a self-report measure can be used beyond research purposes in either clinical (diagnosing/treatment) or even judicial decision making. Future research has to aim not only at identifying psychopathic subgroups and their correlates, but at developing thorough measures to enable practitioners to work adequately with proposed specifiers.

Fourth, our findings on the associations of psychopathy dimensions with response inhibition and cortisol contribute to our knowledge about these controversial topics through thoroughly designed studies. We were able to show that when looking behind global scores not all psychopathy dimensions are related to deficits in response 
inhibition. Particularly the callous dimension was related to better inhibition abilities. Furthermore, our results question the notion of basal cortisol levels as a biological marker for the callous dimension.

In general, the presented findings support the notion that depending on their dimensional profile youths thus show and may manifest different cognitive, behavioral and affective correlates and deficits, possibly reflecting different underlying processes.

\section{SOME FINAL WORDS OF CAUTION}

The extension of the psychopathy concept to child and adolescent samples is critizised by some researchers (Johnstone \& Cooke, 2004; Seagrave \& Grisso, 2002). A number of arguments have already been mentioned throughout the present dissertation. Although the results of the presented studies generally support the usefulness of the construct, we feel that some more words of caution are needed.

First, although initial research supports the relative stability of psychopathic traits from childhood into young adulthood, particularly studies conducted during puberty report no clear answer as to what extent their results are due to puberty specific processes (Burke, Loeber, \& Lahey, 2007; Loney, Taylor, Butler, \& lacono, 2007; Lynam, Caspi, Moffitt, Loeber, \& Stouthamer-Loeber, 2007). As mentioned earlier many aspects of psychopathy are to some extent part of the normal development during puberty (Seagrave \& Grisso, 2002; Steinberg, 2002). Puberty is a period of constant change and intense biological, e.g., frontal lobe and personality, development (Steinberg, 2004, , 2005; Yurgelun-Todd, 2007), that is as well related to biological predispositions as to environmental influences and experiences. One core issue in developmental psychopathology describes the fact that similar pathways can lead to different outcomes, i.e., multifinality (Vitacco, Salekin, \& Rogers, 2010). Regarding psychopathy this means that children and adolescents that show psychopathic traits at some point in their life could further develop a different pathology or even develop into healthy adults. Thus the same developmental trajectories may lead to different outcomes. On the other hand different developmental pathways and origins can lead to the same outcome. A concept known as equifinality (Vitacco et al., 2010). Whereas antisocial behavior is commonly believed to develop for a large part through poor environmental conditions (Raine, 2002; Raine et al., 2001), psychopathic core traits, in particular the callous dimension might develop along three different lines: 1. from a biological predisposition, 2. through poor environmental conditions (poor attachment, maltreatment) or 3. through the interaction between the first two (Salekin, 2002). Furthermore, it is possible that due to maturational and environmental changes a trait can be expressed differently during adolescence and adulthood, thereby limiting the predictive power of childhood and adolescent expressions of psychopathic traits in predicting the adult disorder (Vitacco \& Vincent, 2006). 
There might thus be a group of children and adolescents where high callousness might have developed as a coping mechanism to deal with poor environmental conditions, e.g., threatening, maltreatment, a lack of affection from caregivers paired with inconsistent parenting towards the child. In these children callousness might be related to experiences of anxiety and depression underneath, whereas in others there might be a more biological origin and these influences can also change during the development of a child. Identifing the origin of CU traits within a certain child, and understanding what may have influenced developmental pathways, might lead the way to understanding the complex concept such as psychopathy as a developmental disorder.

Next to the identification of risk factors and their role in the development of severe antisocial behavior it would be important to also focus more on the identification of protective factors in relation to psychopathy dimensions. It has been shown that promoting protective factors and prosocial behavior are as important during the development of a child than preventing risk behavior (e.g., Jessor et al., 2003; e.g., Lodewijks, de Ruiter, \& Doreleijers, 2010). Longitudinal research that takes the discussed concepts into account might lead the way to a more complex understanding of psychopathy as a developmental disorder and to new, more specific intervention methods respectively.

Until then, we can not draw definite conclusions on the stability of youth psychopathic traits as we are currently not able to distinguish phenotypically callous and psychopathic youth into those with and without a stable disorder (Seagrave \& Grisso, 2002; Vitacco \& Vincent, 2006).

Second, meta-analytic research suggests that there is little scientific basis for the clinical lore that psychopathy is a generally untreatable disorder (Salekin, 2002). Particularly, treatment of youths seems promising (Salekin et al., 2010). Nevertheless, more research in this respect is highly warranted. The pure fact that psychopathic traits are partly genetic, related to brain abnormalities and difficult to treat should not bias us to conclude that this condition is unchangeable and that interventions would be useless (Salekin et al., 2010). As put forward by Salekin and colleagues (2010) conditions as ADHD or depression are also partly genetic, related to brain abnormalities and difficult to treat. Still, the treatability of these disorders is generally not questioned. Another difficulty that could further bias our ideas about the treatability of (youth) psychopathy might be related to the fact that a large part of research on youth psychopathy is conducted in child and adolescent community samples, whereas in adulthood research on psychopathy focuses mainly on severe forensic samples. Research in community samples is important to understand differences in the appearance of psychopathic traits. However, when combining findings from youth and adult research it is questionable whether we talk about the same construct of psychopathy.

Third, as with many forms of psychopathology, in psychopathy it is just a thin line between the adaptive traits needed to be a highly successful professional and the maladaptive, malevolent forms of the psychopathic personality traits leading to crimi- 
nal behavior. Future research should further focus on the dimensional approach of psychopathy to identify the differences between these groups in their environmental and biological predispositions as well as cognitive, biological and affective deficits. According to a dimensional approach of psychopathy in which an individual can be either more or less psychopathic (on the different dimensions), the goal of interventions should focus on change towards more adaptive forms of behavior.

In summary, youth psychopathy is like an impressionist painting, fine from a distance, but messier as one gets closer (Hart, Watt, \& Vincent, 2002). It is our job to find better ways of recognizing and treating this multidimensional psychopathology at a very early age. Only by showing that psychopathic youths (and psychopaths in general) might look the same from a distance, based on global indices, but actually are highly different, when taking a closer look, we might be able to make a difference, in order for psychopaths not only to know the words, but also to hear the music (Blair et al., 2006; Johns \& Quay, 1962). 


\section{REFERENCES}

APA. (2012). DSM-5 Development: Personality disorders. http://www.dsm5.org/proposedrevision/Pages/PersonalityDisorders.aspx.

Barry, C. T., Chaplin, W. F., \& Grafeman, S. J. (2006). Aggression following performance feedback: The influences of narcissism, feedback valence, and comparative standard. Personality and Individual Differences, 41, 177-187.

Barry, T. D., Thompson, A., Barry, C. T., Lochman, J. E., Adler, K., \& Hill, K. (2007). The importance of narcissism in predicting proactive and reactive aggression in moderately to highly aggressive children. Aggress Behav, 33(3), 185-197.

Blair, K. S., Richell, R. A., Mitchell, D. G., Leonard, A., Morton, J., \& Blair, R. J. (2006). They know the words, but not the music: affective and semantic priming in individuals with psychopathy. Biological Psychology, 73(2), 114-123.

Blair, R. J. (2004). The roles of orbital frontal cortex in the modulation of antisocial behavior. Brain and Cognition, 55(1), 198-208.

Burke, J. D., Loeber, R., \& Lahey, B. B. (2007). Adolescent conduct disorder and interpersonal callousness as predictors of psychopathy in young adults. Journal of Clinical Child and Adolescent Psychology, 36(3), 334-346.

Cima, M., Tonnaer, F., \& Hauser, M. D. (2011). Psychopaths know right from wrong but don't care. Social Cognitive and Affective Neuroscience, 5(1), 59-67.

Cleckley, H. (1941). The mask of sanity. St. Louis, MO: C.V. Mosby.

Dadds, M. R., Hawes, D. J., Frost, A. D., Vassallo, S., Bunn, P., Hunter, K., et al. (2009). Learning to'talk the talk: the relationship of psychopathic traits to deficits in empathy across childhood. Journal of Child Psychology and Psychiatry and Allied Disciplines, 50(5), 599-606.

Edens, J. F., Marcus, D. K., Lilienfeld, S. O., \& Poythress, N. G., Jr. (2006). Psychopathic, not psychopath: taxometric evidence for the dimensional structure of psychopathy. Journal of Abnormal Psychology, 115(1), 131-144.

Edens, J. F., Marcus, D. K., \& Vaughn, M. G. (2011). Exploring the taxometric status of psychopathy among youthful offenders: is there a juvenile psychopath taxon? Law and Human Behavior, 35(1), 13-24, online publication.

Fairchild, G., van Goozen, S. H., Stollery, S. J., Brown, J., Gardiner, J., Herbert, J., et al. (2008). Cortisol diurnal rhythm and stress reactivity in male adolescents with early-onset or adolescence-onset conduct disorder. Biological Psychiatry, 64(7), 599-606.

Feilhauer, J., Cima, M., \& Arntz, A. (2012). Assessing callous-unemotional traits across different groups of youths: further cross-cultural validation of the Inventory of Callous-Unemotional Traits. International Journal of Law and Psychiatry, 35, 251-262.

Frick, P. J. (2003). The Inventory of Callous-Unemotional Traits. University of New Orleans.

Frick, P. J., \& Marsee, M. A. (2006). Psychopathy and developmental pathways to antisocial behavior in youth. In C. J. Patrick (Ed.), Handbook of Psychopathy (pp. 355-374). New York: Guilford. 
Frick, P. J., \& Moffitt, T. (2010). A Proposal to the DSM-V Childhood Disorders and the ADHD and Disruptive Behavior Disorders Work Groups to Include a Specifier to the Diagnosis of Conduct Disorder based on the Presence of Callous-Unemotional Traits. American Psychiatric Association. DSM IV Development. http://www.dsm5.org/ProposedRevision/Pages/proposedrevision.aspx?rid S=424\#.

Frick, P. J., \& White, S. F. (2008). Research review: the importance of callous-unemotional traits for developmental models of aggressive and antisocial behavior. Journal of Child Psychology and Psychiatry and Allied Disciplines, 49(4), 359-375.

Hart, S. D., Watt, K. A., \& Vincent, G. M. (2002). Commentary on Seagrave and Grisso: impressions of the state of the art. Law and Human Behavior, 26(2), 241-245.

Jessor, R., Turbin, M. S., Costa, F. M., Dong, Q., Zhang, H. C., \&Wang, C. H. (2003). Adolescent problem behavior in China and the United States: A cross-national study of psychosocial protective factors. Journal of Research on Adolescence, 13(3), 329-360.

Johns, J. H., \& Quay, H. C. (1962). The effect of social reward on verbal conditioning in psychopathic and neurotic military offenders. Journal of Consulting and Clinical Psychology, 26, 217-220.

Johnstone, L., \& Cooke, D. J. (2004). Psychopathic-like traits in childhood: conceptual and measurement concerns. Behavioral Sciences and the Law, 22(1), 103-125.

Jones, A. P., Happe, F. G., Gilbert, F., Burnett, S., \& Viding, E. (2010). Feeling, caring, knowing: different types of empathy deficit in boys with psychopathic tendencies and autism spectrum disorder. Journal of Child Psychology and Psychiatry and Allied Disciplines, 51(11), 1188-1197.

Kamphaus, R. W., \& Frick, P. J. (2005). Clinical assessment of child and adolescent personality and behavior (2nd ed.). New York: Springer.

Karpman, B. (1948). The myth of the psychopathic personality. The American Journal of Psychiatry, 104, 523534.

Lodewijks, H. P. B., de Ruiter, C., \& Doreleijers, T. A. H. (2010). The Impact of Protective Factors in Desistance From Violent Reoffending A Study in Three Samples of Adolescent Offenders. Journal of Interpersonal Violence, 25(3), 568-587.

Loney, B. R., Butler, M. A., Lima, E. N., Counts, C. A., \& Eckel, L. A. (2006). The relation between salivary cortisol, callous-unemotional traits, and conduct problems in an adolescent non-referred sample. Journal of Child Psychology and Psychiatry and Allied Disciplines, 47(1), 30-36.

Loney, B. R., Taylor, J., Butler, M. A., \& lacono, W. G. (2007). Adolescent psychopathy features: 6-year temporal stability and the prediction of externalizing symptoms during the transition to adulthood. Aggress Behav, 33(3), 242-252.

Lynam, D. R., Caspi, A., Moffitt, T. E., Loeber, R., \& Stouthamer-Loeber, M. (2007). Longitudinal evidence that psychopathy scores in early adolescence predict adult psychopathy. Journal of Abnormal Psychology, 116(1), 155-165.

Murrie, D. C., Marcus, D. K., Douglas, K. S., Lee, Z., Salekin, R. T., \& Vincent, G. (2007). Youth with psychopathy features are not a discrete class: a taxometric analysis. Journal of Child Psychology and Psychiatry and Allied Disciplines, 48(7), 714-723.

Patrick, C. J., Fowles, D. C., \& Krueger, R. F. (2009). Triarchic conceptualization of psychopathy: Developmental origins of disinhibition, boldness, and meanness. Development and Psychopathology, 21(3), 913-938. 
Popma, A., Doreleijers, T. A., Jansen, L. M., Goozen van, S. H., Engeland van, H., \& Vermeiren, R. (2007). The diurnal cortisol cycle in delinquent male adolescents and normal controls. Neuropsychopharmacology, 32(7), 1622-1628.

Poustka, L., Maras, A., Hohm, E., Fellinger, J., Holtmann, M., Banaschewski, T., et al. (2010). Negative association between plasma cortisol levels and aggression in a high-risk community sample of adolescents. Journal of Neural Transmission, 117(5), 621-627.

Poythress, N. G., \& Hall, J. R. (2011). Psychopathy and impulsivity reconsidered. Aggression and Violent Behavior, 16(2), 120-134.

Raine, A. (2002). Biosocial studies of antisocial and violent behavior in children and adults: a review. Journal of Abnormal Child Psychology, 30(4), 311-326.

Raine, A., Venables, P. H., Dalais, C., Mellingen, K., Reynolds, C., \& Mednick, S. A. (2001). Early educational and health enrichment at age 3-5 years is associated with increased autonomic and central nervous system arousal and orienting at age 11 years: evidence from the Mauritius Child Health Project. Psychophysiology, 38(2), 254-266.

Rogers, R. D. (2006). The functional architecture of the frontal lobes: Implications for research with psychopathic offenders. In C. J. Patrick (Ed.), Handbook of Psychopathy (pp. 313-334). London: The Guilford Press.

Roussy, S., \& Toupin, J. (2000). Behavioural Inhibition Deficits in Juvenile Psychopaths. Aggressive Behaviour, 26, 413-424.

Salekin, R. T. (2002). Psychopathy and therapeutic pessimism. Clinical lore or clinical reality? Clinical Psychology Review, 22(1), 79-112.

Salekin, R. T., Worley, C., \& Grimes, R. D. (2010). Treatment of psychopathy: a review and brief introduction to the mental model approach for psychopathy. Behavioral Sciences and the Law, 28(2), 235-266.

Seagrave, D., \& Grisso, T. (2002). Adolescent development and the measurement of juvenile psychopathy. Law and Human Behavior, 26(2), 219-239.

Sellbom, M., \&Verona, E. (2007). Neuropsychological correlates of psychopathic traits in a non-incarcernated sample. Journal of Research in Personality, 41, 276-294.

Sharp, C., \& Kine, S. (2008). The Assessment of Juvenile Psychopathy: Strengths and Weaknesses of Currently Used Questionnaire Measures. Child and Adolescent Mental Health 13(2), 85-95.

Skeem, J. L., Poythress, N., Edens, J. F., Lilienfeld, S. O., \& Cale, E. M. (2003). Psychopathic personality or personalities? Exploring potential variants of psychopathy and their implications for risk assessment. Aggression and Violent Behavior, 8(5), 513-546.

Snowden, R. J., \& Gray, N. S. (2011). Impulsivity and psychopathy: associations between the barrett impulsivity scale and the psychopathy checklist revised. Psychiatry Research, 187(3), 414-417.

Steinberg, L. (2002). The juvenile psychopath: Fads, fictions, and facts. National Institutes of Justice Perspectives on Crime and Justice: 2001 Lecture Series 5, 35-64.

Steinberg, L. (2004). Risk-taking in adolescence: What changes, and why? Annals of the New York Academy of Sciences(1021), 51-58.

Steinberg, L. (2005). Cognitive and affective development in adolescence. TRENDS in Cognitive Sciences, 9(2), 69-74. 
Toupin, J., Dery, M., Pauze, R., Mercier, H., \& Fortin, L. (2000). Cognitive and familial contributions to conduct disorder in children. Journal of Child Psychology and Psychiatry and Allied Disciplines, 41(3), 333-344.

Vitacco, M. J., Salekin, R. T., \& Rogers, R. (2010). Forensic Issues for Child and Adolescent Psychopathy. In R. T. Salekin \& D. Lynam (Eds.), Handbook of child and adolescent psychopathy (pp. 374-400). London: Guilford Press.

Vitacco, M. J., \& Vincent, G. (2006). Understanding the downward extension of psychopathy to youth: Implications for Risk Assessment and Juvenile Justice. International Journal of Forensic Mental Health, 5(1), 29-38.

Yurgelun-Todd, D. (2007). Emotional and cognitive changes during adolescence. Current Opinion in Neurobiology, 17(2), 251-257.

Zuckerman, M. (1979). Sensation Seeking: Beyond the Optimum Level of Arousal. Hillsdale, NJ: Erlbaum. 

Dutch summary 
Het concept psychopathie duidt op een complexe problematiek met patholologische afwijkingen op affectief, interpersoonlijk en gedragsmatig gebied. Psychopaten worden beschreven als emotioneel kil en onverschillig, narcistisch, antisocial en impulsief (o.a. Cooke, Michie, \& Hart, 2006). Onderzoek naar de ontwikkeling van deze zware problematiek heeft aangetoond dat de aanwezigheid van emotioneel kille en onverschillige trekken al op zeer jonge leeftijd kunnen voorkomen (Frick \& White, 2008). Over de invloed van de overige trekken is echter minder bekend. Terwijl onderzoek bij volwassenen in het verleden vooral gebruik gemaakt heeft van algemene psychopathie-scores, werd er bij kinderen en jeugdigen met namen onderzoek verricht naar de specifieke rol van de emotioneel kille en onverschillige trekken als mogelijke voorloper van psychopathie. Verder is er in het meeste onderzoek naar psychopathie gebruik gemaakt van een categoriale benadering.

In dit proefschrift wordt het concept psychopathie bij jeugdigen onderzocht vanuit een dimensionele benadering waarin de traditionele psychopathie factoren worden beschouwd als continue dimensies (lopend van weinig aanwezig tot helemaal aanwezig) in tegenstelling tot een taxonische benadering (wel of niet aanwezig; o.a. Edens, Marcus, Lilienfeld, \& Poythress, 2006). Door het gebruik van algemene psychopathie-scores lijjkt het alsof alle pyschopathen gelijk zijn, terwij) zij in feite heel verschillend kunnen zijn (o.a. Vitacco, Neumann, Caldwell, Leistico, \& Van Rybroek, 2006). Het verschil is gelegen in de mogelijk verschillende bijdrage van de onderliggende psychopathie dimensies, waardoor er per persoon een individueel psychopathie profiel zichtbaar wordt. In het huidige proefschrift wordt in 5 hoofdstukken onderzoek beschreven naar het concept psychopathie bij jeugdigen. Het eerste deel, bestaande uit 2 hoofdstukken, betreft een introductie deel, waarin de validiteit van psychopathie bij jeugdigen wordt bestudeerd. Het tweede deel bestaat uit 3 hoofdstukken waarin verschillende correlaten (impulsiviteit, cortisol en moraliteit) van de psychopathie dimensies worden bestudeerd.

Deel I In hoofdstuk 1 wordt het concept psychopathie (in de volwassenheid) gedefiniëerd en de uitbreiding van het psychopathie concept naar de kinderen- en jeugdtijd belicht. Hierin wordt de veronderstelde rol van de emotioneel kille trekken, de zogenaamde'callous unemotional (CU) traits' kritisch onder de loep genomen. Vervolgens wordt het beschikbare onderzoek naar cognitieve, gedragsmatige en affectieve correlaten van de verschillende psychopathie dimensies (callous, narcistisch en impulsief) bij gedetineerde jeugdigen met gedragsproblemen besproken. Samenvattend kan gesteld worden dat het ondanks eerste bevindingen, te vroeg is om conclusies te trekken met betrekking tot verschillende psychopathie-profielen bij jeugdigen. Tot slot worden in dit hoofdstuk de vraagstellingen, die vervolgens verderop in het proefschrift aan de orde komen, opgesomd. 
In hoofdstuk 2 werden de psychometrische eigenschappen van de Nederlandse vertaling van de 'Inventroy of Callous-Unemotional Traits' (ICU; Frick, 2003) onderzocht. De ICU, een vragenlijst, is tot nu toe het enige meetinstrument waarmee CU traits gedetailleerd in kaart kunnen worden gebracht.

Twee onderzoeksvragen werden onderzocht. Ten eerste werd onderzocht in hoeverre het mogelijk is om CU traits op een betrouwbare en valide manier te meten op grond van zelf-rapportage. Ten tweede werd onderzocht of de ICU in staat zou zijn tussen gedetineerde jeugdigen met gedragsproblemen en gezonde jeugdigen uit de bevolking onderscheid te maken. Met betrekking tot de eerste onderzoeksvraag lieten de resultaten een goede betrouwbaarheid zien van de Nederlandse ICU, zoals een adequate test-hertest. Tevens waren de convergente en critierion validiteit van de Nederlandse ICU in orde. Er werd echter middels een confirmative factor analyse geen steun gevonden voor de originele ICU bifactor oplossing (Essau, Sasagawa, \& Frick, 2006). Een daaropvolgende exploratieve factor analyse liet een alternatieve, vijf-factor oplossing zien. Op grond van de verkregen resultaten wordt geadviseerd met name met de totaal ICU-scoren te rekenen.

Vanuit de literatuur blijkt dat de aanwezigheid van CU traits tijdens de jeugd een belangrijke rol kan spelen bij de ontwikkeling van psychopathie op latere leeftijd (Christian, Frick, Hill, Tyler, \& Frazer, 1997; Frick et al., 2003). Maar ook tijdens de normale ontwikkeling van puber naar volwassenen kunnen deze CU traits optreden. Pubers zijn ook vaak minder empathisch, hebben geen duidelijke toekomstplannen en kunnen kil of onverschillig overkomen (Seagrave \& Grisso, 2002). CU traits staan echter voor pathologische trekken en om die reden zou de ICU in staat moeten zijn een onderscheidt te maken tussen CU traits bij gedragsproblemen en als normale puberteitseffect. Om een antwoord te krijgen op de tweede onderzoeksvraag, werd de ICU bij vier verschillende groepen jeugdigen afgenomen. Ondanks dat het op basis van statistische redenen mogelijk was onderscheid te maken tussen de gedetineerde en de controle groep op basis van de ICU, bleven de CU traits laag met een klein bereik (21-29; op een mogelijke totaal-score van 72). Op basis van deze resultaten werd een meta-analyse uitgevoerd waarin de ICU totaal-scores van de algemene bevolking en gedetineerde steekproeven werden vergeleken. Deze analyse liet met betrekking tot de ICU totaal-scores eveneens geen klinisch relevant verschil tussen deze groepen zien. Samengevat kan gesteld worden dat ondanks de gevonden ondersteuning voor de convergente en criterion validiteit van deze vragenlijst, de ICU in zijn huidige vorm niet in staat is tussen pathologische en puberteitsgerelateerde CU traits te kunnen onderscheiden. Om die reden wordt een multi-informant benadering geadviseerd.

Deel II Dit deel omvat drie studies die zich richten op bestaande controversies omstreeks cognitieve, gedragsmatige en affectieve correlaten van de verschillende psychopathie dimensies in de groep jeugdigen met een verhoogd risico op de ontwikkeling van psychopathie. 
In Hoofdstuk $\mathbf{3}$ werd de vraag onderzocht of psychopathie bij jeugdigen gekenmerkt wordt door een algemeen impulsiviteits-probleem, gemeten a.d.h.v. response inhibitie. Eerder onderzoek naar de samenhang tussen psychopathie en response-inhibitie-problemen werd gekenmerkt door twee voornamelijke tekortkomingen. Ten eerste werd onderzoek uitgevoerd bij antisociale steekproeven, waarbij een gebrek aan impuls controle bekend is (Gorenstein, 1982); ten tweede werd alleen naar de samenhangen met een globale diagnose psychopathie gekeken, zonder uitsplitsingen naar verschillende dimensies binnen dit concept (Lapierre, Braun, \& Hodgins, 1995; Roussy \& Toupin, 2000). Hierdoor bleven mogelijke verschillen in samenhangen tussen response-inhibitie met de verschillende psychopathie dimensies onopgespoord. Gegeven dat met name psychopaten proactieve agressie vertonen welke gekenmerkt wordt door planmatig gedrag en executieve controle (o.a. Cima \& Raine, 2009), lijkt het vrij onwaarschijnlijk dat alle psychopathie dimensies een samenhang vertonen met response-inhibitie-problemen.

Daarom werd in hoofdstuk $\mathbf{3}$ de samenhang tussen response-inhibitie en de verschillende psychopathie dimensies onderzocht in een steekproef van gedetineerde antisociale jeugdigen en een steekproef jeugdigen uit de algemene populatie. Responseinhibitie werd gemeten door middel van een neuropsychologische (GoNoGo) test. Agressie werd gemeten met de 'Reactive Proactive Aggression Questionnaire (RPQ)' en psychopathie dimensies werden gemeten met de 'Psychopathy Checklist: Youth Version (PCL:YV)'. Resultaten vertoonden dat in de groep van gedetineerde jeugdigen, reactieve agressie en de impulsief/antisociale dimensie (twee factor model/vier facetten model) geassocieerd waren met response-inhibitie-problemen. De callous/narcissistische dimensie (twee factor model), proactieve agressie en verbaal IQ bleken juist samen te hangen met een beter inhibitievermogen. De resultaten uit deze studie spreken daarom een algemeen inhibitie-probleem binnen jeugdigen met psychopathische trekken tegen. De mate waarin de jeugdigen uit deze studie inhibitie-problemen vertonen, lijkt dus duidelijk in verband te staan met hun dimensionele psychopathie profiel. Het kijken naar de globale diagnose psychopathie, schiet hier te kort. Een dimensioneel profiel zou dus de toepassing van het beste behandelaanbod kunnen faciliteren door nog specifieker op individuele kenmerken te kunnen ingaan.

Op zoek naar toegepaste behandelmethodes werd er de afgelopen jaren ook naar biologische mogelijkheden gekeken. Zo werd er steeds vaker gesteld dat laag basaal cortisol een biologische marker voor de aanwezigheid van CU traits zou kunnen zijn (Loney, Butler, Lima, Counts, \& Eckel, 2006). Deze uitspraak berust echter op weinig empirische ondersteuning. Bovendien is er weinig bekend over de mogelijke samenhang van lage cortisol niveau's met de andere psychopathie dimensies. In de empirische studie beschreven in hoofdstuk 4 werd daarom onderzocht hoe de verschillende dimensies van psychopathie samenhangen met basale cortisol niveaus. Tegelijkertijd werd onderzocht of er verdere aanwijzing is om basaal cortisol als een biologische marker voor CU traits 
te beschouwen. Het onderzoek werd uitgevoerd in een steekproef gedetineerde antisociale jeugdigen en een steekproef jeugdigen uit de algemene populatie. Psychopathie dimensies (CU traits, narcissime en impulsiviteit) werden gemeten door middel van zelfrapportage (ICU, NPIC en RPQ). Cortisol werd gemeten in het speeksel. De twee groepen verschilden niet in hun basale cortisol niveau's en de fluctuatie in cortisol over de dag. Daarnaast bleek alleen de impulsiviteits dimensie samen te hangen met een laag cortisol niveau maar specifiek binnen de steekproef jeugdigen uit de algemene bevolking. De huidige resultaten bieden daarom geen onderbouwing voor de stelling dat lage basale cortisol niveau's een biologische marker zouden zijn voor de callous dimensie in het bijzonder. Een kunstmatige verhoging van basale cortisol nivau's om individuen met hoge mate van psychopathische trekken responsiever te maken (Glenn, 2009; Stadler, Poustka, \& Sterzer, 2010), lijkt dus geen succesvole medische behandeling voor CU triats.

In Hoofdstuk 5 werd onderzocht hoe de combinatie van CU traits en externalizerende symptomen gerelateerd is aan cognitieve versus affectieve moraliteit. Onderzoek wijst uit dat volwassen psychopaten en kinderen met CU traits op cognitief niveau wel weten wat goed en kwaad is, maar niet de nodige emoties erbij kunnen voelen (o.a. Cima, Tonnaer, \& Hauser, 2011; Jones, Happe, Gilbert, Burnett, \& Viding, 2010). Bij kinderen en jeugdigen is deze samenhang nog weinig onderzocht. Dieper inzicht in deze samenhangen zou de ontwikkeling en vroege toepassing van specifieke behandelingen kunnen bevorderen. De huidige studie werd uitgevoerd in een steekproef jongens uit de algemene bevolking. Externaliserend gedrag werd gemeten met de YSR, CU traits werden gemeten met de ICU, cognitieve en affectieve moraliteit werden met de AMI. De combinatie van sterk externaliserend gedrag en hoge mate van CU-traits bleek in bijzonder mate samen te hangen met een gebrek in affectieve moraliteit (met name zich minder schuldig voelen en vooral vrolijk en geprikkeld voelen na het plegen van een antisociale daad), maar intact cognitieve moraliteit (in overeenkomst met de normen en waarden van de samenleving kunnen beschrijven hoe een ander zich zou moeten voelen na het plegen van een antisociale daad). Op basis van de bevindingen werd concludeerd dat vooral kinderen met de combinatie van CU traits en externaliserende symptomen in het algemeen weten wat goed en fout is (cognitieve moraliteit), maar dit op affectief niveau niet kunnen voelen (affectieve moraliteit). Gezien deze resultaten zou behandeling daarom minder op het leren van goed en kwaad moeten focussen (cognitieve moraliteit) en meer op het beleven van schuld en empathie (affectieve moraliteit).

De resultaten van onderzoeken die in de verschillende hoofdstukken zijn gerapporteerd, onderstrepen het nut en belang van een dimensionele benadering van het concept psychopathie bij jeugdigen (hoofdstuk 6). Een aantal methodologische bedenkingen, richtlijnen voor toekomstig onderzoek en klinische implicaties worden in dit hoofdstuk beschreven. Tot slot concluderen we dat hoewel jeugdigen met psychopathische trek- 
ken vaak als een gelijke groep worden beschouwd, er duidelijke verschillen bestaan. Ook wijzen de resultaten erop dat jeugdigen binnen verschillende ontwikkelingstrajecten psychopathische trekken kunnen vertonen. De gevonden verschillen in de samenhangen tussen psychopathie dimensies en externe factoren, zouden een goed startpunt kunnen bieden voor longitudinal onderzoek naar de ontwikkeling van verschillende psychopathie profielen. 


\section{REFERENCES}

Christian, R. E., Frick, P. J., Hill, N. L., Tyler, L., \& Frazer, D. R. (1997). Psychopathy and conduct problems in children: II. Implications for subtyping children with conduct problems. Journal of the American Academy of Child and Adolescent Psychiatry, 36(2), 233-241.

Cima, \& Raine, A. (2009). Distinct characteristics of psychopathy relate to different subtypes of aggression. Personality and Individual Differences, 47(8), 835-840.

Cima, M., Tonnaer, F., \& Hauser, M. D. (2011). Psychopaths know right from wrong but don't care. Social Cognitive and Affective Neuroscience, 5(1), 59-67.

Cooke, D. J., Michie, C., \& Hart, S. (2006). Facets of clinical psychopathy: Toward clearer measurement. In C. J. Patrick (Ed.), The handbook of psychopathy (pp. 91-106). New York: Guilford Press.

Edens, J. F., Marcus, D. K., Lilienfeld, S. O., \& Poythress, N. G., Jr. (2006). Psychopathic, not psychopath: taxometric evidence for the dimensional structure of psychopathy. Journal of Abnormal Psychology, 115(1), 131-144.

Essau, C. A., Sasagawa, S., \& Frick, P. J. (2006). Callous-unemotional traits in a community sample of adolescents. Assessment, 13(4), 454-469.

Frick, P. J. (2003). The Inventory of Callous-Unemotional Traits. University of New Orleans.

Frick, P. J., Cornell, A. H., Bodin, S. D., Dane, H. E., Barry, C. T., \& Loney, B. R. (2003). Callous-unemotional traits and developmental pathways to severe conduct problems. Developmental Psychology, 39(2), 246-260.

Frick, P. J., \& White, S. F. (2008). Research review: the importance of callous-unemotional traits for developmental models of aggressive and antisocial behavior. Journal of Child Psychology and Psychiatry and Allied Disciplines, 49(4), 359-375.

Glenn, A. L. (2009). Neuroendocrine markers of psychopathy. In M. S. Ritsner (Ed.), The Handbook of Neuropsychiatric Biomarkers, Endophenotypes, and Genes (Vol. 3). Dordrecht, The Netherlands: Springer.

Gorenstein, E. E. (1982). Frontal lobe functions in psychopaths. Journal of Abnormal Psychology, 91(5), 368379.

Jones, A. P., Happe, F. G., Gilbert, F., Burnett, S., \& Viding, E. (2010). Feeling, caring, knowing: different types of empathy deficit in boys with psychopathic tendencies and autism spectrum disorder. Journal of Child Psychology and Psychiatry and Allied Disciplines, 51(11), 1188-1197.

Lapierre, D., Braun, C. M., \& Hodgins, S. (1995). Ventral frontal deficits in psychopathy: neuropsychological test findings. Neuropsychologia, 33(2), 139-151.

Loney, B. R., Butler, M. A., Lima, E. N., Counts, C. A., \& Eckel, L. A. (2006). The relation between salivary cortisol, callous-unemotional traits, and conduct problems in an adolescent non-referred sample. Journal of Child Psychology and Psychiatry and Allied Disciplines, 47(1), 30-36.

Roussy, S., \& Toupin, J. (2000). Behavioural Inhibition Deficits in Juvenile Psychopaths. Aggressive Behaviour, 26, 413-424.

Seagrave, D., \& Grisso, T. (2002). Adolescent development and the measurement of juvenile psychopathy. Law and Human Behavior, 26(2), 219-239. 
Stadler, C., Poustka, F., \& Sterzer, P. (2010). The heterogeneity of disruptive behavior disorders-implications for neurobiological research and treatment. Frontiers in Psychiatry |Child and Neurodevelopmental Psychiatry, 1(1-12).

Vitacco, M. J., Neumann, C. S., Caldwell, M. F., Leistico, A. M., \& Van Rybroek, G. J. (2006). Testing factor models of the Psychopathy Checklist: Youth Version and their association with instrumental aggression. Journal of Personality Assessment, 87(1), 74-83. 
Dankwoord 
Nu is het dus zo ver. Na zes jaar bloed, zweet en ook wel sommige tranen is het boekje af. Naast de wetenschappelijke uitdaging en verdieping van kennis en vaardigheden heb ik de afgelopen 6 jaar ook over mezelf ontzettend veel geleerd. Graag wil ik een woord van dank aan al die mensen richten die aan deze ontwikkeling en aan het tot staat komen van dit proefschrift een bijdrage hebben geleverd.

Allereerst gaat mijn dank uit naar mijn promotoren, Prof. dr. Arnoud Arntz en mijn copromotor dr. Maaike Cima. Beste Maaike, dank je wel voor de kans om te promoveren en van jouw deskundigheid te kunnen leren. De vrijheid en zelfstandigheid waarmee ik mocht werken was een constante uitdaging en heeft mij enorm verrijkt als onderzoeker en als persoon. Ondanks je drukke agenda had ik altijd het gevoel met alles bij jou terecht te kunnen. Dit heeft mij veel rust gegeven! Ik bewonder je optimisme en energie. Dank je wel voor de fijne samenwerking, je betrokkenheid, de fijne werkoverleggen in Vaals, en de vele inspirerende gesprekken over onderzoek (en zo).

Beste Arnoud, ik heb groot respect en bewondering voor je enthousiasme, kennis en gedrevenheid. Ik had even nodig, om aan je kritische blik te wennen, maar ik heb er ontzettend veel van geleerd. Bedankt ervoor! Heel erg bedankt voor je altijd snelle reacties en je betrokkenheid bij dit project op momenten waar ik het moeilijk vond om het licht aan het eind van de tunnel te zien. Een bijzonder dank ook ervoor dat je mij de kans hebt gegeven om het project af te maken.

Veel dank aan Prof. dr. Andries Korebrits en dr. Nancy Nicolson voor hun inzet vanaf het begin van het project en de samenwerking als co-auteurs. Beste Andries, hartelijk dank voor het meedenken en jouw ondersteuning omstreeks de werving van de gedetineerde proefpersonen. Dear Nancy, thank you so much for all your valuable and constructive suggestions during the planning and conduction of the cortisol study. I am deeply impressed by your expertise and your enthusiasm. Thanks for all your support and all that you taught me.

Ein besonderer Dank gilt ebenso PD Dr. Hans Jürgen Kunert und PD Dr. Christine Norra. Lieber Jürgen, liebe Christine, bei Euch durfte ich meine ersten Forschungserfahrungen sammeln und meine Freude an wissenschaftlichem Arbeiten entdecken. Danke, dass ich soviel von Euch lernen durfte und dafür, dass Ihr mich ermutigt habt zu promovieren. Lieber Jürgen, vielen Dank für die Zusammenarbeit der letzten Jahre. Euch beiden von Herzen Dank für Eure Unterstützung und Euer aufrechtes Interesse an meinem Werdegang!

De leden van de leescommissie ben ik erkentelijk voor de tijd en aandacht die zij hebben besteed aan het lezen en beoordelen van dit proefschrift. 
Zonder de hulp van een groot aantal assistenten en studenten was dit project nooit mogelijk geweest. Jullie allen van harte dank! Ook wil ik graag alle proefpersonen, ouders, instellingen, klinieken en scholen bedanken voor de medewerking aan dit project. Bedankt voor het vertrouwen en de ondersteuning.

Special thanks to the Society for the Scientific Study of Psychopathy (SSSP) for the wealth of inspiring research and for recognizing the hard work of a Dutch PhD student.

Een bijzonder dank gaat uit naar de afdeling persoonlijkheidsstoornissen van de RIAGG Maastricht. Ik ben enorm onder de indruk van de therapeutische kwaliteiten en compassie in de omgang met deze speciale doelgroep die ik daar tegenkwam. Beste Wiesette, Mieps, Andrea, Wil en alle andere collega's, ik voel me nog steeds vereerd dat ik van jullie mocht leren. Mieps een speciale dank voor je enorme betrokkenheid en de gezellige lunchafspraken. Hopelijk zien wij elkaar binnen kort weer eens!

De medewerkers en collega's van de FPN. Ten eerste mijn oprechte dank voor de uitdagende en inspirerende studie die ik in Maastricht mocht volgen. Het was geen toeval dat ik voor mijn AiO project terugkwam aan de UM. Nu, na 11 jaar wordt het (met een lachend en een wijnend oog) tijd om te gaan, maar niet zonder een aantal mensen speciaal te bedanken. Angela, bedankt voor jouw betrokkenheid bij de AiOs en jouw hulp met van alles en nog wat. Erik, bedankt voor al het rustige uitleg, je tegenvragen en ervoor dat je mij nooit 'gewoon'zei wat ik moest doen. Van je 'statistisch coaching' heb ik veel geleerd.

De collega's van CPS/DMKEP en de sectie CP in het bijzonder: bedankt voor al de inspiratie en de collegiale uitwisseling, voor de gezellige EPP cursussen, borreltjes en uitjes. De AiOs van de eerste verdieping. Bedankt voor de leuke tijd! Speciale woorden van dank aan Andrea (voor alle Cupcakes en Muffins en de fijne gesprekken), Lotte B. (voor al je positivisme, behulpzaamheid en je groot hart!), Marjolein (voor de leuke gesprekken, je uitleg over het verschil tussen mediatie en moderatie en ervoor dat je altijd de eerste was die een nieuwe kapsel opviel) en Lotte L. (voor de regelmatige bezoeken op de eerste). Astrid, danke für die vielen gemeinsamen Stunden im Auto zwischen Maastricht und Aachen die den Weg soviel kurzweiliger gemacht haben. Bedankt dat jullie zo fijne collega's waren en voor jullie steun. Ik zal jullie missen! Verder dank ik Ken (voor de altijd 'just in time' herinnering aan de openingstijden van de parkeergarage), Ivo (voor de fijne gesprekken bij de koffieapparaat en op de werkvloer over cortisol onderzoek en zo), Jeanine (Je optimisme en vrolijkheid hebben jou een perfecte AiO-peter gemaakt. Ik zal die warme welkom op de UM nooit vergeten.), Gerda (voor de gezellige en altijd inspirerende gesprekken), Maaike L. (voor je waarschuwend uitleg over de verschillende fases van een AiO project en mogelijke samenhangen met de geestelijke gezondheid van de promovendus). 
Next to my colleagues at the university I met a number of highly inspiring researchers at workshops and conferences in the field of psychopathy research. Particularly, Hedwig, Hanna and Kasia thank you so much for all the interesting and inspiring discussions (scientific and personal ones), the shared excitement before a presentation and the after work drinks. You girls are just great!

Meine liebsten Freundinnen aus der Studienzeit in Maastricht: Miriam, Karen, Steffi und Christine. Danke für die tolle gemeinsame Zeit. Auch, wenn wir immer weiter verstreut sind, seid Ihr immer in meinem Herzen. Ich bin froh und glücklich Euch zu kennen. Mimi und Britta, als Studentin habe ich die neue Welt bereist und Euch gefunden. Schön, dass es Euch gibt!

Sjoertje en Miriam, jullie zijn de afgelopen jaren een belankrijke bron van afleiding, steun en inspiratie voor mij geweest. Sjoertje, als kamergenoten hebben wij veel intense gesprekken over grote en kleine dingen gehad. Dank je wel voor je wijsheid en je luisternd oor en je steun. Miriam, vielen Dank für all die vielen relativierenden Gespräche. Ich bin immer wieder erstaunt wie ähnlich und doch verschieden zwei Menschen sein können. Wat rustgewend dat jullie op deze grote dag als mijn paranimfen achter mij staan.

Meine lieben Freunde. Von Herzen Dank für alle moralische Unterstützung, Euer Interesse, viele schöne (Mädels-)Abende, tolle Reisen, interessante Gespräche, intensive Begegnungen, Freud und Leid, Kaffee und Cocktails, Shopping, Karneval, Kindergeschichten, Wellness...kurzum, all die wunderbaren Ablenkungen im echten Leben! Wir haben zusammen gelacht und geweint. Schön, dass beides mit Euch geht!

Meine Familie, ich kann Euch nicht genug danken für Eure Liebe und Unterstützung. Meine geliebten Großeltern, mein liebster Patenonkel: Danke für Eure stets offene Tür und das immer offene Ohr. Meine Eltern, danke für alle Chancen und Möglichkeiten und Euer unendliches Vertrauen in mich. Liebe Mama: Danke für alles!

Lieber Tobi, mein großer Bruder. Danke, dass Du immer da bist, wenn Deine kleine Schwester Dich braucht. Jeder sollte einen großen Bruder haben. Danke auch für das schöne Cover Design. Liebe Inga, wie schön, dass es Dich gibt. Deine Fröhlichkeit ist so wunderschön ansteckend. Liebe Helena, zu sehen die Du strahlst, wächst und gedeihst macht mich zu einer sehr stolzen Tante.

Mein liebster Thomas, von all den Menschen die zum Gelingen dieses Projekts beigetragen haben, hattest Du mit Abstand am meisten auszuhalten. Danke für Deine Ruhe, Deine Geduld, die unendliche Unterstützung, Deinen unerschöpflichen Humor und dafür, dass ich bei Dir einfach ich selbst sein kann. Du bist mein großes Glück! 
Curriculum vitae 


\section{ABOUt THE AUTHOR}

Johanna Christiane Feilhauer was born on Juli 30th, 1979 in Waiblingen, Germany. In June 2000, she graduated from secondary school (Kreisgymnasium Heinsberg). From October 2000 till May 2001 she worked as an Aupair in London, Great Britain. In September 2001 she started studying Psychology at Maastricht University. She graduated in August 2006 and received her master's degree in Biological Psychology. From 2006 to 2012 she conducted her PhD research at the Department of Clinical Psychological Science at Maastricht University. During these years she also gained clinical experience at the Child and Adolescent Division of the Mondriaan Zorg Group, Heerlen. Later she worked partly as therapist at the Division for Personality Disorders at the Riagg Maastricht and as a teaching assistant at the Department of Clinical Psychological Science, Maastricht University. Currently, she works as a therapist at the Klinik für Psychiatrie und Psychotherapie, Gangelter Einrichtungen Maria Hilf, Gangelt, Germany. Also, since April 2012 she works as an independent consultant and trainer for the Schiel Consulting GmbH (SCG), Köln, Germany. 


\section{LIST OF PUBLICATIONS}

Norra, C., Feilhauer, J., Wiesmüller, G.A., Kunert, H.J. (2006). Auswirkungen der Lithiumkonzentration durch ubiquitäre Hintergrundbelastung auf die psychische Befindlichkeit (Abstract). Umweltmed Forsch Prax, 11(4), p. 214.

Norra, C., Feilhauer, J., Wiesmüller, G.A., Kunert, H.J. (2010). Differential neurobiological effects of endogenous lithium: A study on auditory evoked potentials. Psychiatry Research, 178 (1), 176-181.

Feilhauer, J., Cima, M., Korebrits, A. \& Kunert, H.J. (2012). Differential associations of psychopathy dimensions, types of aggression and response inhibition. Aggressive Behavior, 38(1), 77-88

Feilhauer, J., Cima, M., Arntz, A. (2012). Assessing callous-unemotional traits across different groups of youths: further cross-cultural validation of the Inventory of Callous-Unemotional traits International Journal of Law and Psychiatry, 35(4), 251-262.

Feilhauer, J., Cima, M., Korebrits, A. \& Nicolson, N. (in press). Cortisol, psychopathy dimensions and types of aggression in detained youths. Psychoneuroendocrinology

Feilhauer, J. \& Cima, M. (2013). Youth psychopathy: Differential correlates of callous-unemotional traits, narcissism, and impulsivity. Forensic Science International, 224 (1-3), 1-7.

Feilhauer, J., Cima, M., Benjamins, C. \& Muris, P. (2013). Knowing right from wrong, but just not always feeling it: Relations among callous-unemotional traits, psychopathological symptoms, and cognitive and affective morality judgments in 8- to 12-year-old boys. Journal of Child Psychiatry and Human Development, DOI 10.1007/s10578-013-0363-0.

\section{MANUSCRIPTS IN PREPARATION}

Kunert H.J., Tuchtenhagen F., Feilhauer J., Norra C. Impact of intelligence on therapeutic outcome in a psychiatric rehabilitation treatment program for patients with dual diagnosis.

Kunert H.J., Tuchtenhagen F., Feilhauer J., Norra C. Clusters of personality disorders in patients with dual diagnosis. 


\section{Presentations}

Feilhauer, J. (2006) Neurobiological correlates of endogenous lithium. Oral presentation at the workshop on occurrences and influences of endogenous lithium, Institut für Mineralogie und Geochemie Universität Karlsruhe, Germany.

Feilhauer, J. (2008) Emotion processing using an implicit measure in adolescents with conduct disorder: Preliminary findings. Oral presentation at the European Association of Psychology and Law, Maastricht, the Netherlands.

Feilhauer, J. (2008) Emotion processing using an implicit measure in adolescents with conduct disorder: Preliminary findings. Oral presentation at third international conference on child and adolescent psychopathology, London, Great Britain.

Feilhauer,J. (2008) Invited oral presentation on the neurobiology of delinquency (masterclass) at EFCAP 10th anniversary congress on mental health, delinquency and juvenile justice. Amsterdam, the Netherlands.

Feilhauer, J. (2009) Relationship between different types of aggression and executive (frontal lobe) functioning: The influence of CU-traits in adolescents at risk for developing psychopathy as compared to healthy controls. Poster presentation at the 3 rd conference of the Society for the Scientific Study of Psychopathy (SSSP), New Orleans, USA.

Feilhauer, J. (2009) Psychophysiological and neurobehavioral effects of endogenous lithium. Invited oral presentation at the workshop of the Vietnamese-German network of experts for the assessment of arsenic in the food chain and on the development, optimization and implementation of filter techniques groundwater in rural areas of the Red River Delta, Vietnam [supported by the International Bureau of the Federal Ministry of Education and Research, (BMBF), Bonn, Germany]. Ruhr University Bochum, Germany.

Feilhauer, J. (2009) How to measure psychopathy in youths? On the utility of the Inventory of Callous-Unemotional Traits in relation to the PCL: YV and in predicting emotion processing deficits in conduct disorder. Oral presentation at the European Autumn School on Research in Forensic Populations, Seeon, Germany.

Feilhauer, J. (2011) Cortisol, psychopathy dimensions and types of aggression in at risk youths. Poster presentation at the 4th conference of the Society for the Scientific Study of Psychopathy (SSSP) Montréal, Canada. 
Feilhauer, J. (2013) Knowing right from wrong, but just not always feeling it: Relations among callous-unemotional traits, psychopathological symptoms, and cognitive and affective morality judgments in 8- to 12-year-old boys. Poster Presentation at the European Winter School on Research in Forensic Populations: Novel insights into Antisocial Behavior, Seeon, Germany. 




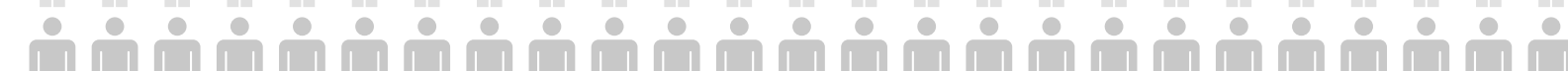

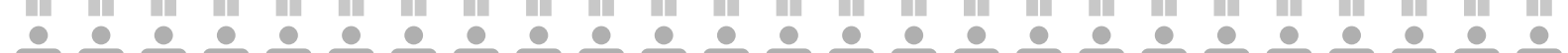
| 0

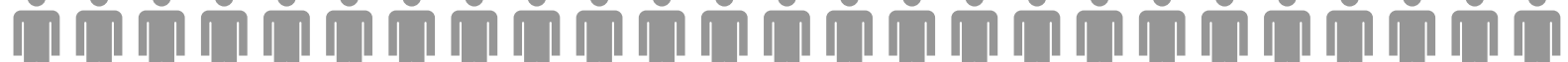

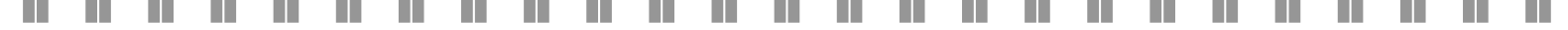

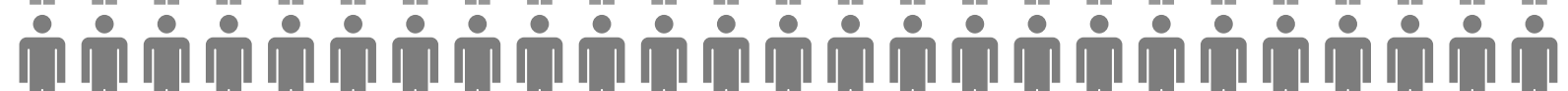

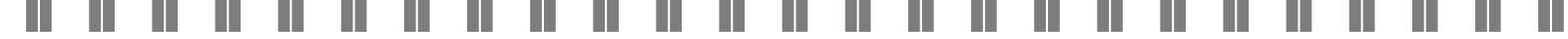
0 $\left.\left.\left.\left.\left.\left.\left.{ }_{\mid}\right|_{\mid}\right|_{\mid}\right|_{\mid}\right|_{\mid}\right|_{\mid}\right|_{\mid}\right|_{\mid}$

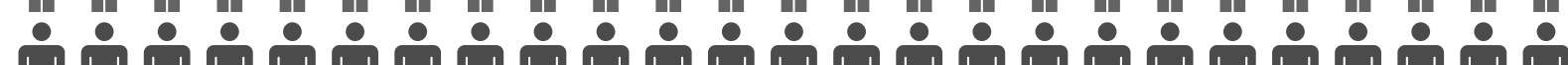

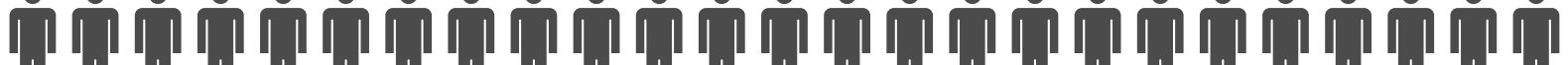

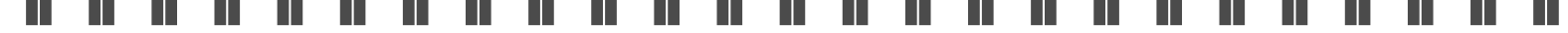

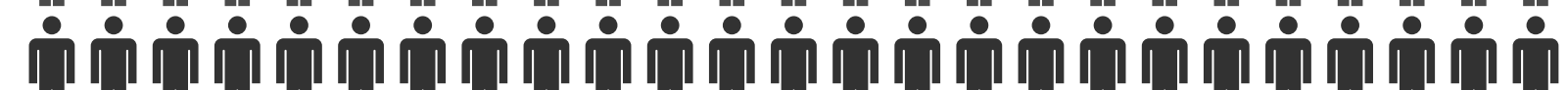

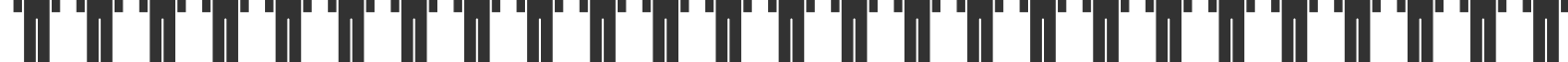

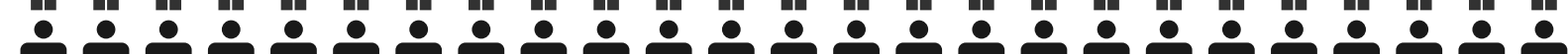

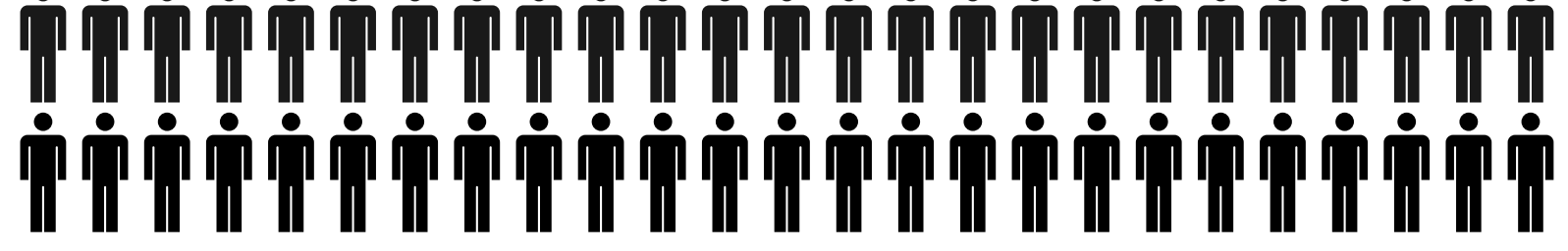

